\title{
Surgical treatment of morbid obesity : Technical, psychological and metabolic aspects
}

Citation for published version (APA):

van Gemert, W. G. (1999). Surgical treatment of morbid obesity : Technical, psychological and metabolic aspects. [Doctoral Thesis, Maastricht University]. Universiteit Maastricht. https://doi.org/10.26481/dis.19990115wg

Document status and date:

Published: 01/01/1999

DOI:

10.26481/dis.19990115wg

Document Version:

Publisher's PDF, also known as Version of record

\section{Please check the document version of this publication:}

- A submitted manuscript is the version of the article upon submission and before peer-review. There can be important differences between the submitted version and the official published version of record.

People interested in the research are advised to contact the author for the final version of the publication, or visit the DOI to the publisher's website.

- The final author version and the galley proof are versions of the publication after peer review.

- The final published version features the final layout of the paper including the volume, issue and page numbers.

Link to publication

\footnotetext{
General rights rights.

- You may freely distribute the URL identifying the publication in the public portal. please follow below link for the End User Agreement:

www.umlib.nl/taverne-license

Take down policy

If you believe that this document breaches copyright please contact us at:

repository@maastrichtuniversity.nl

providing details and we will investigate your claim.
}

Copyright and moral rights for the publications made accessible in the public portal are retained by the authors and/or other copyright owners and it is a condition of accessing publications that users recognise and abide by the legal requirements associated with these

- Users may download and print one copy of any publication from the public portal for the purpose of private study or research.

- You may not further distribute the material or use it for any profit-making activity or commercial gain

If the publication is distributed under the terms of Article $25 \mathrm{fa}$ of the Dutch Copyright Act, indicated by the "Taverne" license above, 
SURGICAL TREATMENT OF MORBID OBESITY

TECHNICAL, PSYCHOSOCIAL AND METABOLIC ASPECTS 



\title{
SURGICAL TREATMENT OF MORBID OBESITY TECHNICAL, PSYCHOSOCIAL AND METABOLIC ASPECTS
}

\author{
PROEFSCHRIFT \\ ter verkrijging van de graad van doctor \\ aan de Universiteit van Maastricht, \\ op gezag van Rector Magnificus \\ Prof.dr. A.C. Nieuwenhuijzen Krusemam, \\ volgens het besluit van het College van Decanen, \\ in het openbaar te verdedigen \\ op vrijdag 15 januari 1999 om 14.00 uur
}

door

Wilhelmus Gerardus van Gemert

geboren te Nijmegen op 3 mei 1963 
Promotor

Prof.dr. P.B. Soeters

Co-promotor

Dr. JW.M. Greve

Beoordelingscommissie

Prof.dr. R.W. Stockbrügger (Voorzitter)

Prof.dr. T.W.A de Bruin

Prof.dr. C.J. Van der Linden (Katholieke Universiteit Nijmegen)

Prof.dr. J.A. Romijn (Universiteit Leiden)

Prof.dr.ir. W.H.M. Saris

Prof.dr. H.P. Sauerwein (Universiteit van Amsterdam)

ISBN: $90-9012334-2$

NUGI: 743

Layout: B-Point, Karin Scheele, 's-Hertogenbosch

Cover: Jan Boekhoorn, Nijmegen

Druk: FEBODRUK BV 
Quid faceret eruditio sine dilectone? Inflaret. Quid, absque eruditione dilectio? Erraret.

St. Bernard 



\section{CONTENTS}

Chapter 1 Introduction and aim of this thesis 9

Chapter 2 Surgical treatment of morbid obesity 21

$2.1 \quad$ Long-term results of vertical banded gastroplasty:

Marlex versus Dacron banding 23

2.2 Revisionall surgery after failed vertical banded gastroplasty:

Restoration of vertical banded gastroplasty or conversion to gastric bypass

Chapter 3 Psychosocial aspects of morbid obesity and the effect of surgical treatment

3.1 Quality of life assessment of morbidly obese patients: Effect of weight reducing surgery

3.2 Psychological functioning of morbidly obese patients after surgical treatment

3.3 A prospective quality of life and cost-effectiveness analysis of vertical banded gastroplasty for the treatment of morbid obesity

Chapter 4 Metabolic aspects of morbid obesity and the effect of surgical treatment

4.1 Reduction of sleeping metabolic rate after vertical banded

4.2 Energy, substrate and protein metabolism before, during and after massive weight loss

Summary

Samenvatting

Dankwoord 

Chapter 1

MORBID OBESITY: INTRODUCTION AND AIM OF THIS THESIS 


\section{DEFINITIONS AND EPIDEMIOLOGY}

Obesity is best defined as an abnormal state of health in which there is an excess of body fat ultimately detrimental to health. The following classification of obesty is often used: grade 0 : body mass index (BMI) $20-24.9 \mathrm{~kg} / \mathrm{m}^{2}$ (normal weight), grade I: $B M \mid 25-29.9 \mathrm{~kg} / \mathrm{m}^{2}$ (overweight), grade $11: \mathrm{BM} / 30-40$ $\mathrm{kg} / \mathrm{m}^{2}$ (obesity). grade $11 \mathrm{l}$ : BMl $>40 \mathrm{~kg} / \mathrm{m}^{2}$ (morbid obesity). A person is considered morbidly obese if the BMI is above $40 \mathrm{~kg} / \mathrm{m}^{2}$ or if the percentage excess weight is more than $100 \%$ above ldeal body weight as determined by the 1983 Metropolitan Life Insurance Tables ${ }^{1}$.

The prevalence of obesity $\left(\mathrm{BMI}>30 \mathrm{~kg} / \mathrm{m}^{2}\right)$ in Europe is estimated to be $10-18 \%$ for men and $15-30 \%$ for women ${ }^{2}$. The prevalence of morbid obesity in Europe is not exactly known. In the USA the prevalence of morbid obesity is estimated to be $6 \%$. Furthermare, epidemiological studies demonstrate an increasing prevalence of obesity over the years ${ }^{4}$. Traditional societies undergoing the process of economic modernization exhibit a rapidly increasing prevalence of obesity 5.6 . Obesity has become a serious and widespread health problem in societies characterized by economic modernization and food surplus.

Epidemiological studies revealed striking differences between social groups at risk for obesity. An universal sexual dimorphism in human exists in the site of distribution of fat tissue as well as the prevalence of obesity. The peripheral body fat of women is accumulated in the hips and legs and obesity is more prevalent in women ${ }^{8,9}$. Furthermore, obesity is more prevalent in certain ethmic groups, such as the African Americans ${ }^{10}$, Puerto Ricans ${ }^{11}$ and Southern Europeans ${ }^{12}$, and probably reflects an interaction of genes, social class and culture. The most powerful and complex rellationship is found between social class and obesity. A strong positive association exists between social class and obesity in developing countries, because socially dominant groups have better access to strategic resources ${ }^{13}$. However, in affluent and heterogeneous societies a strong inverse relationship between social class and obesity exists ${ }^{14.15}$. This applies especially for women. Causes may be linked to educational level and cultural influences. Economically advantaged girls are initially more obese than their poor counterparts, but as aduits they have less overweight and obesity ${ }^{16}$. Men of low socioeconomic status may escape obesity when they are performing heavy manual labour ${ }^{17}$.

Family studies have shown that parents and their offspring correlate approximately 0.20 to 0.30 for $B M^{18,19}$. To investigate the genetic and environmental causes of obesity as a famillial disorder adoption studies and twin studies were performed. Adoption studies showed that the BMI of adoptees was closely related to the BMI of their biological parents and not at all related to the $B M \|$ of their adoptive parents $20,21,22$. The results of twin studies suggested a strong genetic influence of obesity. The intraclass correlation of 
the BMI of monozygote twins is very high $(0.77-0.84)$ and twice the intraclass correlation of the BMI of dizygote twins ${ }^{23}$. When monozygote twins are raised apart in a different environment the intraclass correlation is only slightly lower r.24 $^{23}$.

The results of epidemiological studies suggest that genetic influences largely determine whether a person can become obese, whereas the environment determines whether such a person does become obese.

\section{MORBID OBESITY RELATED MORBIDITY AND MORTALITY}

Morbid obesity is accompanied by a high incidence of comorbidity and an accelerated mortality. Cowan et al. defined morbid obesity as a lifelong, progressive disease of fat storage manifested by medical, physical, psychological, social and economic comorbidities ${ }^{25}$. The medical conditions associated with morbid obesity are numerous: Coronary heart disease, hypertension, pulmonary insufficiency, thromboembolism, diabetes mellitus, cancer (endometrium, breast, prostate, kidney, colon), hepatobiliary disease, renal disease, osteoarthritis, skin problems, infertility, sleep apnea, etc. ${ }^{26 \cdot 32}$. The obesity-related comorbidities are responsible for an increased mortality rate. Although some epidemiological studies show that an elevated body weight is associated with an increased morbidity and mortality, they do not specifically investigate the morbidly obese population as defined earlier ${ }^{31,33}$. For this reason, the mortality rate of the morbidly obese is probably more accurately estimated from surgical studies. In the studies of Borelli et al. and Drenick et al. the mortality rates among the morbidly obese patients were seven to 12 times higher than expected ${ }^{34,35}$. It is of interest that all studies investigating the surgical treatment of morbid obesity show a decreased morbidity after weight $\operatorname{loss}^{27,36.40}$. And for this reason it is expected that surgically induced weight loss of the morbidly obese will decrease the mortality rate. Hopefully, the Swedish Obese Subjects Study (SOS) and other studies with large populations which include morbidly obese patients, will elucidate wether surgical treatment of morbidly obese patients will reverse the increased morbidity and mortality rates ${ }^{41}$.

Morbidly obese persons are not only hampered by medical comorbidity, but also suffer from significant prejudice and discrimination. Such prejudice has been observed in children as young as six years of age and in adults ${ }^{42-45}$. This attitude towards obese persons has not changed, although the psychopathology observed in obese individuals is now seen as a consequence rather than a cause of obesity, at least from a scientific point of view ${ }^{46}$. Weight-related prejudice is often accompanied by discrimination and results in a decreased quality of life, social isolation, unsatisfactory relationships, difficulties in finding suitable jobs, etc. ${ }^{46-54}$. Several studies 
demonstrated that weight loss after surgical treatment resulted in an improved quality of life, reversal of psychopathology, more satisfactory interpersonal relationships, better jobs and job promotion ${ }^{4,55-62}$.

\section{GASTRIC BYPASS AND VERTICAL BANDED GASTROPLASTY FOR THE TREATMENT OF MORBID OBESITY: HISTORICAL BACKGROUND}

The seeds for modern obesity surgery were planted by Kremen et al. in the early $1950{ }^{\prime} \mathrm{s}^{63}$. Kremen et al. investigated the nutritional adjustments after resection of comparable segments of proximal and distal small intestine in dogs. These studies demonstrated that proximal small bowel resection produced minimal weight loss and a tendency to regain weight, while distal small bowel resection produced much larger weight loss. Resection of the ileum resulted in fat malabsorption and to a lesser degree protein malabsorption. Animals with an intact ileocecal valve tended to compensation and stabilization of there weight, while animals without the ileocecal valve continued to lose weight. Kremen also performed the first jejunoileal bypass in 34-year-old woman, which was very conservative with $90 \mathrm{~cm}$ of jejunum anastomosed to $45 \mathrm{~cm}$ of ileum. Payne et al. reported their results in which a "planned, controlled intestinal bypass procedure was performed ${ }^{54}$. Payne described ten patients in whom a end-to-side jejunocolic shunt was produced. The jejunum was divided 15-20 inches from the ligament of Treitz and anastomosed to the transverse colon. Lewis et al. and Shibata et al. also reported their results with the jejunocolic bypass ${ }^{65.66}$. The jejunocolic shunt was abandoned because of uncontrollable diarrhea, severe fluid and electrolyte disturbances and hepatic failure.

Later, Payne and DeWind advised against the jejunocolic shunt and instead proposed a jejunoileostomy ${ }^{67}$. Payne reduced his original end-to-side $15^{\prime \prime}$ to $5^{\prime \prime}$ anastomosis (preserving 15 inches jejunum and 5 inches of ileum) to a $14^{\prime \prime}$ to $4^{\prime \prime}$ anastomosis, which was widely adopted. Because almost $10 \%$ of the patients failed to lose significant weight due to reflux of nutrients into the bypassed ileum, Scott et al., Salmon and Buchwald et al. modified Payne's procedure to an end-to-end jejunoileal bypass, and drained the bypassed small bowel into the transverse colon, sigmoid or cecum ${ }^{68-70}$. Palmer and Marliss modified Payne's T-shaped end-to-side anastomosis to a $Y$-shaped anastomosis, which directed the food towards the cecum without reflux ${ }^{71}$. Eriksson and Hallberg combined Payne's end-to-end jejunoileal bypass with a cholecystojejunostomy in patients who still had a gallbladder. With this procedure the bacterial overgrowth in the excluded bowel was reduced and bile salt reabsorption increased. In this way this procedure reduced the occurrence of blind loop syndrome and bile-acid-provoked diarrhea ${ }^{72,73}$. The jejunoileal bypass resulted in a long-term excess weight loss of $80 \%$. 
However, the jejunoileal bypass was abandoned because of the high rate and severity of complications requiring rehospitalization $(>50 \%)$. The late side effects were diarrhea and electrolyte disturbances, enteropathy, malabsorption syndromes, liver failure, gall stones, renal disease and arthralgia.

The golden period for the jejunoileal bypass were the late 1960's and early 1970 's. During this time Dr. Mason and Ito began the work that eventually would lead to the development of the gastric bypass and the vertical banded gastroplasty. Based on the observation that patients with large gastric resections for peptic ulcer disease had difficulty maintaining their weight, Mason reasoned that the creation of a small gastric pouch anastomosed to the upper small bowel might produce satisfactory weight loss. In 1969 Mason and Ito introduced the loop gastroenterostomy with transection of the stomach $^{74}$. Originally, the stomach was transected completely with the creation of a $100 \mathrm{ml}$ pouch, which drained in a retrocolic loop gastrojejunostomy of $2 \mathrm{~cm}$. In the following ten years, the stoma size was reduced to $8-12 \mathrm{~mm}$ and the pouch was reduced to $60 \mathrm{ml}^{75.76}$. Alden modified the gastric bypass of Mason, which involved stapling of the stomach without transection and an antecolic loop gastrojejunostomy ${ }^{77}$. And next, Griffen et al. reported their results of a retrocolic Roux-en- $Y$ anastomosis between the gastric pouch and the jejunum. The gastric pouch of $30 \mathrm{ml}$ or less was created at first with transection of the stomach and later without ${ }^{78}$. Later, Torres et al. created a vertical gastric pouch of $30 \mathrm{ml}$ on the lesser curve by placing a vertical staple line between the angle of $\mathrm{His}$ and the lesser curve. The pouch was drained in a Roux-en-Y gastrojejunostomy at the lesser curve $^{79}$. In time, a lot of modifications of the gastric bypass were applied. Recently, Talieh et all. performed a query among all members of the American Society of Bariatric Surgery (ASBS) to determine the present state of gastric bypass by consensus ${ }^{80}$. It was concluded that the preferred gastric bypass is a vertical pouch of 20-25 $\mathrm{ml}$ on the lesser curve drained in a Roux-en- $Y$ gastrojejunostomy of $12 \mathrm{~mm}$ without restrictive bands or rings.

The gastroplasties were developed to reduce the difficulty of gastric reduction operations and to reduce operative morbidity and risk. It was reasoned that a small pouch and small stoma should be enough to restrict eating and bypass would not be necessary. In 1971 the horizontal gastroplasty was introduced by Mason at the University of lowa ${ }^{8.1}$. The stomach was divided in a horizontal fashion creating a small upper pouch and leaving a small passage or stoma on the greater curve. However, weight loss was inadequate due to dilatation of the fundal pouch or stoma and the procedure was abandoned. In 1977 Gomez modified the horizontal gastroplasty $^{82}$. Gomez used a stapling device to create the horizontal pouch and reinforced the greater curve channel with a plastic mesh and later with polypropylene sutures. The plastic mesh caused stenosis and obstruction and 
the polypropylene sutures cut through the stomach wall which allowed the stoma to dilate again. Mason described the use of a polypropylene mesh to reinforce the greater curve stoma after division of the stomach between the staples $^{31}$. Freeman placed multiple sutures around the greater curve stoma, but this resulted in poor weight loss and frequent early leaks or stoma obstruction ${ }^{83}$. Pace et al. introduced the gastric partitioning which consisted of stapling across the stomach creating a $50 \mathrm{ml}$ horizontal pouch with three staples removed from the midportion of the cartridge ${ }^{84}$. This procedure caused stricture and obstruction of the stoma in some patients and later the stoma dilated. Disruption of the staple line in this procedure could not be prevented by suturing the staple line next to the stoma ${ }^{85}$. Another common procedure was the anterior gastro-gastrostomy. But this procedure also caused early stoma obstruction and unsatisfactory weight loss ${ }^{86}$. Kroyer and Grace were the first to use a Marlex mesh to reinforce the greater curvature stoma ${ }^{87.88}$. The greatest problem of this procedure was kinking from adherence of the Marlex mesh to the diaphragm, which caused obstruction of the stoma. Also a few erosions of the Marlex mesh accurred over the years for both Kroyer and Grace. Tretbar et al. developed the fundic exclusion which consisted of a vertical stapling of the stomach along the lesser curve creating a vertical pouch without reinforcement ${ }^{89}$. Hereafter, everyone used a shorter vertical pouch and reinforced the outlet. Eckhout used a running seromuscular polypropylene suture, Laws used a nonabsorbable suturethreaded silastic catheter and O'Leary used an absorbable suture tied around the lesser curve and covered with interrupted silk sutures to fashion an artificial pylorus ${ }^{90-92}$. In 1982 Mason introduced the vertical banded gastroplasty which has undergone only minor modifications ${ }^{93}$. A vertical pouch of $10-20 \mathrm{ml}$ under a $70 \mathrm{~cm}$ head of water pressure is created along the lesser curve by means of a four-row stapler line (TA 90-B). The stoma should be $10-12 \mathrm{~mm}$ in diameter with reliable calibration. The outlet is reinforced with a Marlex mesh via a window through the stomach, so that the mesh can be sewn to itself.

From the large variety of gastroplasties and intestinal bypasses, the gastric bypass and the vertical banded gastroplasty stood through the test of time and are still the most frequently performed procedures for the treatment of morbid obesity ${ }^{94}$.

\section{AIM OF THIS THESIS}

The main purpose of this thesis was to investigate the effectiveness of the surgical treatment of morbid obesity, together with the psychosocial and metabolic consequences. Furthermore, we tried to find arguments for a 
causal relationship between psychosocial determinants or metabolic (nonpsychosocial) processes and morbid obesity.

The causes and consequences of obesity are often investigated in intervention studies provided with a weight loss program. These studies usually consist of moderately obese subjects undergoing limited weight loss after a dietary intervention. The surgical study population consists of morbidly obese patients undergoing massive and sustained weight loss after surgical treatment. The latter study model has several obvious advantages. Underlying pathological metabolic processes are more likely to be present in morbidly obese patients. Surgical treatment generally results in a massive weight loss and as a consequence the effects are larger and detectable with less difficulties. Long-term effects can be studied since weight loss after surgical treatment is maintained for several years in the majority of patients.

In chapter 2, the results of the primary and secondary surgical procedures for the treatment of morbid obesity, as applied by the surgical department of the University Hospital Maastricht, are described. Paragraph 2.1 describes the long-term results of vertical banded gastroplasty with a Marlex or Dacron band and paragraph 2.2 is focused on the results of secondary bariatric procedures for failed vertical banded gastroplasty.

In chapter 3, the psychosocial and economic aspects of morbid obesity and the effects of surgical treatment are described. Paragraph 3.1 deals with the quality of life of morbidly obese patients and the effect of surgically induced weight loss, while paragraph 3.2 is more specifically directed towards the psychological profile of morbidly obese patients and the influence of surgical treatment. Paragraph 3.3 presents a cost-effectiveness analysis of vertical banded gastroplasty for the treatment of morbid obesity.

In chapter 4, metabolic aspects of morbid obesity and the effect of surgically induced weight loss are investigated with special attention to energy metabolism, body composition and substrate metabolism. In paragraph 4.1, the effect of surgically induced weight loss on sleeping metabolic rate and body composition is investigated. Specifically, to find evidence for a metabolic origin of morbid obesity (body weight setpoint theory). Paragraph 4.2 presents a study which investigates the effect of surgically induced weight loss on energy, substrate and protein metabolism in more detail. The effects on total energy expenditure, sleeping and non-sleeping metabolic rate, physical activity, body composition, protein, carbohydrate and fat metabolism are studied to explore in more detail the possible mechanisms underlying morbid obesity and to study the metabolic effects of massive weight loss. 


\section{REFERENCES}

1. 1983 Metropolitan Height and Weight Tables. Statistical Bulletin Metropolitan Life Insurance Company. 1983,64:2.

2. Seidell $1 \mathrm{C}$, Deerenberg 1 . Obesity in Europe. Prevalence and consequences for use of medical care. Pharmaco Economics $1994 ; 5$ (suppl. 1):38-44.

3. Drenick EJ. Definition and health consequences of morbid obesity. Surg Clin North Am $1979.59: 963-976$

4. Seidell JC. Obesity in Europe. Scaling an epidemic. Int J Obes 1995;19 (suppl.3): $51-54$

5. Christakis $G$. The prevalence of adult obesity. In: Bray $G$, ed. Obesity in perspective, vol.2. Bethesda: Fogarty international Center Series on Preventive Medicine, 1975; $209-213$.

6. Trowell HC, Burkitt DP. Western diseases: Their emerge and prevention. Cambridge, MA: Harvard University Press, 1981.

7. Brown PJ. Culture and the evolution of obesity. Hum Nature 1991:2:31-57.

8. National Center for Health Statistics. Health, US, 1989. Hyattsville, MD: Public Health Service. 1990.

9. Kissebah AH, Freedman DS, Peiris AN. Health risks of obesity. Med Clin North Am $1989: 73: 111-138$.

10. Gillum RF. Overweight and obesity in black women. J Natl Med Assoc 1987;79: $865-871$.

11. Centers for Disease Control. Prevalence of overweight for Hispanics-United States, 1982-1984. MMWR 1989:38:838-842.

12. Seidell JC, Cigolini M, Charzewska J, Ellsinger BM, Contaldo F. Regional obesity and serum lipids in European women born in 1948. A multicenter study. Acta Med Scand 1988;723:189-198.

13. Arteaga P, Dos Santos JE, Dutra de Oliveira JE. Obesity among schoolchildren of different socioeconomic levels in a developing country. Int $\mathrm{J}$ Obes 1982;6:291-297.

14. Goldblatt PB. Moore ME, Stunkard AJ. Social factors in obesity. JAMA 1965:192: $1039-1044$.

15. Sobal J. Obesity and socioeconomic status: a framework for examining relationships between physical and social variables. Med Anthropol 1991:13:231-248.

16. Garn $S M$ Clark DC. Trends in fatness and the origin of obesity. Pediatrics 1976,57: 443.456 .

17. Silverstone $\sqrt{ }$ C, Gordon RP, Stunkard AJ. Practitioner 1969:202:682-688.

18. Khoury P. Morrison JA, Laskarzewski PM, Glueck CJ. Parent/offspring and sibling body mass index associations during and after sharing common household environments: the Princeton School District Family Study. Metabolism 1983:32:82-89.

19. Moll PP. Burns TL. Lauer RM. The genetic and environmental sources of body mass index variability: the Muscatine Ponderosity Family Study. Am J Hum Genet $1991 ; 49: 1243 \cdot 1255$

20. Price RA, Cadoret RJ, Stunkard AJ, Troughton E. Genetic contributions to human fatness: a adoption study. Am J Psychiatry 1987:144:1003-1008.

21. Sorensen TIA, Price RA. Stunkard A.J. Schulsinger F. Genetics of obesity in adult adoptees and their biological siblings. Br Med $\downarrow 1989 ; 298: 87 \sim 90$.

22. Stunkard AJ, Sorensen TIA, Hanis $C$. Teasdale TW, Chakraborty $R$, Schull WJ, Schulsinger F. An adoption study of human obesity. N Eng $\$$ Med 1986;314:193-198.

23. Slunkard A.J. Foch TT. Hrubec Z. A twin study of human obesity. JAMA 1986;256: 52-54. 
24. Price RA, Gottesman II. Body fat in identical twins reared apart: roles for genes and environment. Behav Genet 1991:21:1-7.

25. Cowan GSM, Cowan KB, Hiler ML, Smalley MD, Sehner W. Obesity stereotypes. Probi Gen Surg 1992:9:218-226.

26. Kral JG. Morbid obesity and related health risks. Ann Int Med 1985:103:1043-1047.

27. Drenick EJ. Definition and health consequences of morbid obesity. Surg Clin North Am 1979;59:963-976.

28. Surgical management of morbï obesity. Eds. WO Griffen, Ka Printen. Marcel Dekker Inc. New York/Basel 1987.

29. Angel A, Winocur JT, Roncari DAK. Morbid obesity - The problem and its consequences. In: Surgery for the morbidly obese patient. Eds. Deitel M. Lea \& Febiger, Philadelphia/London 1989.

30. Bray GA. Complications of obesity. Ann Int Med 1985,103:1052-1062.

31. Sjöström LV. Morbidity of severely abese subjects. Am J Clin Nutr 1992;55:508S-515S.

32. Kral JG. Morbid obesity: Definitions, epidemiology, and methodological problems. Gastroenteral Clin North Am 1987;16:197-205.

33. Sjöström LV. Montality of severely obese subjects. Am J Clin Nutr 1992; 55:516S-523S.

34. Drenick EJ Gurunanjappa SB, Seltzer FSA, Johnson DG. Excessive mortality and causes of death in morbidly abese men. JAMA 1980;243:443-445.

35. Borelli $R$, Isernia $C$, Di Biase $G$, Contaldo $F$. Mortality rate, causes and predictive factors of death in severely obese patients. Int J Vitam Nutr Res 1988:58:343-350.

36. Pories WJ, Swanson MS, MacDonald KG, Long SB, Morris PG, Brown BM, Barakat HA. deRamon RA, Israel G, Dolezal JM. Who would have thought it? An operation proves to be the most effective therapy for adult-onset diabetes mellitus. Ann Surg 1995;222: 339-352.

37. Flickinger EG, Pories WJ "Meelheirm HD, Sinar DR, Blose IL, Thomas FT. The Greenvile gastric bypass. Progress report at 3 years. Ann Surg 1984;199:555-560.

38. Brolin RE. Critical analysis of results: Weight loss and quality of life data. Am J Clin Nutr $1992,55: 5775-581 \mathrm{~S}$.

39. Hall JC. Watts JM, O'Brien PE, Dunstan RE, Walsh JF, Slavotinek AH, et al. Gastric surgery for morbid obesity. The Adellaide study. Ann Surg 1990;211:419-427.

40. Benotti BN, Bistrian $B$, Benotti JR, Blackburn $G$, Forse RA. Heart disease and hypertension in severe obesity: The benefits of weight reduction. Am J Clin Nutr $1992 ; 55: 5865-5905$

41. Sjoström L, Larsson B, Backman L, Bengtsson K, Bouchard C, Dahlgren S, Hallgren P.

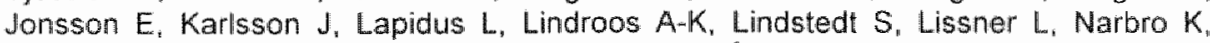
Näslund I, Olbe L. Sullivan M, Sylvan A, Wedel H, Agren G. Swedish Obese Subjects (SOS). Recruitment for an intervention study and a selected description of the obese state. Int J Obes 1992;16:465-479.

42. Staffieri JR. A study of social stereatype of body image in children. I Pers Soc Psychol 1967:7:101-104.

43. Goodman N, Dornbusch SM, Richardson SA, Hastorf AH. Variant reactions to physical disabilities. Am Sociol Rev 1963:28:429-435.

44. Maddox GL, Back K, Liederman V. Overweight as social deviance and disability. J Health Soc Behaw 1968;9:287-298

45. Richardson SA, Goodman N, Hastorf AH, Dornbusch SM. Cultural uniformily in reaction to physical disabilities. Am Sociol Rev 1961;26:241-247.

46. Obesity. Theory and Therapy. AJ Stunkard, TA Wadden eds. Raven Press. New York, 1993.

47. Kral JG, Sjöström LV. Sulliwan MBE. Assessment of quality of life before and after surgery for severe obesity. Am J Clin Nutr 1992;55(suppl):611S-614S. 


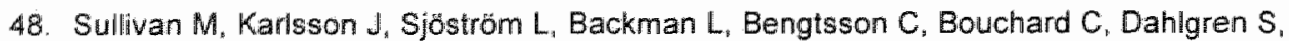
Jonsson E, Larsson B, Lindstedt S. Swedish Obese Subjects (SOS) - an intervention study of obesity. Baseline evaluation of health and psychosocial functioning in the first 1743 subjects examined. Int J obes 1993;17:503-512.

49. Roe DA, Eickwort KR. Relationships between obesity and associated health factors with unemployment among low-income women. J Am Med Wom Assoc 1976;31:193-194. 198-199, 203-204.

50. Goldblatt PB, Moore ME, Stunkard A.J. Social factors in obesity. JAMA 1965;192: $1039-1044$.

51. Soball J. Stunkard A.J. Socioeconomic status and obesity: A review of the literature. Psychol Bull 1989:105:260-275.

52. Johnson SF, Swension WF, Gastineau CF. Personality characteristics in abesity: Relation of MMPI profile and age of onset of obesity to success in weight reduction. Am $\checkmark$ Clin Nutr $1976 ; 29: 626-632$.

53. Pomerantz AS, Greenberg S, Blackburn GL. MMPI profiles of obese men and women. Psychol Rep 1977:41:731-734

54. Rosen LW, Aniskiewicz AS. Psychosocial functioning of two groups of morbidly obese patients. Int J Obes 1983;7:53-59.

55. Rand SCW, Mecgregor AMC. Successfull weight loss following obesity surgery and the perceived liability of morbid obesity. Int \& Obes 1991:15:577-579.

56. Sarlio-Lähteenkorva S, Stunkard A, Rissanen A. Psychosocial factors and quality of life in obesity. Int J Obes 1995;19(suppl): S1-S5.

57. Hafner RJ, Watts JM, Rogers J. Quality of life after gastric bypass for morbid obesity. Int J Obes 1991;15:555-560.

58. Martin LF, Tan TL, Holmes $P A$, et al. Preoperative insurance status influences postoperative complication rates for gastric bypass. Am J Surg 1991;161:625-634.

59. Näslund I, Agren G. Social and economic effects of bariatric surgery. Obes Surg 1991; $1: 137-140$.

60. Solow $C_{\text {n }}$ Silberfarb PM, Swift $K$. Psychosocial effects of intestinal bypass surgery for severe obesity. N Eng J Med 1974;290:300-304.

61. La Manna A, Ricci GB, Giorgi I, Gossemberg M, La Manna L, Catona A. Psychological effects of vertical banded gastroplasty on pathologically obese patients. Obes Surg 1992;2:239-243.

62. Harris MB, Green D. Psychosocial effects of gastric reduction surgery for obesity. Int $J$ Obes 1982;6:527-539.

63. Kremen $\mathrm{AJ}$, Linner JH. Nelson $\mathrm{CH}$. An experimental evaluation of the nutritional importance of proximal and distal small intestine. Ann Surg 1954:140:439-448.

64. Payne JH, DeWind LT, Commons RR. Metabolic observations in patients with jejunocolic shunts. Am J Surg 1963:106:273-289.

65. Lewis LA, Tumbull RB Jr, Page IH. Effects of jejunocolic shunt on obesity, serum lipoproteins, lipids and electrolytes. Arch Intern Med 1966;117:4-16.

66. Shibata HR, MacKenzie JR, Long RC. Metabolic effects of controlled jejunocolic bypass. Arch Surg 1967;95:413-428.

67. Dewind LT. Payne $\mathrm{JH}$. Intestinal bypass surgery for morbid obesity: Long term results JAMA 1976;236:2298-2301.

68. Scott HW Jr, Dean RH, Shull HJ. Results of jejunoileal bypass in two hundred patients with morbid obesity. Surg Gynecol Obstel 1977:145:661-673.

69. Salmon PA. The results of small intestinal bypass operations for the treatment of obesity. Surg Gynecol Obstet 1971;132:965-979.

70. Buchwald H, Schwartz MZ, Varco RL. Surgical treatment of obesity. 1973;7:235-255. 
71. Palmer JA, Marliss EB. The present status of surgical procedures for obesity. In:

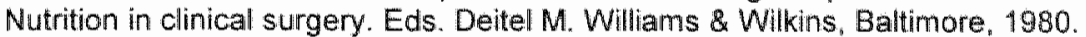

72. Eriksson F. Biliointestinal bypass. Int J Obes 1981:5:437-447.

73. Hallberg D. A suirvey of surgical techniques for treatment of obesity and a remark on the bilio-intestinal bypass method. Am J Clin Nutr 1980;33(suppl): $499-501$.

74. Mason EE, Ito C. Gastric bypass. Ann Surg 1969;170:329-339.

75. Printen KJ "Mason EE. Gastric surgery for relief of morbid obesity. Arch Surg 1973;106: 428-431.

76. Mason EE. Printen KJ, Blommers Td, Scott DM. Gastric bypass for obesity after 10 years experience. Int J Obes 1978:2:197-206.

77. Aiden JF. Gastric and jejunoileal bypass. Arch Surg 1977;112:799-806.

78. Griffen WO Jr, Young VL, Stevenson CC. A prospective comparison of gastric and jejunoileal bypass procedures for morbid obesity. Ann Surg 1977:186:500-509.

79. Torres JC, Oca CF. Garrison RN. Gastric bypass: Roux-en-Y gastrojejunostomy from the lesser curvature. South Med J 1983;76:1217-1221.

80. Talieh J, Kirgan D, Fisher BL. Gastric bypass for morbid obesity: A standard surgical technique by consensus. Obes Surg 1997;7:198-202.

81. Mason EE. Surgical treatment of obesity. WB Saunders, Philadelphia, 1981.

82. Gomez CA. Gastroplasty in the surgical treatment of morbid obesity. Am J Clin Nutr 1980;33(2 suppl): 406-415.

83. Freeman $\mathrm{JB}$, Burchett $H \downarrow \Downarrow$. A comparison of gastric bypass and gastroplasty for morbid obesity. Surgery 1980;88:433-444.

84. Pace WG, Martin EW, Tetirick T, Fabri PJ, Carey LC. Gastric partitioning for morbid obesity. Ann Surg 1979;190:392-400.

85. Smith LB. Modification of the gastric partitioning operation for morbid obesity. Am $J$ Surg 1981:142:725-730.

86. Pories WJ, Flickinger EG, Meelheim D, Van Rij AM, Thomas FT. The effectiveness of gastric bypass over gastric partition in morbid obesity. Ann Surg 1982;196:389-399.

87. Kroyer JM. The evolution of horizontal banded gastroplasty. Proceedings of the American Saciety of Bariatric Surgery. 1984;1:143.

88. Grace DM. Use of Marlex in horizontal gastroplasty. Can J Surg 1984;27:231.

89. Tretbar LL, Taylor TT, Sifers EC. Weight reduction, gastric plication for morbid obesity. al Kans Med Soc 1976;77:488.

90. Eckhout GV. Surgery for morbid obesity: Comparison of vertically stapled gastroplasty with gastric bypass. Int J Obes 1981:5:538-543.

91. Laws HL. Standardized gastroplasty orifice. Am J Surg 1981;141:393-394.

92. O'Leary JP. Partition of the lesser curvature of the stomach in morbid obesity. Surg Gynecol Obstet 1982;154:85-86.

93. Mason EE. Vertical banded gastroplasty for obesity. Arch Surg 1982;117:701-706.

94. Renquist KE. Surgical treatment of obesity in America: Data according to the National Bariatric Surgery Registry. Probl Gen Surg 1996;9:231-238. 
$-20-$ 
Chapter 2

SURGICAL TREATMENT OF MORBID OBESITY 
$-22-$ 
Chapter 2.1

LONG-TERM RESULTS OF VERTICAL BANDED GASTROPLASTY: MARLEX VERSUS DACRON BANDING.

Wim G. van Gemert, Jan Willem M. Greve, Peter B. Soeters.

Obesity Surgery 1997:7:1-8. 


\section{ABSTRACT}

Background: The vertical banded gastroplasty (VBG) was originally performed with a Marlex band and characterized by a satisfactory weight loss and low morbidity. The effect of the material used for the banding procedure (Marlex vs Dacron) in VBG is evaluated.

Methods: In 49 consecutive obese patients treated with a VBG, a Marlex band was used in 17 patients and a Dacron band in 32 patients. Data were analyzed retrospectively with regard to the type of band, weight loss and complications.

Results: A significant difference was found in the percentage excess weight five years postoperatively in favor of the Dacron group $(59.2 \%$ vs $39.2 \%$; $p<0.05)$ because of more band-related complications in the Marlex group. The difference in percentage excess weight disappeared eight years postoperatively $(43.3 \%$ vs $46.8 \%)$, due to the renewed weight loss of the Marlex group following reoperation.

Conclusion: The Dacron band is superior to the Marlex band in VBG because sustained weight loss is satisfactory and morbidity is low.

\section{INTRODUCTION}

The vertical banded gastroplasty (VBG) and the gastric bypass are the two operations most frequently used to treat morbid obesity ${ }^{1}$. The VBG results in a restriction of oral intake, while the gastric bypass combines restriction of oral intake with selective malabsorption. Weight loss after gastric bypass appears to be greater than that obtained with VBG, but is associated with a higher incidence of complications ${ }^{2}$. The VBG is often preferred because of its technical simplicity, satisfactory weight reduction and low complication rate ${ }^{3 \cdot 9}$. The VBG was originally developed by Mason in $1982^{10}$. He used a Marlex (polypropylene) mesh band to reinforce the stoma and thus prevent dilatation. The use of foreign material around the stomach wall can cause serious complications such as erosion of the band through the gastric wall.

Erosion of foreign bodies applied to the serosal side of the gastrointestinal tract has been described following several surgical procedures using devices: examples of this are the vertical silastic ring gastroplasty ${ }^{11}$ and the Angelchik prosthesis $^{12}$. The tendency of the Marlex mesh to erode the gastrointestinal wall is also known from several surgical procedures such as the horizontal banded gastroplasty ${ }^{13}$, the Kock pouch continent urinary diversion ${ }^{14}$ and the repair of abdominal wall defects ${ }^{15}$. The material most frequently used to reinforce the stoma in VBG is Marlex. Nevertheless, the reported incidence of Marlex erosion after VBG is low. As a consequence, the potential implications 
of the material used for the banding procedure in VBG has not received much attention in the literature.

In this study we propose the use of a Dacron (woven polyester) band instead of a Marlex band in VBG to overcome this complication. This study was carried out to evaluate the effect of the material used for the banding procedure (Marlex versus Dacron) on long-term surgical complications and weight reduction.

\section{METHODS}

Only morbidly obese patients were selected for the VBG. Patients were considered morbidly obese if their body mass index (BMI) was more than 40 $\mathrm{kg} / \mathrm{m}^{2}$ or if they weighed more than $100 \%$ above ideal body weight, as determined by the 1983 heightweight tables of the Metropolitan Life Insurance Company ${ }^{16}$. All patients had undertaken several unsuccessful attempts at weight reduction by conservative means. The patients were reviewed by a physician and a psychologist to exclude underlying endocrinopathy or psychological disorders. Postoperatively, all patients were checked routinely at the outpatient clinic. Patients were studied retrospectively with regard to the type of band, weight loss and complications.

Body weight is expressed as absolute weight (BW), BMI and percentage excess weight above ideal body weight ( $\%$ EW). Weight loss was analyzed as absolute weight loss (WL) and percentage of excess body weight lost (\%EWL).

This study was performed according to the "intention to treat" principle. Data are expressed as the mean value \pm SD. Differences between complication rates were tested with the Mann-Whitney $U$ test. Analysis of body weight data was performed with the Student's t-test. Statistical significance was set at 0.05 .

\section{SURGICAL TECHNIQUE}

The VBG was performed with a Marlex or Dacron band. Because of the retrospective study design, patients were not randomized. Initially, both materials were used with equal frequency for the banding procedure. After a while only Dacron was used, because a high complication rate was encountered after VBG with a Marlex band. The surgical technique used was identical for both procedures and did not change over time.

The operation was performed under combined general and epidural anesthesia. The epidural catheter was also used for postoperative pain management. The laparotomy was performed through an upper midline 
incision. The proximal pouch was created with aid of a 32 French nasogastric tube. Seven centimeter distal from the angle of His a window was created with the $31 \mathrm{~mm}$ circular stapler (CEEA. Autosuture, Zeist, The Netherlands). With a linear stapler (TEA-90B, Autosuture, Zeist, The Netherlands) four staple-lines were applied as close as possible to the lesser curve, running from the angle of His to the circular stapler hole creating a pouch of $20 \mathrm{ml}$. The pouch volume was not measured at $70 \mathrm{~cm}$ of water pressure. The pouch exit was reinforced with a Marlex or Dacron band (width $1.5 \mathrm{~cm}$, final circumference $5 \mathrm{~cm}$, overlap $2 \mathrm{~cm}$ ) sutured to itself with prolene sutures in most cases. Initially, silk sutures were used in a few cases for this procedure. The Dacron band was constructed from a Dacron vascular prosthesis of 18 $\mathrm{mm}$. This resulted in a Dacron band of two layers because the tubular prosthesis was not opened. The Marlex or Dacron band was covered with omentum to prevent adherence of surrounding tissues. Abdominal drains were not used. The abdominal wall was secured in layers with a running resorbable vicryl suture for the rectus aponeurosis and a running nonabsorbable suture for the skin.

Perioperatively, patients received intravenous prophylactic antibiotic (cefuroxim) and subcutaneous heparin. The nasogastric tube was generally removed on the second postoperative day. All patients received vitamin $A, B$, $D$ and iron supplementation for one year after operation.

\section{RESULTS}

\section{Growp characteristics}

From October 1984 till May 1993, 49 consecutive morbidly obese patients were treated with a VBG as described by Mason ${ }^{10}$. Seventeen patients underwent a VBG with a Marlex band (referred to as the Marlex group) and 32 patients underwent a VBG with a Dacron band (referred to as the Dacron group). Both groups were comparable with regard to age, gender, preoperative weight and excess weight (Table 1). Mean age was $34.4 \pm 9.7$ years in the Marlex group and $30.6 \pm 7.1$ years in the Dacron group. The BMI was $46.8 \pm 4.9 \mathrm{~kg} / \mathrm{m}^{2}$ and $47.0 \pm 7.5 \mathrm{~kg} / \mathrm{m}^{2}$ in the Marlex group and Dacron group respectively. The $\%$ EW was $109.2 \pm 21.0 \%$ in the Marlex group and $112.7 \pm 36.5 \%$ in the Dacron group. For the purpose of this study we reexamined $44(91.7 \%)$ patients. One patient died in the postoperative period and four patients were lost to follow-up because they could not be traced (follow-up $94 \%$; compliance $100 \%$ ). The mean follow up was $81 \pm 49$ months. 
Table 1. Group characteristics.

\begin{tabular}{|lcc|}
\hline & Marlex $( \pm \mathrm{SD})$ & Dacron $( \pm \mathrm{SD})$ \\
\hline Number & 17 & 32 \\
Age $($ years $)$ & $34.4(9.7)$ & $30.6(7.1)$ \\
Female/male & $12 / 5$ & $22 / 10$ \\
BMl $\left(\mathrm{kg} / \mathrm{m}^{2}\right)$ & $46.8(4.9)$ & $47.0(7.5)$ \\
BW $(\mathrm{kg})$ & $133.6(15.7)$ & $142.2(30.9)$ \\
$\%$ EW & $109.2(21.0)$ & $112.7(36.5)$ \\
\hline
\end{tabular}

Data are expressed as the mean with standard deviation given in parentheses. BMI=body mass index; $B W=b o d y$ weight; $E W=e x c e s s$ weight above ideal body weight; $\%$ EW=percentage excess weight above ideal body weight.

Weight loss results

Three years after operation the weight loss was not statistically different between the Marlex and Dacron group. The \%EW decreased to $42.0 \pm 26.2 \%$ in the Marlex group and to $37.3 \pm 27.2 \%$ in the Dacron group, the BMI decreased to $31.8 \pm 5.7 \mathrm{~kg} / \mathrm{m}^{2}$ in the Marlex group and to $30.2 \pm 5.6 \mathrm{~kg} / \mathrm{m}^{2}$ in the Dacron group (Figure 1 and Table 2).

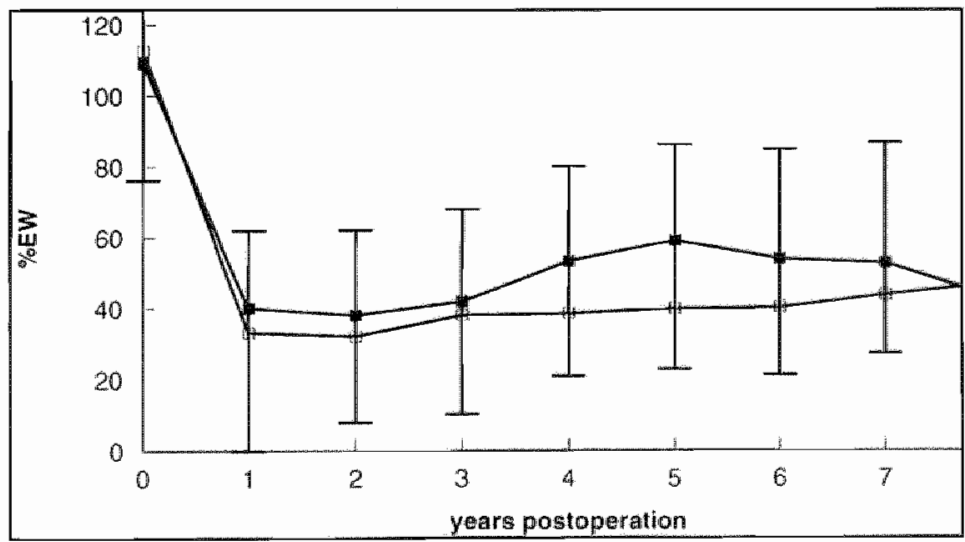

Figure 1. Weight loss after vertical banded gastroplasty with a Marlex band (closed box) or a Dacron band (open box) expressed as the percentage excess weight (\%EW) above ideal body weight. Weight loss is more satisfactory and stable after VBG with a Dacron band. At 8 years postoperation the \% EW is comparable between the two groups due to renewed weight loss of the Marlex group following reoperation. Eight years after the initial operation three of the seven patients in the Marlex group were converted to a VBG with a Dacron band.

${ }^{*} p<0.05$ 
Table 2. Weight loss after vertical banded gastroplasty with a Marlex or Dacron band.

\begin{tabular}{|c|c|c|c|c|c|c|}
\hline & \multicolumn{2}{|c|}{3 years postoperation } & \multicolumn{2}{|c|}{5 years postoperation } & \multicolumn{2}{|c|}{8 years postoperation } \\
\hline & Marlex & Dacron & Marlex & Dacron & Marlex & Dacron \\
\hline Number & 16 & 19 & 14 & 12 & 7 & 5 \\
\hline WL & $42.5(18.6)$ & $48.0(15.2)$ & $31.9(19.4)$ & $40.8(13.4)$ & $36.1(20.8)$ & $33.9(14.2)$ \\
\hline BNAI & $31.8 \quad(5.7)$ & $30.2 \quad(5.6)$ & $35.6 \quad(6.4)$ & $30.7(3.3)^{m}$ & $31.9(7.7)$ & $32.7 \quad(4.8)$ \\
\hline$\% E W$ & $42.0(26.2)$ & $37.3(27.2)$ & $59.2(27.1)$ & $39.2(16.3)$ & $43.3(33.9)$ & $46.8(21.7)$ \\
\hline$\% E W L$ & $61.6(25.6)$ & $66.9(16.7)$ & $44.9(2.5 .0)$ & $60.9(16.0)$ & $57.1(32.1)$ & $52.0(21.8)$ \\
\hline
\end{tabular}

Data are expressed as the mean with standard deviation given in parentheses. WL=absolute weight loss $(\mathrm{kg}) ; B M=$ body mass index $\left(\mathrm{kg} / \mathrm{m}^{2}\right) ; \%$ EW =percentage excess weight above ideal body weight (\%); \%WL=percentage excess weight loss $(\%)$. "p $<0.05$.

Five years postoperatively a marked increase in body weight occurred in the Marlex group, which was explained by band erosion and disruption. At that time the \%EW was $59.2 \pm 27.1 \%$ in the Marlex group and $39.2 \pm 16.3 \%$ in the Dacron group $(p<0.05)$ and the BMI was $35.6 \pm 6.4 \mathrm{~kg} / \mathrm{m}^{2}$ in the Marlex group and $30.7 \pm 3.3 \mathrm{~kg} / \mathrm{m}^{2}$ in the Dacron group $(p<0.05)$.

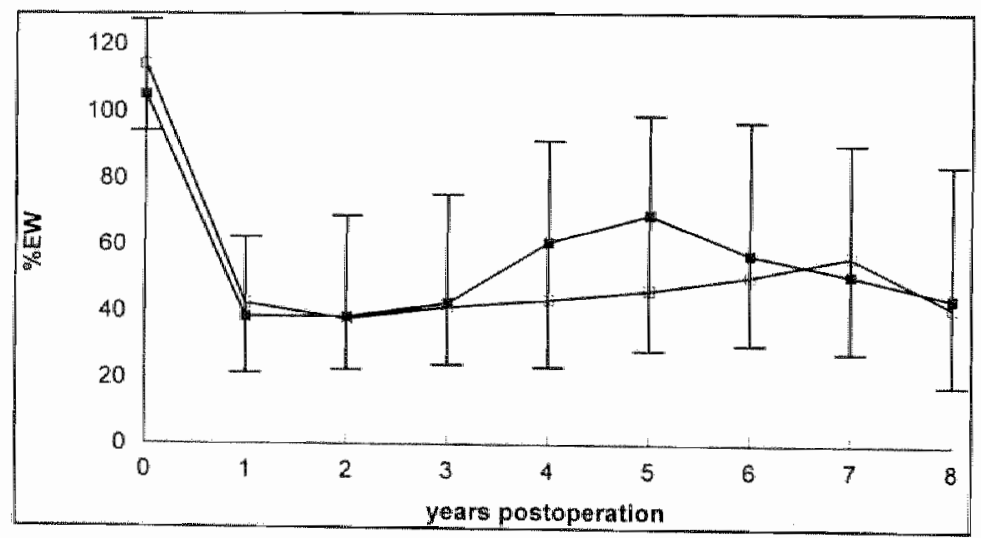

Figure 2. The \%EW after vertical banded gastroplasty with a Marlex band with revision $(n=9$; closed box $)$ and without revision $(n=8$; apen box $)$ is shown. The former group showed a marked increase of percentage excess weight at 3 years after initial surgery. At 8 years after initial surgery the two groups were comparable in terms of \%EW due to revisional surgery. The average time interval from initial surgery to revisional surgery was 46 months.
$* 0<0.05$. 
Eight years postoperatively the weight loss in the Marlex group was corrected and again comparable with the weight loss in the Dacron group due to revisional surgery (Figure 2). The \%EW was $43.3 \pm 33.9 \%$ in the Marlex group and $46.8 \pm 21.7 \%$ in the Dacron group and the BMI was $31.9 \pm 7.7 \mathrm{~kg} / \mathrm{m}^{2}$ in the Marlex group and $32.7 \pm 4.8 \mathrm{~kg} / \mathrm{m}^{2}$ in the Dacron group. It should be noted that eight years after the initial operation three of the seven patients in the Marlex group had undergone a conversion to a VBG with a Dacron band.

\section{COMPLICATIONS}

The overall in-hospital morbidity was similar for the Marlex and Dacron groups. Two patients in the Marlex group had a subphrenic abscess in the direct postoperative period, which required surgical drainage (Table 3 ). The Marlex band was not removed at the time of drainage. These two patients developed a band erosion more than two years after initial surgery. One patient of the Marlex group died as a result of a postoperative leakage and subsequent fulminant sepsis, which did not resolve after relaparotomy. One patient of the Dacron group required enlargement of the band by reoperation within two weeks after initial surgery because the stoma size was too small.

Table 3. In-hospital morbidity and mortality after vertical banded gastroplasty with a Marlex or Dacron band.

\begin{tabular}{|lrrrr|}
\hline & \multicolumn{2}{c}{ Marlex } & \multicolumn{2}{l|}{ Dacron } \\
\hline Wound infection & 0 & & 4 & $(12.5 \%)$ \\
Pneumonia & 1 & $(5.9 \%)$ & 0 & $(3.1 \%)$ \\
Food impaction & 0 & & 1 & $(1.8 \%)$ \\
Subphrenic abscess & 2 & $(11.9 \%)$ & 0 & \\
Leakage & 1 & $(5.9 \%)$ & 0 & \\
Stoma too small & 0 & & 1 & $(3.1 \%)$ \\
Overall morbidity & 4 & $(23.5 \%)$ & 6 & $(18.8 \%)$ \\
Overall mortality & 1 & $(5.9 \%)$ & 0 & \\
\hline
\end{tabular}

* One patient in the Marlex group died in the postoperative period as a result of leakage.

The long-term complications are listed in Table 4. Subclinical deficiencies of vitamin $B_{6}(n=1)$, iron $(n=1)$ or a combined iron and vitamin $B_{12}$ deficiency $(n=1)$ occurred in three patients of the Marlex group. In the Dacron group a vitamin $B_{12}$ deficiency $(n=1)$, vitamin $B_{1}$ deficiency $(n=3)$, vitamin $B_{8}$ deficiency $(n=1)$ and magnesium deficiency $(n=1)$ occurred in six patients. 
Two of these patients developed a polyneuropathy as a resuit of a vitamin $B_{1}$ deficiency in one and a magnesium deficiency in the other. After supplementation of vitamin $B_{1}$ and magnesium the polyneuropathy resolved. Esophagitis was diagnosed endoscopically in five patients in the Marlex group and four patients in the Dacron group.

Table 4. Long-term complications after vertical banded gastroplasty with a Marlex or Dacron band.

\begin{tabular}{|lcccc|}
\hline & \multicolumn{2}{c}{ Marlex } & \multicolumn{2}{c|}{ Dacron } \\
\hline Metabolic & 3 & $(17.6 \%)$ & 6 & $(18.8 \%)$ \\
Neuropathy & 0 & & 2 & $(6.3 \%)$ \\
Esophagitis & 5 & $(29.4 \%)$ & 4 & $(12.5 \%)$ \\
Incisional hernia & 5 & $(29.4 \%)$ & 1 & $(3.1 \%)^{*}$ \\
Cholecystolithiasis & 2 & $(11.8 \%)$ & 0 & \\
Food impaction & 2 & $(11.8 \%)$ & 3 & $(9.4 \%)$ \\
Technical failure & 9 & $(52.9 \%)$ & 2 & $(6.3 \%)^{* *}$ \\
Overall morbidity & 14 & $(87.5 \%)$ & 13 & $(40.6 \%)^{* *}$
\end{tabular}

" $p<0.01 ; " * 0<0.005$

These patients were successfully treated with $\mathrm{H}_{2}$-receptor antagonists. Incisional hernia developed in five patients of the Marlex group and one patient of the Dacron group. Only two patients of the Marlex group needed operative correction of their incisional hernia. The other patients had a small incisional hernia detected by physical examination which caused no symptoms.

Long-term technical failures were related to the band size or material (Table 5). The stoma size had to be adjusted in two patients in the Dacron group during the late postoperative period. After correction of the band size these patients exhibited a good weight loss. In the Marlex group technical failures occurred in nine patients. The band size was adjusted in one patient in the Marlex group because the stoma size was too large. This patient had a relapse after initial weight loss two years after revision caused by a staple-line disruption for which a second reoperation was necessary. One patient of the Marlex group was converted to a gastric bypass because of stomal stenosis with severe reflux esophagitis. This patient showed satisfactory weight loss after reoperation.

Stomal dilatation due to band disruption occurred in three patients in the Marlex group compared to none in the Dacron group. In all patients the stomal dilatation was diagnosed by endoscopic examination. In these patients the VBG was restored with a Dacron band. Only one of these patients showed an 
unsatisfactory result caused by a subphrenic abscess in the immediate postoperative period, which required surgical drainage and removal of the Dacron band.

Table 5. Long-term technical failures related to the band size or material after vertical banded gastroplasty (VBG).

\begin{tabular}{|c|c|c|c|c|c|}
\hline Patient & Operation & Complication & Interval & Revision & Result \\
\hline 1 & VBG Dacron & stoma too small & 2 weeks & enlaigement & good weight loss \\
\hline 2 & VBG Dacron & stoma too small & 6 weeks & enlargement & good weight loss \\
\hline 3 & VBG Dacron & stoma too large & 10 months & tightening & good weight loss \\
\hline 4 & VBG Marlex & $\begin{array}{l}\text { stomal stenosis + } \\
\text { severe } \\
\text { esophagitis }\end{array}$ & 21 months & $\begin{array}{l}\text { gastric } \\
\text { bypass }\end{array}$ & $\begin{array}{l}\text { Satisfactory welgh } \\
\text { loss }\end{array}$ \\
\hline 5 & VBG Marlex & stoma too large & 22 months & tightening & $\begin{array}{l}\text { staple-line } \\
\text { disruption after } \\
\text { initial weight loss }\end{array}$ \\
\hline 6 & VBG Marlex & band disruption & 62 months & VBG Dacron* & good weight loss \\
\hline 7 & VBG Marlex & band disruption & 12 months & VBG Dacron* & $\begin{array}{l}\text { band removal for a } \\
\text { subphrenic abscess } \\
\text { satisfactory weight } \\
\text { loss }\end{array}$ \\
\hline 8 & VBG Marlex & band disruption & 61 months & VBG Dacron* & good weight loss \\
\hline 9 & VBG Marlex & band erosion & 72 months & band removal & $\begin{array}{l}\text { enterocutaneous } \\
\text { fistula/good weight } \\
\text { loss }\end{array}$ \\
\hline 110 & VBG Marlex & band erosion & 24 months & band removal & $\begin{array}{l}\text { Unsatisfactory } \\
\text { weight loss }\end{array}$ \\
\hline 11 & VBG Marlex & lband erosion & 20 months & $\begin{array}{l}\text { proximal } \\
\text { gastric } \\
\text { resection }\end{array}$ & good weight loss \\
\hline 12 & VBG Marlex & band erosion & 68 months & VBG Dacron" & good weight loss \\
\hline
\end{tabular}

* VBG with Marlex band was restored with a Dacron band. 
Band erosion through the gastric wall occurred in four patients in the Marlex group compared to none in the Dacron group $(p<0.005)$. In two of these patients the Marlex band was located inside the gastric lumen only attached by a small bridge of mucosa on the dorsal side. In both patients the Marlex band was removed. One of them developed an enterocutaneous fistula, which was managed conservatively. In the third patient the Marlex band was perforated through the ventral side of the gastric wall. Because the large defect of the gastric wall was accompanied by a pus collection, a proximal gastric resection was performed. This patient showed a good weight loss after reoperation. In the fourth patient the Marlex band had completely disappeared. It was assumed that the Marlex band was excreted via the digestive tract after complete erosion. In this patient the VBG was restored with a Dacron band, which resulted in a good weight loss. Band erosion was diagnosed in three patients by endoscopic examination. One patient refused endascopy.

All patients with band erosion and stomal dilatation due to band dispuption had regained unlimited eating capacity and showed a prompt increase of body weight. Two patients showed transient symptoms of upper gastrointestinal obstruction. The average time interval from the initial operation until the reoperation was 45 months (range 12-62 months) for band erosion and 46 months (range 20-72 months) for band disruption.

\section{DISCUSSION}

The VBG is the most commonly performed bariatric procedure in the USA ${ }^{\prime}$. The reported weight reduction three years postoperatively is $33-63.5 \%$ excess weight loss $3,6,7,17-20$. Our three years results compare favorable with these results. There are only few studies reporting results extending beyond three years postoperation ${ }^{3,6,7}$. MacLean et al. ${ }^{7}$ found a $\%$ EWL of $60 \%$ five years postoperatively; Mason et al. ${ }^{3}$ achieved $58.8 \%$ EWL at five years postoperation. In the present study the VBG with a Marlex band and Dacron band resulted in a $\%$ EWL five years postoperatively of $44.9 \%$ and $60.9 \%$ respectively. The mean $\% \mathrm{EW}$ in the Marlex group increased from $42.0 \%$ at three years to $59.2 \%$ at five years postoperation, caused by the high incidence of technical failures, especially band erosion and disruption. Because the incidence of technical failures was much lower in the Dacron group, a significant difference in the \%EW occurred five years postoperatively in favor of the Dacron group (59.2\% vs $39.2 \% ; p<0.05)$. Due to revisional surgery the $\%$ EW eight years postoperatively was comparable between the Marlex 
and Dacron group, $43.3 \%$ and $46.8 \%$ respectively. At this time three of the seven patients in the Marlex group were converted to a VBG with a Dacron band and one patient was converted to a gastric bypass. These data show that successful weight loss can be achieved by careful followup of the patients and reoperation if weight loss is unsatisfactory, because insufficient weight loss may be caused by technical failure.

The incidence of revisional surgery after VBG is reported to be $0 \%$ $41 \%, 4,7,10,19,21-23$. In the present study the revision rate was $9.4 \%$ for the Dacron group and $52.9 \%$ for the Marlex group. The high rate of revisional surgery in the Marlex group compared to the literature is probably caused by the biomechanic properties of the Marlex band. It is unlikely to be the consequence of a learning curve as revisional surgery was barely necessary after Dacron banding. The most important indications for revisional surgery were band erosion and stomal dilatation. Acute stomal dilatation more than one year after operation can only be explained by disruption of the band. Since there are no reports of this complication in the literature, band disruption probably occurred because the silk sutures, which were initially used to fix the band in a few cases, dissolved. The use of silk sutures to fix the band to itself is clearly a technical error. Currently only nonabsorbable suture material (Prolene) is used. The patients with band disruption were converted to a VBG with a Dacron band, although the band material was probably not responsible for the band disruption. At the time of reoperation the Dacron band was already used as the standard material for the banding procedure in VBG.

Marlex erosion was the most serious indication for revisional surgery. The incidence of Marlex erosion after horizontal gastroplasty is $6 \%$. $24 \%{ }^{13,24}$. Grace et al.$^{13}$ found an average interval of 44 months between initial surgery and reoperation for Marlex erosion, almost identical to the results of the present study. Endoscopic examination proved to be the most helpful procedure in establishing the diagnosis. The reported incidence of band erosion after VBG is $0.4-3 \% \%, 8,10,18,25$. This complication is not given much consideration in most reports.

In the current study band erosion occurred only in the Marlex group, in $23.5 \%$ of the patients. Two of these patients had a subphrenic abscess in the early postoperative period, which could be the explanation for the band erosion. Foreign material is known for its erosiveness if there is an infection. However, the other two cases with band erosion did not have any signs of infection. The incidence of Marlex erosion in the literature is possibly underestimated due to incorrect diagnosis after weight gain or 
to an inadequate follow-up. Studies with a follow-up of three years or less will underestimate this complication, because the mean time between the diagnosis and reoperation is 45 months. Even during operation the recognition of Marlex erosion can be difficult because it is obscured by an inflammatory mass and adhesions to surrounding organs. The Marlex band is often located completely inside the gastric wall. Grace et al. ${ }^{13}$ point out that band erosion can be easily mistaken for staple line disruption in horizontal banded gastroplasty. Furthermore, patients who gain weight feel ashamed and guilty. They tend to withdraw from follow-up.

The mechanism by which erosion occurs has not yet been elucidated. The tendency of Marlex mesh to erode the bowel is well known from the repairs of large abdominal wall defects. Despite the short term advantages of Marlex mesh in the repair of abdominal wall defects, long term follow-up reveals mesh erosion, formation of extensive adhesions, chronic infection and sometimes enteric fistulas ${ }^{15,26-28}$. Experimental studies in animals and humans showed that implanted Marlex, compared to other biomaterials, generates a greater inflammatory response, local fibrosis and the formation of adhesions which tend to adhere strongly to adjacent tissue ${ }^{29.30,31}$. Pans and Pierard ${ }^{32}$ demonstrated that macroporous materials like Marlex enhance the process of fibroblastic infiltration and the incorporation of tissue into the area of the implant. These properties of Marlex may be responsible for the tendency of the Marlex band in VBG to erode through the gastric wall. In this study, erosion of the Dacron band did not occur. The patients of the Marlex group who had undergone a conversion to a VBG with a Dacron band did not show any signs of erosion. Therefore, Dacron appears to be a more suitable material for the banding procedure in VBG and can be successfully used in revisional surgery.

In conclusion, the VBG results in a satisfactory weight loss but unacceptable complication and revision rates were found when Marlex was used for the banding procedure. The high revision rate was caused mainly by erosion of the Marlex band through the gastric wall. The tendency of Marlex to erode the gastric wall is supported by data of experimental studies. The data presented, despite being retrospective, strongly suggest that erosion of the Marlex band is a serious complication which can be prevented by using a Dacron band. 


\section{REFERENCES}

1. Renquist KE: Surgical treatment of obesity in America: Data according to the National Bariatric Surgery Registry. Problems Gen Surg 1992:9:231-8.

2. MacDonald KG. Pories WJ: Roux gastric bypass or vertical banded gastroplasty. Problems Gen Surg 1992;9:321-31.

3. Mason EE. Maher JW. Scott DH, el all. Ten years of vertical banded gastroplasty for severe obesily. Problems Gen Surg 1992;9:280-9.

4. Carr ND, Harrison RA, Tomkins $A_{1}$ et al: Vertical banded gastroplasty in the treatment of morbid obesity: Results of three year follow up. Gut 1989;30:1048-53.

5. Harrison RA, Clark CG: Vertical banded gastroplasty: Operation for morbid obesity. Ann Royal Coll Surg Engl 1984;66:3-4.

6. Jacobs PPM, Croiset van Uchelen FAAM, Bruyninckx CMA, et al.: Goede resultaten op middellange termijn van verticale maagverdeling ter behandeling van overmatige vetzucht. Ned Tijdschr Geneeskd 1991:135:1445-9.

7. Maclean LD, Rhode BM. Forse RA: Late results of vertical banded gastroplasty for morbid and super obesity. Surgery 1990;107:20-27.

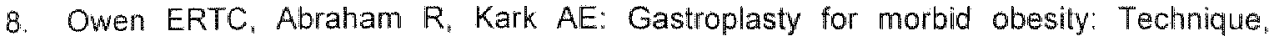
complications and results in 60 cases. Br J Surg 1989;76:131-5.

9. Shamblin JR, Shamblin AE: Gastroplasty in morbid obesity: Observations in 300 patients. South Med J 1985;78:1036-9.

10. Mason EE: Vertical banded gastroplasty for obesity. Arch Surg 1982;117:701-6.

11. Subramanyam K, Robbins HT: Erosion of Marlex band and silastic ring into the stomach after gastroplasty: Endoscopic recognition and management. Am J Gastro-enterol $1989 ; 84: 1319-21$.

12. Stelling T, Ferwerda J, Mulder CJ: Complications of the Angelchik antireflux prosthesis. Endoscopic management. Gastrointest Endosc 1987;33:453-6.

13. Grace DM, Phil D: Recognition and management of Marlex erosion after horizontal gastroplasty for morbild obesity. Can J Surg 1987;30:282-5.

14. Baskin LS, Stoller ML: Endoscopic extraction of eroded Marlex mesh in a Kock pouch. J Urol 1990;144:974-6.

15. Stone $\mathrm{HH}$, Fabian TC, Turkleson ML, et al: Management of acute full-thickness losses of the abdominal wall. Ann Surg 1981:193:612-7.

16. 1983 Metropolitan Height and Weight Tables. Statistical Bulletin Metropolitan Insurance Company 1983:64:2

17. Makarewicz PA, Freeman JB, Burchett $H$, et al: Vertical banded gastroplasty: Assessment of efficacy. Surgery 1985;98:700-7.

18. Sugerman $H J$, Starkey $J V$, Birkenhauer $R$ : A randomized prospective trial of gastric bypass versus vertical banded gastroplasty for morbid obesity and their effects on sweets versus non-sweet eaters. Ann Surg 1987;205:613-24.

19. Nightengale ML, Sarr $M G$, Kelly $K A$, et all.: Prospective evaluation of vertical banded gastroplasty as the primary operation for morbid obesity. Mayo Clin Proc 1991:66: 773-82.

20. Capella RF. Capella JF: Ethnicity, type of obesity surgery and weight loss. Obesity surgery $1993 ; 3: 375-80$.

21. Linner $\mathrm{JH}$ : Comparative effectiveness of gastric bypass and gastroplasty. Arch Surg 1982;117:695-9.

22. Hall JC, Watts JM, O'Brien PE, et all: Gastric surgery for morbid obesity. The Adelaide Study. Ann Surg 1990;211:419-27. 
23. Brolin RE, Robertson LB, Kenler HA, et al:: Weight loss and dietary intake after vertical banded gastroplasty and roux-en-Y gastric bypass. Ann Surg 1994, 220:782-90.

24. Fardy J. Holliday R. Sullivan S: Marlex erosion: A complication of horizontall banded gastroplasty. Gastrointest Endosc 1988;34:461-2.

25. Yale CE: Gastric surgery for morbid obesity. Complications and long-term weight control. Arch Surg 1989;124:941-6.

26. Dayton $M T$, Buchele BA, Shirazi SS, et al: Use of absorbable mesh to repair contaminated abdominal-wall defects. Arch Surg 1986; 121:954-60.

27. Tyrell $\mathrm{J}$, Silberman $H_{4}$ Chandrasoma $P$, et al.: Absorbable versus permanent mesh in abdominal operations. Surg Gynecol \& Obstet 1989,168:227-32.

28. Voyles $\mathrm{CR}$, Richardson JD, Bland $\mathrm{Kl}$, et al.: Emergency abdominal wall reconsitructions with polypropylene mesh. Short term benefits versus long-term complications. Ann Surg $1981: 194: 219-23$.

29. Stockeld D, GranströmL, Backman L, et al: Inflammatory response to subcutaneously implanted Marlex? and GORE-TEX(B) in massively obese patients. Biomaterials $1992 ; 13: 261-3$.

30. Matloub HS, Jensen P. Grunert BK, et al.: Characteristics of prosthetic mesh and autogenous fascia in abdominal wall reconstruction after prolonged implantation. Ann Plast Surg 1992;29:508-11.

34. Bellon JM, Bujan J, Contreras L, et al.: Macrophage response to experimental implantation of polypropylene prosthesis. Eur Surg Res 1994;26:46-53.

32. Pans $A$, Pierard GE: A comparison of intraperitoneal prostheses for the repair of abdominal muscular wall defects in rats. Eur Surg Res $1992 ; 24: 54-60$. 
Chapter 2.2

REVISIONAL SURGERY AFTER FAILED VERTICAL BANDED GASTROPLASTY: RESTORATION OF VERTICAL BANDED GASTROPLASTY OR CONVERSION TO GASTRIC BYPASS

Wim G. van Gemert, Meike M. Wersch, Jan Willem M. Greve, Peter B. Soeters. Obesity Surgery 1998:8:21-28. 


\section{ABSTRACT}

Background: An increasing number of patients with a falled primary bariatric procedure present themselves for secondary treatment. Only a few studies have investigated critically the success of revisional surgery. In the present study, the effectiveness of revisional surgery for failed vertical banded gastroplasty (VBG) is analyzed: restoration of the VBG (reVBG) is compared to conversion to a Roux-en- $Y$ gastric bypass (RYGB).

Patients and methods: From 1980 to 1996,136 consecutive morbidly obese patients underwent primary RYGB $(n=20)$ or VBG $(n=1.16)$. Weight loss. indications and complications after revisional surgery were registered. The rate of revisional surgery after primary and secondary bariatric procedures was estimated by means of a Kaplan-Meier analysis.

Results: Kaplan-Meier analysis revealed that $56 \%$ of the patients will eventually require revisional surgery after initial $V B G$ over a 12-year period compared to $12 \%$ after initial RYGB ( $p<0.01)$. After reVBG $68 \%$ will need revisional surgery over a 5-year period, while no further revisional surgery was required after conversion to a RYGB $(p<0.05)$. Body mass index dropped significantly after reVBG or conversion to RYGB for insufficient weight loss $(p<0.05)$, however, more revisional surgery was necessary after reVBG to achieve this result. The complication rate was comparable between reVBG and conversion to RYGB $(33 \%)$.

Conclusion: Conversion of a failed VBG to a RYGB is more effective than a reVBG, because conversion to RYGB provides satisfactory weight loss without requiring further revisional surgery.

\section{INTRODUCTION}

Morbid obesity is a lifelong. progressive disease of fat storage eventually leading to serious medical, psychological and socio-economic problems. Without sufficient weight loss these patients are at risk for accelerated mortality and impaired quality of life due to obesity-related comorbidity such as diabetes, cardiovascular and pulmonary disease ${ }^{3.2}$. Conservative treatment does not achieve long-term weight loss and is associated with high initial failure rates or recidivism ${ }^{3.4}$. The National Institutes of Health Consensus Conference defined the role of gastrointestinal surgery in the treatment of morbid obesity and endorsed the vertical banded gastroplasty (VBG) and the gastric bypass as accepted procedures for the treatment of morbidly obese patients $^{5}$. The VBG is an effective operation for the treatment of morbid obesity with a low complication rate ${ }^{6}$. However, the VBG does not achieve the long-term weight loss that occurs after RouX-en-Y gastric bypass (RYGB) and, 
subsequently, more revisional surgery is necessary after VBG to achieve satisfactory long-term weight loss ${ }^{7-10}$.

The high and increasing prevalence of severe obesity has resulted in the performance of a large and increasing amount of primary bariatric procedures. As a consequence, increasing numbers of patients with a failed primary bariatric procedure present themselves for secondary treatment. Despite a higher complication rate, revisional surgery should be seriously considered since conservative treatment of morbid obesity is usually unsuccessful ${ }^{11}$.

Indications for revisional surgery after VBG are mostly staple-line rupture or stoma stenosis. Other indications for revisional surgery are band erosion, band disruption, incorrect band size, pouch dilatation and severe gastroesophageal reflux. Depending on the indication for revisional surgery several procedures can be performed: restoration of the VBG by correcting the band size or applying a new staple-line with or without transection or conversion to a RYGB or another malabsorption procedure.

In the present study the results of revisional surgery for failed VBG are analyzed. Restoration of the VBG (reVBG) is compared to conversion from a VBG to a RYGB

\section{PATIENTS AND METHODS}

From 1980 to 1996,136 consecutive morbidly obese patients underwent bariatric surgery. Patients were considered morbidly obese if their body mass index (BMI) was more than $40 \mathrm{~kg} / \mathrm{m}^{2}$ or if they weighed more than $100 \%$ above ideal body weight as determined by the 1983 height/weight tables of the Metropolitan Life Insurance Company ${ }^{12}$. Postoperatively, all patients were checked routinely at the outpatient clinic. The first 20 patients underwent a RYGB as described by Griffin et al. ${ }^{13}$. Since 1984 the VBG was performed because the VBG appeared to be an effective and technically simple operation with a low morbidity. The operative technique of the VBG is described in detail elsewhere ${ }^{14}$.

In this study we focused on the long-term results of revisional surgery after failed VBG. Weight loss, indications and complications after revisional surgery were registered.

Data are expressed as the mean \pm SD. The rate of revisional surgery after the primary and secondary bariatric procedures was estimated by means of a Kaplan-Meier analysis. The cut-off point for the Kaplan-Meier curves was chosen at a standard error of $10 \%$. Differences between the Kaplan-Meier curves were tested with the log rank test. Statistical significance was set at 0.05 . 


\section{SURGICAL TECHNIQUE}

A failed VBG was either restored (reVBG) or converted to a RYGB. Restoration of the VBG included the application of a new staple-line with or without transection, the application of a new band or correcting the band size

When converting a failed VBG to a RYGB the following procedure was used. The laparotomy was performed through an upper midline incision; the operative field was freed by sharp and blunt dissection; after freeing the omental sac from adhesions, the band of the VBG was carefully removed if possible; the GIA-60 (Autosuture, Zeist, The Netherlands) was positioned above the old band on the lesser curve to the angle of His; four staple-lines were applied and transected with the GIA-60 creating a small proximal pouch on the lesser curve; a small hole was cut distally in the new pouch; the continuity of the bowel was restored by means of a Roux-en- $Y$ reconstruction; the anastomosis was created with a diameter of $8-10 \mathrm{~mm}$; the efferent and afferent loop of the Roux-en-Y reconstruction were $60 \mathrm{~cm}$; the proximal anastomosis was covered with omentum; the abdominal wall was secured in layers. Perioperatively, patients received intravenous prophylactic antibiotics (cefuroxim) and subcutaneous heparin.

\section{RESULTS}

Revisional surgery

Group characteristics are listed in Table 1. Twenty patients were initially treated with a RVGB from 1980 to 1984 and 116 patients underwent a VBG from 1984 to 1996 . Revisional surgery was necessary in 36 patients $(31 \%)$ after VBG and two patients (10\%) after RYGB.

Table 1. Group characteristics.

\begin{tabular}{|lcccc|}
\hline & Initial VBG & Initial GB & revBG & $\begin{array}{c}\text { Conversion } \\
\text { VBG to GB }\end{array}$ \\
\hline Number & 116 & 20 & 26 & 15 \\
Age (years) & $33 \pm 8$ & $38 \pm 10$ & $33 \pm 7$ & $38 \pm 12$ \\
Male/female & $20 / 96$ & $3 / 17$ & $5 / 21$ & 36131 \\
BMt (kg/m $)$ & $46.8 \pm 6.9$ & $48.8 \pm 6.3$ & $48.7 \pm 8.6$ & $49.4 \pm 9.8$ \\
Follow-up & $52 \pm 45$ & $145 \pm 19$ & $33 \pm 7$ & $54 \pm 40$ \\
(months) & $(6-171)$ & $(115-176)$ & $(8-171)$ & $(8-144)$
\end{tabular}

Data are expressed as the mean walue $\pm \mathrm{SD}$. 


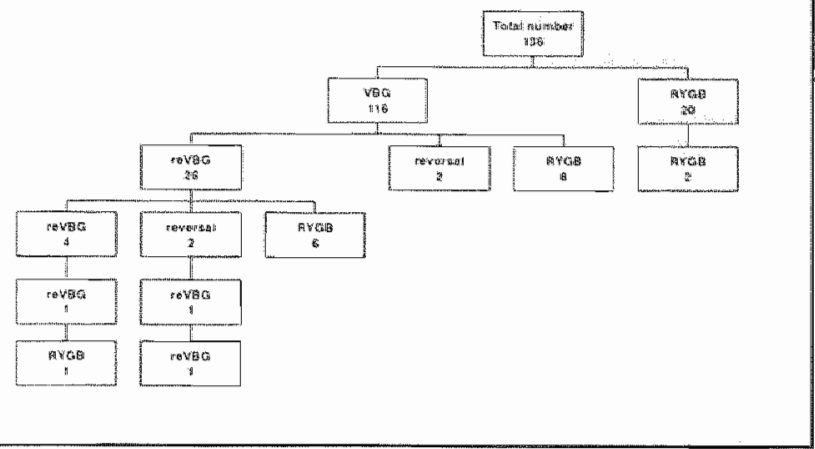

Figure 1. Flow diagram of initial and revisional surgery.

The flow-diagram in Figure 1 shows that further revisional surgery was necessary in 12 of the 26 patients $(46 \%)$ after reVBG. After conversion of the VBG to a RYGB in 15 patients no further revisional surgery was required. Kaplan-Meier analysis revealed that $44 \%$ of the patients will not require revisional surgery, thus, $56 \%$ will require revisional surgery over a 12 -year period (Figure 2).

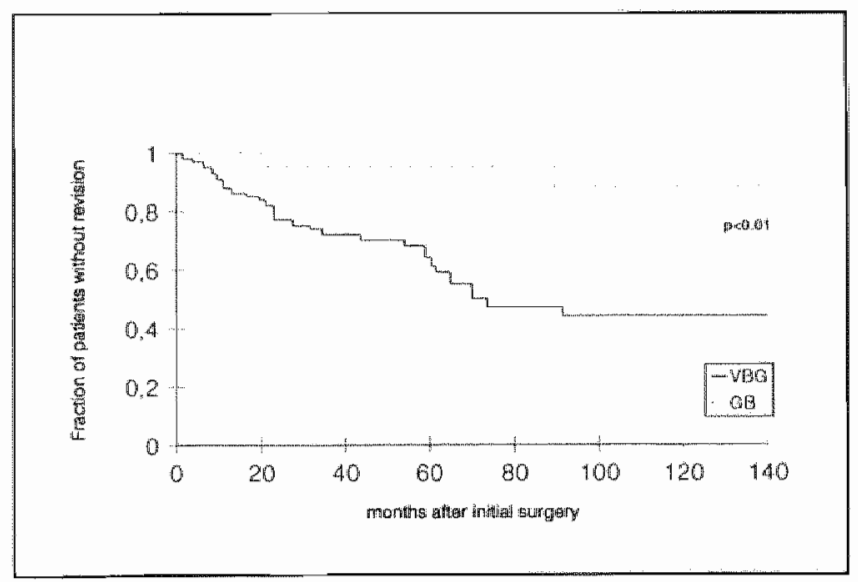

Figure 2. Kaplan-Meier analysis of initial VBG and RYGB. 
However, after reVBG only $32 \%$ will not require further revisional surgery and $68 \%$ will require revisional surgery over a 5 -year period (Figure 3 ). The Kaplan-Meier analysis of initial RYGB revealed that $88 \%$ will not need revisional surgery and that only $12 \%$ revisional surgery will be necessary over a 12-year period.

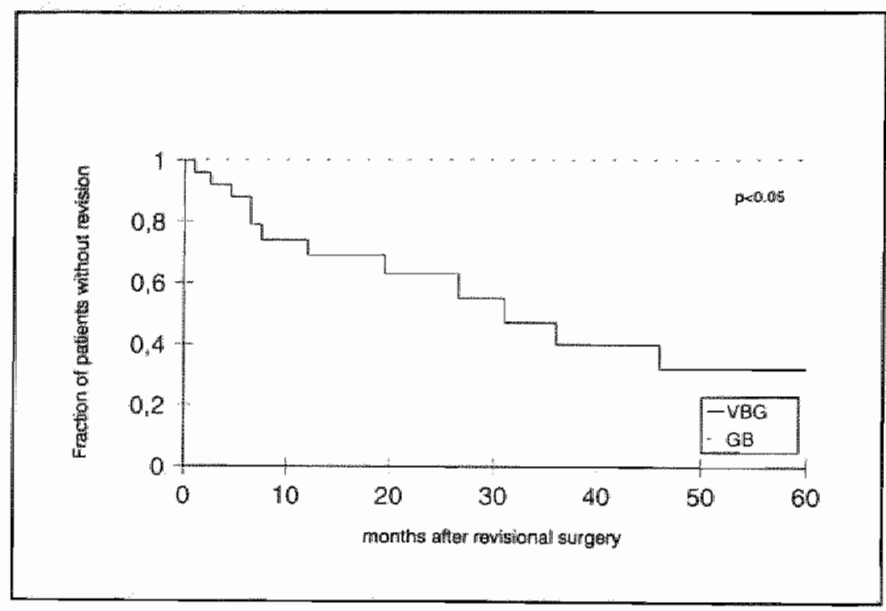

Figure 3. Kaplan-Meier analysis of reVBG and conversion to RYGB.

Table 2. Indications for revisional surgery after initial VBG, initial GB and reVBG.

\begin{tabular}{|c|c|c|c|c|c|}
\hline \multirow{9}{*}{$\begin{array}{l}\text { Stoma stenosis } \\
\text { Stoma toolarge } \\
\text { Band erosion } \\
\text { Band disruption } \\
\text { Staple-line rupture } \\
\text { Fistula } \\
\text { Subphrenic abscess } \\
\text { Pouch dilatation } \\
\text { Insufficient weight loss } \\
\text { Regret }\end{array}$} & \multicolumn{2}{|c|}{ After initial VBG } & After initial GB & \multicolumn{2}{|c|}{ After reVBG } \\
\hline & 11 & $(31 \%)$ & & 5 & $(33 \%)$ \\
\hline & 5 & $(14 \%)$ & & 1 & $(7 \%)$ \\
\hline & 4 & $(11 \%)$ & & & \\
\hline & 3 & $(8 \%)$ & & & \\
\hline & 11 & $(39 \%)$ & & $\begin{array}{l}4 \\
2\end{array}$ & $\begin{array}{l}(27 \%) \\
(13 \%)\end{array}$ \\
\hline & & & & 1 & $(7 \%)$ \\
\hline & 1 & $(3 \%)$ & & & \\
\hline & 1 & $(3 \%)$ & $(10 \%)$ & 2 & $1130 \%$ \\
\hline
\end{tabular}

Data are expressed as the absolute value (percentage). 
The most trequent indications for revisional surgery after initial VBG and after reVBG were stoma stenosis and staple line rupture (Table 2).

With regard to revisional surgery after initial $R Y G B$ the indication was insufficient weight loss in two patients. The reason for insufficient weight loss was not completely clear, however, it was suspected that the afferent loop of the Roux-en-Y bypass was too short.

\section{Weight loss}

The mean overall BMl dropped from $46.8 \pm 6.9 \mathrm{~kg} / \mathrm{m}^{2}$ to $34.2 \pm 7.0 \mathrm{~kg} / \mathrm{m}^{2}$ after initial VBG $(p<0.001)$ and from $48.8 \pm 6.3 \mathrm{~kg} / \mathrm{m}^{2}$ to $33.5 \pm 7.0 \mathrm{~kg} / \mathrm{m}^{2}$ after initial RYGB $(p<0.001)$ (Figure 4). However, significantly more revisional surgery was necessary after initial VBG to achieve this result. The BMI also dropped significantly after reVBG or conversion to RYGB for insufficient weight loss (Figure 5).

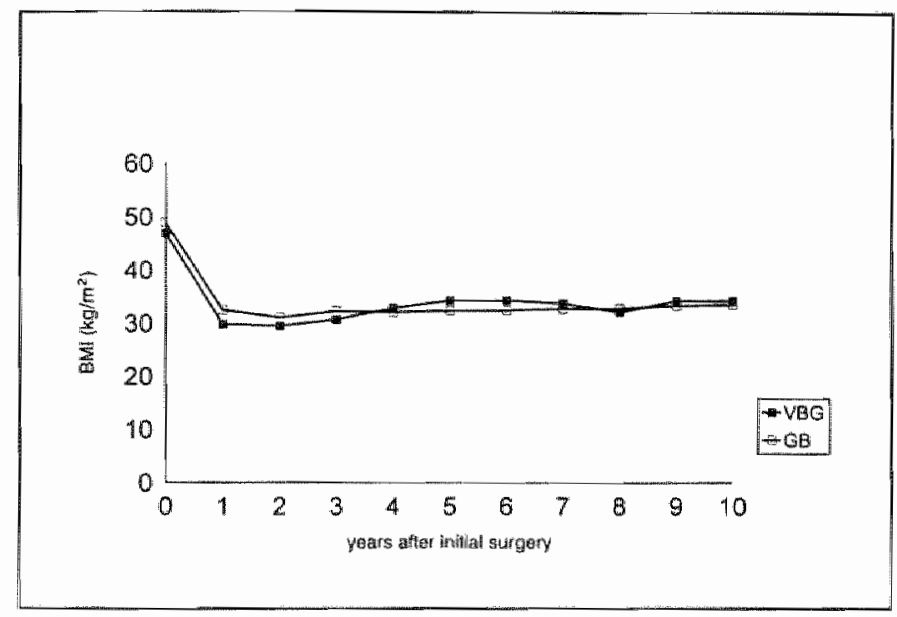

Figure 4. Owerall body mass index (BMI) after initial VBG and RYGB. The overall mean BMI dropped significantly after initial VBG and RYGB ( $p<0.01)$, although more revisional surgery was necessary after initial VBG to achieve this result.

\section{Complications}

The overall morbidity after revisional surgery was high and comparable between the reVBG and the conversion of (re)VBG to RYGB (Table 3). Although more reoperations were necessary after conversion to RYGB

to resolve the complications. It should be kept in mind, however, that almost half of the conversions to RYGB were second, third or fourth revisionall 
procedures. The serious complications were gastric fistulas and leakage, which mostly occurred after the second, third or fourth revisional procedure. After (re)VBG the gastric fistula or leakage was usually managed by conversion to a RYGB, while the gastric fistula or leakage after conversion to RYGB was managed by drainage and total parenteral feeding.

One female patient developed multiple fistulas from the pancreas to the stomach and to the skin after her third reVBG. This was managed successfully by conversion to a modified RYGB. A proximal gastrectomy was performed except for a small proximal pouch on the lesser curve. The distal stomach was anastomosized with the corpus of the pancreas which contained the origin of the fistulas. Reconstruction was performed by means of a gastrojejunostomy with a Roux-en-Y loop to the small proximal pouch on the lesser curve. Another patient developed a fistula between the proximal pouch and the stomach after a reVBG with transection of the staple-line for a staple line rupture. This was managed by conversion to a RYGB. Postoperatively, he again developed a fistula at the same location. This time the fistula drained into the abdominal cavity and the patient suffered a severe septic episode requiring intensive care treatment. Several surgical drainage procedures and tatal parenteral feeding were necessary before the septic episode resolved. A further male patient had a leakage and fistula from his proximal anastomosis after conversion of a reVBG to a RYGB. The leakage was caused by small bowel obstruction due to adhesions. This patient had a sepsis which could be resolved by surgical drainage and total parenteral feeding in the intensive care unit. The other patients with gastric leakage and fistulas could be managed conservatively with drainage via a nasogastric tube and total parenteral feeding.

Table 3. Complications after reVBG and conversion of VBG to RYGB.

\begin{tabular}{|lcc|}
\hline & reVBG & Conversion to RYGB \\
\hline Incisional hernia & 3 & 3 \\
Bowel obstruction & 3 & 1 \\
Esophagitis & 1 & 3 \\
Food impaction & 3 & \\
Metabolic & 1 & $5 / 15(33 \%)$ \\
Gall stones & 3 & $4 / 15(27 \%)$ \\
Seakagelfistula & 1 & \\
\hline Morbidity & $11 / 33(33 \%)$ & \\
\hline Reoperation & $5 / 33(15 \%)$ &
\end{tabular}




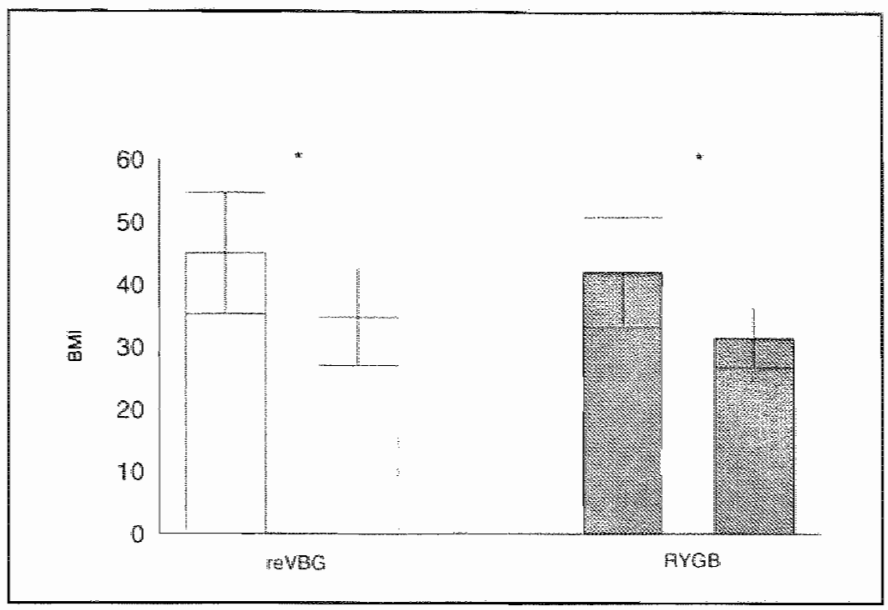

Figure 5. Change of body mass index (BMI) after reVBG and conversion to RYGB for insufficient weight loss. ${ }^{*} p<0.05$

\section{DISCUSSION}

The increasing number of morbidly obese patients treated by bariatric surgery has led to an increasing number of patients requiring revisional surgery. The reported incidence of revisional surgery after VBG is $10 \%-41 \%{ }^{44-21}$. However, the incidence of revisional surgery depends on several aspects, such as the completeness and duration of follow-up and method of calculation. In almost all studies the incidence of revisional surgery is calculated by dividing the number of revisions by the total population. By means of this method the true incidence of revisional surgery is underestimated, since it does not account for the fact that some patients will need revisional surgery beyond the study period, especially patients with a short follow-up. In the present study the Kaplan-Meier analysis was used to make a more realistic estimation of the incidence of revisional surgery corrected for the length of follow-up. By means of this method the incidence of revisional surgery over a 12-year period after initial VBG was found to be very high $(56 \%)$. This contrasted with the incidence of revisional surgery after initial $R Y G B$ over a 12-year period which was only $12 \%$. From this point of view the RYGB appears to be more effective than the VBG as a primary bariatric procedure. To our knowledge, all studies comparing primary VBG with RYGB arrive at the same conclusion ${ }^{7-10,22}$. Sugerman et al. found that the RYGB was more effective than the VBG for patients with a large intake of carbohydrates in the form of simple sugars, the 
so called "sweets eaters"22. The RYGB forces the patients to comply with dietary measures since ingestion of simple carbohydrates is associated with unpleasant dumping symptoms.

The superior results of the RYGB are even more striking after revisional surgery. The incidence of further revisional surgery after reVBG was $68 \%$ in this study, while no further revisional surgery was necessary after conversion to a RYGB. Most studies regarding revisional surgery conclude that a failed VBG is best converted to a RYGB, since restoration of a failed VBG appears to be ineffective ${ }^{16,23-27}$.

The most frequent indications for revisional surgery after VBG or reVBG were staple-line rupture and stoma stenosis. The former results in an insufficient weight loss, while the latter causes too extreme weight loss. For this reason weight loss alone is not a good criterium for success. Stoma stenosis is often caused by scar tissue formation and is usually accompanied by gastroesophageal reflux and food intolerance. Revisional surgery for stoma stenosis is recommended when endoscopic dilatation of the stenosis has failed. In our experience, endoscopic dilatation only results in transient relief of symptoms, although satisfactory results after endoscopic dilatation have been reported ${ }^{28}$. Endoscopic dilatation may lead to microscopic lesions in the scar tissue resulting in even more progressive scar tissue formation and thus stenosis of the stoma. For this reason many of our patients with stoma stenosis are reoperated without first undergoing endoscopic dilatations. The most frequent cause of failed VBG is staple-line rupture. Maclean et al., who performed routine endoscopic examination in all patients, found an incidence of staple-line rupture of $48 \%{ }^{19}$. To date now no effective measure has been found by which to prevent staple-line disruption. The use of the TA $90 \mathrm{~B}$ or transection of the staple-line did not eliminate this problem. In the beginning of this series the failed VBG was reoperated by correcting the cause of the failure. However, we had the same experience as described by Kfoury et al:: ".....the disrupted staple lines disrupted again, and the dilated pouched dilated again.......Tightening the loose stoma did not seem to help, and those operated for stenosis were relieved of their stenotic symptoms but regained much of their lost weight"26.

Taken the above into account, it is difficult to refrain from the impression that the noncompliance of the patient is basically the cause of failure. Continuous overeating and subsequent vomiting may cause staple-line rupture, stoma stenosis and pouch enlargement. However, continuous overeating is the basic feature of morbidly obese patients. They desperately seek help from a bariatric surgeon, since they cannot stop overeating and are unable to loose weight by themselves. Thus, gastric partitioning procedures must cause weight loss by preventing continuous overeating. From this point of view, it is unfair to blame the patient for a failed VBG because of continuous overeating. 
In the present study the overall morbidity was high (33\%) for both the reVBG and the conversion to RYGB. However, there were no postoperative deaths. In the literature the reported morbidity is $12 \%-41 \%$ and the mortality is $0 \%-2 \%, 16,23-26,25,30$. Based on an increased morbidity and mortality after revisional surgery of respectively $71.8 \%$ and $12.5 \%$, Cates et al. cautioned that revisional surgery should be carefully considered ${ }^{30}$. The population of the latter study is, however, not representative for all hospitals performing bariatric surgery, because of the high incidence of urgent referrals for lifethreatening complications (41\%). In our serie, the gastric leakage/fistulas after conversion of a failed VBG to a RYGB caused many clinical problems. The increased incidence of gastric leakage after revisional surgery is well-known ${ }^{34}$. The reason for the gastric leakage is not completely clear: ischaemia, faulty placement of staples or partial outlet obstruction may play a role, and according to some authors, so does the noncompliance by the patient who prematurely ingests food and fluid during the postoperative period ${ }^{31}$. In our experience, the gastric leakage/fistula after (re)VBG was successfully managed by conversion to a RYGB. The gastric leakage after conversion to RYGB was managed by surgical intra-abdominal drainage, drainage via a nasogastric tube and total parenteral feeding.

The data of the present study suggest that the RYGB is more effective than the VBG as a primary operation with respect to the rate of revisional surgery. Conversion of a failed VBG to a RYGB is more effective than a reVBG. Conversion to a RYGB results in a satisfactory weight loss with a complication rate comparable with reVBG and no further revisional procedures are required. Although the complication rate of revisional surgery is high, revisional surgery of a failed or complicated initial operation should be seriously considered since nonsurgical treatment of morbid obesity is largely unsuccessful. 


\section{REFERENCES}

1. Kral JG. Morbid obesity and related health risks. Ann Int Med 1985;103:1043-1046.

2. Vanitalie TB. Obesity: Adverse effects on health and longevity. Am $J$ Clin Nutr $1979: 32: 2723-2733$.

3. Van Itallie TB. Morbid obesity. A hazardous disorder that resists conservative treatment. Am J Clin Nutr 1980;33:358-363.

4. Stunkard A.J. Penick SB. Behavior modification in the treatment of obesity: The problem of maintaining weight loss. Arch Gen Psychiatry 1979;36:801-806.

5. Consensus Development Conference Panel. Gastrointestinal surgery for severe obesity. Ann Int Med 1991;115:956-961.

6. Mason EE, Maher "WW Scott DH, Rodriquez EM, Doherty C. Ten years of vertical banded glastroplasty for severe obesity. Probl Gen Surg 1992;9:280-289.

7. Sugerman HJ, Londerry GL. Kellum JM et al. Weight loss with vertical banded gastroplasty and Roux-Y gastric bypass for morbid obesity with select versus random assign. Am J Surg 1989;157:93-102.

8. MacDonald KG. Pories W.J. Roux gastric bypass or vertical banded gastroplasty. Probl Gen Surg 1992;9:321-331.

9. Headley WM. Gastric bypass versus vertical banded gastroplasty. Probll Gen Surg $1992 ; 9: 332-344$.

10. Fobi MAL. Vertical banded gastroplasty versus gastric bypass: 10 years' followmup. Obes Surg 1993:3:161-164.

11. Johmson D, Drenick EJ. Therapeutic fasting in morbid obesity. Long-term follow-up. Arch Int Med 1977;137:1381-1382.

12. 1983Metropolitan Height and Weight Tables. Statistical Bulletin Metropolitan Insurance Company $1983 ; 64: 2$.

13. Griffin WO, Young $V L$. Stevenson CC. A prospective comparison of gastric and jejunoileal bypass procedures for morbid obesity. Ann Surg 1977;186:500-509.

14. Van Gemert WG, Greve JWM, Soeters PB. Long-term results of vertical banded gastroplasty: Marlex versus, Dacron banding. Obes Surg 1997;7:128-135.

15. Hall JC Watts JM, O'Brien PE, Dunstan RE, Walsh JF slavotinek AH, Elmslie RG. Gastric surgery for marbid obesity. The Adellaide study. Ann Surg 1990;211:419-427.

16. Sugerman HJ, Wolper JL. Failed gastroplasty for morbid obesity. Revised gastroplasty versus Roux-Y gastric bypass. Am J Surg 1984;148:331-336.

17. Carr ND, Harrison RA, Tomkins $A$, Baughen $R$, Demmer $S$, Godfrey J, Clark CG. Vertical banded gastroplasty in the treatment of morbid obesity: Results of three year follow up. Gut 1989;30:1048-1053.

18. Shamblin JR. Shamblin AE. Gastroplasty in morbid obesity: Observations in 300 patients. South Med J 1985:78:1036-1039.

19. Maclean LD, Rhode BM, Forse RA. Late results of vertical banded gastroplasty for morbid obesity and super obesity. Surgery 1990;107:20-27.

20. Nightengale ML. Sarr MG, Kelly KA, Jensen MD, Zinsmeister AR, Palumbo PJ. Prospective evaluation of vertical banded gastroplasty as the primary operation for morbid obesity. Mayo Clin Proc 1991;66:773-782.

21. Näslund $E$, Backman L, Granström L, Stockeld D. Seven year results of vertical banded gastroplasty for morbid obesity. Eur J Surg 1997;163:281-286.

22. Sugerman $H J$, Starkey $J V$, Birkenhauer $\mathbb{R}$. A randomized prospective trial of gastric bypass versus vertical banded gastroplasty for morbid obesity and their effects on sweets versus non-sweets eaters. Ann Surg 1987;205:613-622.

23. Benotti PN. Forse RA. Saftety and long-term efficacy of revisional surgery in severe obesity. Am J Surg 1996:172:232-235. 
24. Linner $\mathbb{U H}$, Drew RL. Reoperative surgery-indications, efficacy, and long-term follow-up. Am J Clin Nutr 1992;55:606S-610S.

25. Behrns KE, Smith CD, Kelly KA, Sarr MG. Reoperative bariatric surgery. Lessons learned to improve patient selection and results. Ann Surg 1993:218:646-653.

26. Koury $E$. Vanguri A. Distal Roux-en-Y gastric bypass conversion operation for failed vertical banded gastroplasty. Obes Surg 1993;3:41-43.

27. Sugerman HJ, Kellum JM, Rothrock MK. Results of conversion of failed or complicated vertical banded gastroplasty (VBG) to gastric bypass (GBP). Obes Surg 1993:3:103 (abstr).

28. Freeman JB. The use of endoscopy after gastric partitioning for morbid obesily. Gastroenterol Clin North America 1987; 6:339-347.

29. Yale $C E$. Conversion surgery for morbid obesity: Complications and long-term weight control. Surgery 1989;106:474-480.

30. Cates JA, Drenick EJ, Abedin MZ, Doty JE, Saunders KD, Roslyn JJ. Reoperative surgery for the morbidly obese. A university experience. Arch Surg 1990;125:14001403.

31. Buckwalter JA, Herbst CA. Leaks occurring after gastric bariatric operations. Surgery $1988 ; 103: 156-160$. 
$-50-$ 
Chapter 3

PSYCHOSOCIAL ASPECTS OF MORBID OBESITY AND THE EFFECT OF SURGICAL TREATMENT 
$-52-$ 
Chapter 3.1

QUALITY OF LIFE ASSESSMENT OF MORBIDLY OBESE PATIENTS: EFFECT OF WEIGHT-REDUCING SURGERY

Wim G. van Gemert, Eddy M. Adang, Jan Willem M. Greve, Peter B. Soeters. Am J Clin Nutr 1998;67:197-201 


\section{ABSTRACT}

The effect of surgically induced weight loss on the quality of life of morbidly obese patients was investigated in a controlled cross-sectional study. A postoperative group of 62 patients was compared with a control group of 20 preoperative patients. The Nottingham Health Profile part I (NHP-I) and part II (NHP-1I) and a visual analogue scale were used for quality of life assessment. Significant differences were found on the NHP-II $(p<0.0001)$, the visual analogue scale $(p<0.001)$, and on the domains of mobility $((p<0.0001)$, energy $(p<0.001)$, and emotional reaction $(p<0.001)$ on the NHP-I in favor of the postoperative group. Better quality of life outcome was related to larger weight loss and shorter length of postoperative follow-up. No correlation was found between quality of life outcome and the type of surgical procedure or surgical complications. The unemployment rate was $53 \%$ for the overall postoperative group and $64 \%$ for the female postoperative group compared with $80 \%$ $(p<0.05)$ and $84 \%$ (NS) in the overall and female control groups, respectively. Overweight as the reason for un-employment was more frequent in the control group. The results of this study show that quality of life is better after surgically induced weight loss and is not related to the type of surgical procedure nor to surgical complications. Postoperative quality of life tends to decrease with time.

\section{INTRODUCTION}

Studies of the effects of medical interventions on quality of life are gaining in popularity in clinical research, reflecting an increasing interest in the patient as a whole. The concept of quality of life is complex because it must incorporate all aspects of life. The World Health Organization defines quality of life as a state of complete physical, mental, and social well-being and not merely the absence of disease or infirmity?. In a quality of life study, an overall outcome index encompassing physical, psychologic, social and financial aspects of certain health states and medical interventions is added to the conventional clinical indexes studied. For most patients quality of life is more important than the traditional outcome measures in medical care.

This is certainly true for patients with severe overweight because morbid obesity results in a significantly impaired quality of ife $^{2}$. Serious obesity, as defined by Cowan et al. ${ }^{3}$, is a lifelong. progressive disease of fat storage manifested by medical, physical, psychologic, social, and economic comorbidities. The presentation of these problems in obese persons is related to the amount of excess weight ${ }^{2,4.5}$. These aspects of morbid obesity and its related comorbidities justify surgical treatment, which is widely recognized as the treatment of choice for morbid obesity. 
Morbidly obese patients undergoing surgical treatment are a suitable population for evaluating quality of life and the effect of weight loss because surgical treatment generally results in a substantial and long-lasting weight reduction ${ }^{6.7}$. Furthermore, the worst quality of life and subsequently the greatest improvement in quality of life is expected in morbidly obese patients who are determined to undergo radical treatment, such as surgery, to resolve their problems. The objective of this study was to evaluate the effect of surgically induced weight loss on the quality of life of morbidly obese patients.

\section{SUBJECTS AND METHODS}

A controlled cross-sectional study design was used in which a postoperative group was compared with a preoperative control group of morbidly obese patients. The surgical procedures performed were vertical banded gastroplasty (VBG) with a Marlex (Bard, Billerica, MA) band (VBGM), VBG with a Dacron (Maedox, Boston) band (VBGD), and the Roux-en-Y gastric bypass (GB). The GB was performed from 1980 until 1984 as described by Griffin et al. ${ }^{8}$. From 1984 until 1993 VBG was performed because the technique was found to be simple and effective with a low complication rate. The technique and results of the VBG are described in detail elsewhere ${ }^{9}$. All patients who were surgically treated from February 1980 through May 1993 were invited to participate in this study. The patients were reexamined and completed quality of life questionnaires. In the control group quality of life was assessed before surgery with the same questionnaires. The study was approved by the local medical ethical committee and all patients gave their written informed consent before participating in the study.

Quality of life analysis

Quality of life was tested with the Nottingham Health Profile part $\|(N H P-1)$ and part II (NHP-II) ${ }^{10}$ and a visual analogue scale (VAS) for global quality of life assessment. The NHP-\| is a questionnaire designed as a comprehensive instrument to measure perceived health in six specific domains of life: mobility, pain, energy, sleep, social isolation and emotional reaction. The scores are not added to get aggregate score of all domains, but are reported separately as a profile of six independent domains [range: 0 (best score) to 100 (worst score)]. The standard for the general population (Dutch version) was chosen as a reference value ${ }^{11}$. This reference value is 15 for all domains of the NHP-I and is independent of sex. The NHP-II is a questionnaire related to those areas of task performance most affected by health. It consists of seven statements that refer to the effects of health problems on occupation. ability to perform domestic tasks, hobbies, personal relationships, sex life, social life, and holidays [range: 0 (best score) to 21 (worst score)]. The VAS 
scores quality of life on a linear scale ranging from the worst possible quality of life (score of 0 ) to the best possible quality of life (score of 10).

The relationship between quality of life outcome and clinical indexes was investigated by correlating the clinical indexes with the scores on the VAS, the NHP-II, and the separate domains of the NHP-I. The clinical indexes tested were body weight, weight loss, sex, length of follow-up, type of surgical procedure, and surgical complications, including revisional surgery. Surgical complications were defined as complications requiring reoperation, including revisional surgery. Minor complications which could be managed easily with conservative means were not accounted for because no relevant effect on the quality of life outcome was expected in view of the long-term follow-up of this study. The occupational and financial status of the patients was assessed by a questionnaire designed especially for the purposes of this study. For occupational and financial status, the groups were stratified by sex.

\section{Statistical analysis}

Statistical analysis of the weight loss data was performed with Student's $t$ test for dependent samples for differences within the postoperative group and with Student's $t$ test for independent samples for differences between the postoperative and control group. Data concerning body weight are expressed as means $\pm \mathrm{SD}$.

Statistical analysis of quality of life data was performed with the MannWhitney $U$ test (nonparametric). Correlations were tested with the Spearman rank correlation coefficient. Quality of life data are presented as medians and interquartile ranges. Statistical significance was defined as $P<0.05$. Data were analyzed with SPSS (SPSS release 6.1.2; SPSS Inc, Chicago)

\section{RESULTS}

\section{Group characteristics}

Sixty-nine patients were operated on consecutively during the study period. One patient died after a VBGM in the postoperative period and six patients could not be traced and were lost to follow up ( $91 \%$ of patients were followed up). The mean follow-up time was $85.9 \pm 48.1$ mo (range 6-168 mo). The GB, VBGM, and VBGD were performed in 18,14 , and 30 patients respectively. The control group consisted of 20 consecutive patients who were subsequently operated on from June 1994 to August 1995. The control group and postoperative group were comparable in age, body mass index, and excess weight before surgery (Table 1). 
Table 1. Group characteristics before surgery.

\begin{tabular}{|c|c|c|c|c|}
\hline & \multicolumn{2}{|c|}{$\begin{array}{l}\text { Preoperative control group } \\
\qquad(n=20)\end{array}$} & \multicolumn{2}{|c|}{$\begin{array}{c}\text { Postoperative group betore } \\
\text { surgery }(n=62)\end{array}$} \\
\hline Men:Women & \multicolumn{2}{|c|}{$1: 19$} & \multicolumn{2}{|c|}{$18: 44^{12}$} \\
\hline Age $(y)$ & 32.9 & $(8.2)$ & 33.1 & $(9.4)$ \\
\hline Body weight (kg) & 124.0 & $(25.9)$ & 138.9 & $(28.2)^{* 4}$ \\
\hline Excess weight (kg) & 64.3 & $(23.1)$ & 73.7 & $(24.2)$ \\
\hline $\mathrm{BM}\left(\mathrm{kg} / \mathrm{m}^{2}\right)$ & 46.6 & $(7.0)$ & 47.7 & $(7.4)$ \\
\hline PEW (\%) & 107.1 & $(33.7)$ & 112.2 & $(32.6)$ \\
\hline
\end{tabular}

Data are expressed as the mean value $(\mathrm{SD})$. $B M I=$ body mass index; $P E W=$ percentage excess weight above ideal body weight. " $p=0.03$, " $p=0.04$ for differences with the preoperative control group (unpaired Student's t test).

\section{Weight loss and complications}

The three surgical procedures resulted in significant weight loss (Table 2). The body weight curve increased slightly, but not significant, after 2 years (Figure 1).

Table 2. Body weight (BW), body mass index (BMI), and percentage excess weight (PEW) before and after surgery in the postoperative group.

$\left.\begin{array}{|ccccccc|}\hline & \multicolumn{2}{c}{\text { GB }(\mathrm{n}=18)} & \multicolumn{2}{c}{\text { VBGM }(\mathrm{n}=14)} & \multicolumn{2}{c|}{\text { VBGD }(\mathrm{n}=30)} \\ & \text { preop } & \text { postop } & \text { preop } & \text { postop } & \text { preop } & \text { postop } \\ \hline \text { BW }(\mathrm{kg}) & 136.4(29.6) & 95.0(27.5) & 134.9(16.4) & 96.9(19.5) & 142.3(31.9) & 94.0(26.2) \\ \text { BM }\left(\mathrm{kg} / \mathrm{m}^{2}\right) & 48.7(6.6) & 33.7(7.9) & 46.6(5.4) & 33.6(7.1) & 47.6(8.6) & 30.9(6.7) \\ \text { PEW (\%) } & 115.1(30.9) & 49.1(34.9) & 108.5(23.0) & 50.2(31.1) & 112.3(37.7) & 40.9(31.6)\end{array}\right]$

Data are expressed as the value mean (SD). GB, Roux-en-Y gastric bypass; VBGM, verticall banded gastroplasty with a Marlex band; VBGD, vertical banded gastroplasty with a Dacron band. The GB, VBGM and VBGD groups were comparable in age $\left(38.5,32.5\right.$, and $31.5 y_{0}$ respectively), ratio of men to women $(3: 15,5: 9$, and $11: 20$, respectively), preoperative weight, and excess weight. All postoperative values are significantly different from preoperative values. $\mathrm{P}<0,0001$ (paired Student's $t$ test). 


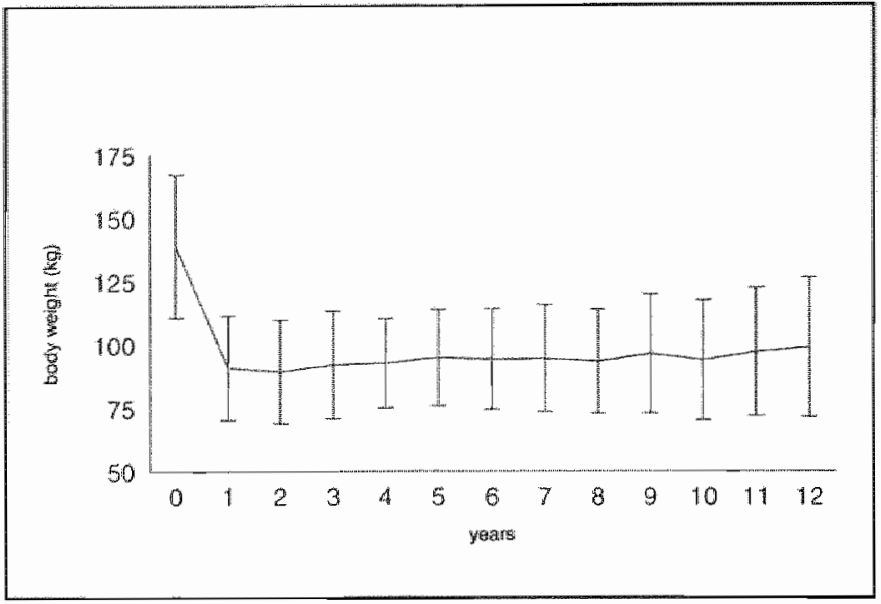

Figure 1. Overall mean ( $\mathbb{S D}$ ) body weight after surgical treatment. A slight but not significant increase in mean body weight occurred 2 y after surgery.

Surgical complications occurred mainly after VBGM. Revisional surgery was necessary in nine patients $(64 \%)$ after VBGM, in one patient $(6 \%)$ after GB, and in two patients $(7 \%)$ after VBGD (Table 3 ).

Table 3. Surgical complications in the postoperative group after the three types of weightreducing surgery.

\begin{tabular}{|lccc|}
\hline & GB $(n=18)$ & VBGM $(n=14)$ & VBGD $(n=30)$ \\
\hline Stoma stenosis & & 1 & 2 \\
Stoma dilatation & 1 & 1 & 1 \\
Band erosion & & 3 & \\
Band disruption & 4 & 2 & \\
Incisional hernia & & 2 & $3(10 \%)$ \\
Gallstones & $5(28 \%)$ & $12(86 \%)$ & \\
\hline Total & & 3 & \\
\hline
\end{tabular}

Surgical complications defined as complications requiring reoperation, including revisional surgery. GB, Roux-en-Y gastric bypass; VBGM, vertical banded gastroplasty with a Marlex band; $V B G D$, vertical banded gastroplasty with a Dacron band. 


\section{Quality of life analysis}

Compared with the reference values, the control group had elevated scores on all domains of the NHP-I except for sleep (Table 4). This was clearly in contrast with the postoperative group, who had values close to the reference values on all quality of life tests. A significant difference in favor of the postoperative group compared with the control group was found on the NHP-1 for the following the domains: emotional reaction, energy, and mobility (Table 4). Scores on the NHP-2 and the VAS also differed significantly in favor of the postoperative group. No differences in quality of life outcome were found between males and females in the postoperative group.

Table 4. Comparison of quality of life scores between the control and postoperative groups.

\begin{tabular}{|lcccc|}
\hline & $\begin{array}{c}\text { Preoperative control group } \\
(\mathrm{n}=20)\end{array}$ & $\begin{array}{c}\text { Postoperative group after } \\
\text { surgery }(\mathrm{n}=62)\end{array}$ \\
\hline NHP-1 & & & & \\
Mobility & 33.3 & $(21.4-44.9)$ & 0.0 & $(0.0-31.1)^{* * *}$ \\
Energy & 63.2 & $(33.2-100.0)$ & 0.0 & $(0.0-63.2)^{*}$ \\
Pain & 18.6 & $(2.5-41.3)$ & 0.0 & $(0.0-26.4)$ \\
Sleep & 16.1 & $(0.0-49.1)$ & 12.6 & $(0.0-56.6)$ \\
Social isolation & 19.7 & $(0.0-56.7)$ & 0.0 & $(0.0-22.5)$ \\
Emotional reaction & 28.9 & $(11.5-55.7)$ & 7.2 & $(0.0-21.2)^{*}$ \\
NHP-ll & 16.0 & $(14.0-20.8)$ & 9.0 & $(7.0-14.3)^{* *}$ \\
VAS & 3.5 & $(3.0-5.3)$ & 8.0 & $(5.0-9.0)^{* *}$ \\
\hline
\end{tabular}

Data are expressed as the median value and interquartile range in parentheses. NHP, Notingham Health Profile; VAS, visual analogue scale. "p<0.001, "p<0.00001 for differences with the preoperative control group (Mann-Whitney $U$ test).

Body mass index correlated significantly with the NHP-I domains of mobility $(r=0.38 ; p=0.002)$ and pain $(r=0.30 ; p=0.009)$. Furthermore, the percentage of excess weight loss correlated significantly with the domains of mobility $(r=-0.40 ; p=0.001)$, energy $(r=-0.27 ; p=0.017)$, and pain $(r=-0.36 ; p=0.003)$. A lower body mass index and a higher percentage of excess weight loss resulted in a better quality of life outcome. No significant correlation was found between surgical complications including revisional surgery and quality of life. This was also found for the type of surgical procedure performed. The length of the postoperative follow-up correlated significantly with the NHP-I domains of mobility $(r=0.36 ; p=0.002)$ and sleep $(r=0.33 ; p=0.005)$. Longer postoperative fallow-up resulted in a decreased quality of life outcome, although 
the quality of life outcome of the postoperative group remained significantly better than that of the control group.

\section{Occupational and financial status}

In the control group $80 \%$ of all patients and $84 \%$ of the female patients were unemployed compared with $53 \%(p<0.05)$ and $64 \%(\mathrm{~ns})$ in the postoperative group, respectively. Overweight as the reason for unemployment was more frequent in the control group, whereas full-time housekeeping was the main reason for unemployment in the postoperative group (Table 5).

The yearly income after taxes was on average 22200 Dutch guilders (11 100 US\$) in the overall control group and 25850 guilders (12 925 US\$) in the overall postoperative group (ns). In female patients the average yearly income after taxes was 21500 Dutch guilders (10 750 US\$) in the control group and 20500 Dutch guilders (10 250 US $\$$ ) in the postoperative group (ns).

Table 5. Reasons for unemployment in the overall and female control and postoperative groups.

\begin{tabular}{|lcccc|}
\hline & $\begin{array}{c}\text { Preoperative control group } \\
(n=20)\end{array}$ & $\begin{array}{c}\text { Postoperative group after } \\
\text { Surgery }(n=62)\end{array}$ \\
& Overall & Females & Overall & Females \\
\hline Unemployment rate & $16 / 20(80 \%)$ & $16 / 19(84 \%)$ & $33 / 62(53 \%)^{*}$ & $28 / 44(64 \%)$ \\
Full-time housekeeping & $6(37.5 \%)$ & $6(37.5 \%)$ & $15(45 \%)$ & $15(54 \%)$ \\
Retirement & - & - & $3(9 \%)$ & $3(11 \%)$ \\
Overweight & $6(37.5 \%)$ & $6(37.5 \%)$ & $5(15 \%)^{* *}$ & $3(11 \%)^{*}$ \\
Miscellaneous & $4(25 \%)$ & $4(25 \%)$ & $10(60 \%)$ & $7(25 \%)$ \\
\hline
\end{tabular}

"p<0.05 for differences with the overall preoperative control group, " $p<0.05$ for differences with the respective preoperative control group (Mann-Whitney $U$ test).

\section{Discussion}

In the present study the quality of life of morbidly obese patients undergoing surgical treatment was investigated. To evaluate the long-term results, a cross-sectional study was used. The mean follow-up of the present study was $>7 y$, longer than the follow-up of most studies. Characteristics of the control group matched those of the postoperative group closely, although the ratio of men to women was significantly lower in the control group, as was the 
body weight compared with the postoperative group before surgery. The difference in body weight is explained by the difference in the ratio of men to women, as body mass index was similar for both groups. The difference in the ratio of men to women did not seem to be important for the quality of life analysis because no differences were found in quality of life indicators between the male and female subgroups. However, for occupational and financial status, this difference in the ratio was important because employment and income were different between the sexes. To overcome this shortcoming, the groups were stratified by sex for the analysis of the occupational and financial status.

The morbidly obese patients had an impaired quality of life, as indicated by elevated values on almost all quality of life tests in the control group. Sullivan et al. ${ }^{12}$ described the effect of obesity on perceived health and psychosocial functioning in the first 1743 subjects of the Swedish Obese Subjects study. The average mental well-being of morbidly obese patients was worse than in the chronically ill or in cancer survivors. The impaired quality of life shown for the control group in the present study was not shown for the postoperative group, indicating that the impaired quality of life was the result of morbid obesity and was reversed by surgically induced weight loss. An improvement of quality of life after surgical treatment was also shown in other studies ${ }^{2,13-17}$. It is of interest that in the present study the highest preoperative quality of life scores and maximum improvement after weight loss were shown for the domains of energy and mobility on the NHP-I. Stunkard and Wadden ${ }^{18}$ pointed out that the psychosocial benefit of weight-reducing surgery is the result of increased mobility. Increased energy and mobility are a direct result of weight loss and enable the formerly obese person to participate in social and physical activities. Furthermore, the chances of successful employment increase after weight-reducing surgery ${ }^{16,17,19-24}$. This phenomenon was also shown by the significantly better scores on the NHP-II in the postoperative group.

In this study, surgical complications did not influence the quality of life outcome. This can be explained by the fact that most patients experienced the complications many years previously as a result of the long-term follow-up. This minor effect of complications on quality of life was also demonstrated by others ${ }^{24,25}$. The fact that patients with complications nevertheless experienced a significant improvement in quality of life compared with the control group highlights the severity of mental and physical suffering of these patients before surgery. Apparently, these patients prefer a nonobese state with surgical complications over an obese state. Results of a study of 47 patients $>$ 3 years after gastric restrictive surgery by Rand and Macgregor ${ }^{13}$ showed that patients who successfully maintained weight loss considered morbid obesity to be a tremendous personal liability. These patients preferred to be of a normal weight with another major handicap than to be morbidly obese. 
All three types of surgical procedures resulted in significant weight loss but there was a marked difference in the complication rate and the severity of complications among the procedures. The fact that no significant correlation was found between the type of surgical procedure and the quality of life outcome agrees with our observation that quality of life outcome was related mainly to weight loss and that complications had only a minor effect. Roscha et al. ${ }^{26}$ compared the quality of life of patients after intestinal bypass biliointestinal shunt, and VBG. Quality of life improved significantly in $75 \%$ of the patients irrespective of the surgical technique.

In the present study, short-term quality of life was better than the long-term quality of life, although the quality of life of patients after surgery remained superior to that of patients before surgery. This negative relation between the postoperative follow-up and quality of life outcome was also shown by Waters et al. ${ }^{27}$, who conducted a prospective study of mental health in 157 patients undergoing a Greenville gastric bypass. These authors found a significant improvement in mental health indexes at 6 and 12 mo postoperatively. However, health indexes eroded to preoperative values 2 y after surgery. There are several possible explanations for a decreased long-term quality of life outcome. The body weight curve shows a slight increase after $2 \mathrm{y}$. Furthermore, the frequency and intensity of clinical visits decreases with time. As Waters et al. ${ }^{27}$ pointed out, these patients may rely on medical and clinical visits to improve psychologically.

In the present study the employment rate was higher in the overall and female postoperative groups than in the respective control groups. The higher employment rate and possibly job promotion resulted in a higher yearly income of the overall postoperative group compared with the control group. However, the yearly income of the female subgroup was not higher in the postoperative group, possibly because the women are usually not the breadwinner and have jobs with lower salaries. Several studies on economic changes showed increased employment and income after surgically induced weight loss ${ }^{16,28,29}$. Hawke et al, ${ }^{16}$ studied the physical activity and social status of 240 patients $3 \mathrm{y}$ after gastric restrictive surgery. They found that full-time and part-time employment increased from $38 \%$ before to $60 \%$ after surgery. Näslund and Agren ${ }^{29}$ compared the socioeconomic status of 79 patients after gastric restrictive surgery with a similar group of 54 nonsurgical patients. After surgical treatment, $81 \%$ of the patients were employed compared with $65 \%$ of the nonsurgical patients. The average monthly income increased from 7663 Swedish krona (1 036 US\$) to 9009 Swedish krona (1 217 US\$) after surgery.

The data of the present study show a better quality of life after weightreducing surgery, although short-term quality of life outcome was better than long-term quality of life outcome. Quality of life is related to weight loss and not to the type of surgical procedure nor to surgical complications. 


\section{REFERENCES}

1. Spilker B. Quality of Life assessment in clinical trials. New York: Raven Press, Ltd. 1990.

2. Kral JG, Sjöström LV, Sullivan MBE. Assessment of quality of life before and after surgery for severe obesity. Am $\Downarrow$ Clin Nutr 1992;55:611S-4S.

3. Cowan GSM, Cowan KB, Hiler ML, Smalley MD, Sehnert W. Obesity stereotypes. Probl Gen Surg 1992;9:218-26.

4. Deurenberg P. van Poppel G. Hautvast JGAG. Morbiditeit en subjectief welbevinden bij jonge volwassen met overgewicht. Ned Tijdschr Geneeskd 1984:128:940-4.

5. Kral JG. Morbid obesity and related health risks. Ann Int Med 1985;103:1043-7.

6. Mason EE, Maher JW, Scott DH, et al. Ten years of vertical banded gastroplasty for severe obesity. Probl Gen Surg 1992;9:280-9.

7. Reinhold RB. Critical analysis of long-term weight loss following gastric bypass. Surg: Gynecol \& Obstet 1982;155:385-94.

8. Griffin WO, Young VL, Stevenson CC. A prospective comparison of gastric and jejunoileal bypass procedures for morbid obesily. Ann Surg 1977;186:500-509.

9. Van Gemert WG, Greve JWM, Soeters PB. Long-term results of vertical banded gastroplasty: Marlex versus Dacron bainding. Obesity Surgery 1997;7:128-135.

10. Hunt SM. McEwen J, McKenna SP. Measuring health status: A new method for clinicians and epidemiologists. J R Coll Gen Pract 1985;35:185-8.

11. Stouthard MEA, Bonsel GJ. Nederlandse bewerking NHP-DA. 1991

12. Sullivan M. Karlsson J, Sjöström $L$, et al. Swedish obese subjects (SOS) - an intervention study of obesity. Baseline evaluation of health and psychosocial functioning in the first 1743 subjects examined. Int J Obes 1993;17:503-12.

13. Rand CSW. Macgregor AMC. Successful weight loss following obesity surgery and the perceived liability of morbid obesity. Int J Obes 1991;15:577-579.

14. Sarlio-lähteenkorva S, Stunkard A, Rissanen A. Psychosocial factors and quality of life in obesity. Int J Obes 1995;19(suppl. 6):S1-S5.

15. Hafner RJ, Watts JM, Rogers J. Quality of life after gastric bypass for morbid obesity. Int J Obes 1991:15:555-60.

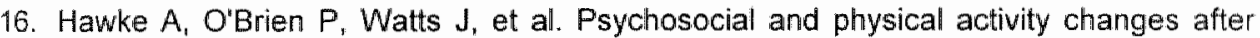
gastric restrictive procedures for morbid obesity. Aust NZ J Surg 1990;60:755-8.

17. Rae AJ. Cleater IGM. Quality of life assessment, of ileogastrostomy. Obesity Surg $1993 ; 3 ; 360-4$.

18. Stunkard AJ, Wadden TA. Psychological aspects of severe obesity. Am J Clin Nutr $1992,55: 524 S-32 S$

19. Gentry $\mathrm{K}$, Halverson JD, Heisler S. Psychologic assessiment of morbidly obese patients undergoing gastric bypass: A comparison of preoperative and postoperative adjustment. Surgery 1984:95:215-20.

20. Valley $V$, Grace DM. Psychosocial risk factors in gastric surgery for obesity: Identifying guidelines for screening. Int $J$ Obes 1987;11:105-13

21. Chandarana P, Holliday $R$, Conlon P. Deslippe T. Psychosocial considerations in gastric stapling surgery. J Psychosom Res 1988;32:85-92.

22. Näslund I, Cgren G. Social effects of surgical treatment of morbid obesity. Probl Gen Surg 1992;9:213-7.

23. La Manna A, Ricci GB, Giorgi I Gossemberg M, La Manna L., Catona A. Psychological effects of vertical banded gastroplasty on pathologically obese patients. Obesity Surg $1992 ; 2: 239-43$.

24. Saltzstein EC, Gutmann MC. Gastric bypass for morbid obesity. Arch Surg $1980 ; 115: 21-8$. 
25. Ryden $O$, Olsson $S$, Danielsson $A$, Nilsson-Ehle P. Weight loss after gastroplasty: Psychological sequelae in relation to clinical and metabolic observations. J Am Coll Nutr $1989 ; 8: 15-23$.

20. Roschal $H$, Lang $B$, Hell $E$. Auswirkungen der chirurgischen therapie extremer adipositas auf korperliches und psychisches befinden. Wien Klin Wochenschr $1992 ; 104: 467-73$

27. Waters GS, Pories WJ, Swanson MS, Meelheim HD, Flickinger EG, May HJ. Long-term studies of mental health after the Greenville gastric bypass operation for morbid obesity. Am J Surg 1991:161:154-8.

28. Martin LF, Tan TL, Holmes $P A$, et al. Preoperative insurance status influences postoperative complication rates for gastric bypass. Am J Surg 1991:161:625-34.

29. Nasslund 1, Cgren $\mathrm{G}$. Social and economic effects of bariatric surgery. Obesity Surgery $1991: 1: 137-40$. 
Chapter 3.2

PSYCHOLOGICAL FUNCTIONING OF MORBIDLY OBESE PATIENTS AFTER SURGICAL TREATMENT

W. G. Van Gemert, Ruud M. Severeijns, Jan Willem M. Greve, Nico H. Groenman, Peter $B$. Soeters.

Int J Obes 1998;22:393-398. 


\section{ABSTRACT}

Objective: To investigate the long-term effects of surgically induced weight loss on the psychological functioning of morbidly obese patients.

Design: Comparison between preoperative and postoperative psychometric test results in a cross-sectional study.

Patients and methods: Three psychometric tests were administered to 62 morbidly obese patients before and after surgery.

Results: The mean follow-up was $85.9 \pm 48.1$ months. Surgical treatment resulted in a mean weight loss of $45.0 \pm 21.3 \mathrm{~kg}(p<0.0001)$. The psychometric test results before surgery demonstrated somatisation, depression, denial of emotional stress, social incompetence and an indifferent attitude towards certain aspects of interpersonal behaviour. All psychopathology, except for somatisation, disappeared after surgical treatment. Improvement of psychological functioning was determined by weight loss and not influenced by the surgical procedure. The level of self-esteem before surgery predicted $15.4 \%$ of the outcome variance $(p<0.05)$

Conclusion: The psychopathology before surgery is almost totally reversed after sustained, surgically induced weight loss. This suggests that the preoperative psychological disturbances are the result, rather than the cause, of morbid obesity.

\section{INTRODUCTION}

For many years obesity was ascribed to psychopathological determinants, such as low frustration tolerance and lack of will-power. However, recent research has changed our understanding of obesity and psychopathology is now seen more as a consequence, rather than a cause, of obesity ${ }^{12}$. Despite the positive change from the scientific point of view, obese individuals are still subject to significant prejudice and discrimination in daily life ${ }^{2.3}$. The adverse psychosocial effects, together with the high incidence of obesity related morbidity, such as cardiovascular disease and diabetes mellitus, makes treatment of obesity worthwhile.

However, conservative treatment of morbid obesity is unlikely to produce a long-lasting weight reduction and results, more often, in negative psychological reactions ${ }^{2.4,5}$. Therefore, surgical treatment is considered as therapy for morbid obesity, even more so because an improvement of psychosocial functioning after surgical treatment of morbid obesity has been reported ${ }^{6-9}$.

As surgical treatment generally results in a substantial and long-lasting weight loss ${ }^{10,11}$, morbidly obese patients undergoing surgical treatment are a suitable population to investigate the long-term effects of weight loss on the 
psychosocial functioning of morbidly obese patients. Especially, because in some studies, a placebo-effect of medical support in the initial period after surgery has been reported ${ }^{12}$. Currently, no studies regarding the long-term effects (more than five years) of sustained weight loss after surgical treatment on the psychological functioning of morbidly obese patients have been reported. We therefore studied the long-term effects of sustained weight loss on the psychological functioning of a population that underwent surgical treatment for morbid obesity on average seven years previously.

\section{PATIENTS AND METHODS}

\section{Study design}

A cross-sectional study design was used. All morbidly obese patients, operated on from 1982-1993, were invited to participate in this study. The surgical procedures performed were the gastric bypass and the vertical banded gastroplasty. Patients were selected for surgery according to the criteria of the National Institutes of Health Development Conference Statement ${ }^{13}$. The reason for the administration of psychometric tests before surgery was twofold. To screen for psychopathology before surgery, but more importantly, to investigate the effect of surgically induced weight loss on the psychological functioning of morbidly obese patients. For the latter reason a battery of psychometric tests was administered.

\section{Psychometric tests}

The psychological tests consisted of the Groninger Intelligence Test (GIT) ${ }^{14}$, the Dutch Shortened MMPI (NVM) ${ }^{15}$, the Dutch Personality Inventory (NPV) ${ }^{16}$ and the Scale for Interpersonal Behaviour (SIG) ${ }^{17}$. All psychological tests were administered before surgery and at the time of this study. The GIT measures overall intelligence and is included to investigate the patients ability to understand and perform the psychometric tests. The NVM is a validated and standardised personality test derived from the Minnesota Multiphasic Personality Inventory. This personality test consists of five scales: negativism, somatisation, shyness, psychopathology and extroversion. The NPV is a validated and standardised test derived from the California Psychological Inventory and consists of seven scales: inadequacy, social inadequacy, rigidity, grievance, self-satisfaction, dominance and self-esteem. Normative values of the NVM and NPV are available. The standard values of a general Dutch population were chosen as the reference values. The $S \mid G$ is a standardised and validated test of certain aspects of interpersonal behaviour. It measures the frequency of expressing yourself, negative feelings, positive feelings and insecurity in a number of social situations "and the level of tension 
when doing so. As the SIG describes interpersonal behaviour, there are no normative values for this test.

\section{Statistics}

The normative values of the NVM and NPV are expressed as the mean value and the $95 \%$ confidence interval (Cl) to allow comparison with the values of the study group (before and after surgery) also expressed as the mean value and the $95 \% \mathrm{Cl}$. The separate variance $t$ test was used to test statistical significance between the results of the study group and the normative values. Statistical differences between the values of the study group before and after surgery were tested with the Student $t$ test for dependent samples.

The relationship between the clinical parameters (surgical procedure, surgical complications and percentage excess weight loss) and the psychological functioning after surgery was determined with the Pearson correlation coefficient. Significant correlations were further tested by means of a multiple regression analysis (enter-method) with the psychological test results after surgery as the dependent variables and the clinical parameters as the independent variables. Predictors for surgical outcome were tested by means of a multiple regression analysis (enter-method). The psychometric test results before surgery, with a significant correlation as determined with the Pearson correlation coefficient, were entered in the multiple regression analysis as the independent variables and the percentage excess weight loss after surgery as the dependent variable.

Statistical significance was considered present at $p<0.05$. Data were analysed using the Statistical Package for Social Science (SPSS, SPSS Inc. Chicago).

\section{RESULTS}

\section{Group characteristics}

All 69 patients operated on during the study period were approached for the study. One patient died in the postoperative period after a vertical banded gastroplasty and six patients could not be traced and were lost to follow-up (follow-up $91 \%$ ). The mean follow-up was $85.9 \pm 48.1$ months. The gastric bypass and the vertical banded gastroplasty were performed in 18 and 44 patients, respectively. The overall mean age was $33.1 \pm 9.4 \mathrm{y}$ and the malefemale ratio was 18:44. Surgical treatment resulted in a reduction of the mean overall body weight from $138.8 \pm 27.3 \mathrm{~kg}$ to $93.8 \pm 24.7 \mathrm{~kg}(p<0.0001)$ and a reduction of the mean overall body mass index (BMI) from $47.8 \pm 7.0 \mathrm{~kg} / \mathrm{m}^{2}$ to $32.0 \pm 7.1 \mathrm{~kg} / \mathrm{m}^{2}(p<0.0001)$. 
Table 1. NVM scores of the study population before and after surgery compared to the reference group (mean and $95 \%$ confidential interval).

\begin{tabular}{|c|c|c|c|c|c|c|}
\hline \multirow[b]{2}{*}{ Negativism } & \multicolumn{2}{|c|}{ Relerence } & \multicolumn{2}{|c|}{ Before surgery } & \multicolumn{2}{|c|}{ After surgery } \\
\hline & 14.7 & $(14.2-15.2)$ & 18.1 & $(15.9-20.3)^{* *}$ & 16.7 & $(14.5 \cdot 18.9)$ \\
\hline Somatisation & 5.3 & $(4.9-5.7)$ & 12.8 & $(10.7-14.9)^{*}$ & 4.6 & $(12.1-17.1)^{*}$ \\
\hline Shyness & 8.0 & $(7.6-8.4)$ & 14.5 & $(12.1-16.9)^{*+*}$ & 9.9 & $(7.8-12.0)$ \\
\hline Psychopathology & 2.7 & $(2.5-2.9)$ & 3.3 & $(2.5 \times 4.1)$ & 3.2 & $(2.5-3.9)$ \\
\hline Extroversion & 17.1 & $(16.7-17.5)$ & 15.1 & $(13.5-16.7)^{*}$ & 16.8 & $(15.3 \times 48.3)$ \\
\hline
\end{tabular}

Separate variance t test for differences between the walues of the studly group (before and after surgery) and the values of the reference group ( $\left.{ }^{*} p<0.02 ; * 0<0.01 ; * * 0<0.001\right)$.

\section{Psychological profile before surgery}

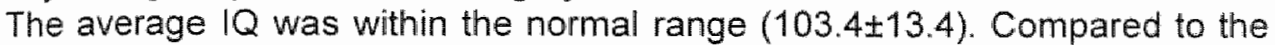
reference values, the NVM demonstrated elevated values on the negativism, somatisation, and shyness scales, and a reduced value on the extroversion scale (Table 1).

Table 2. NPV scores of the study population before and after surgery compared to the reference group (mean and $95 \%$ confidential interval).

\begin{tabular}{|c|c|c|c|c|c|c|}
\hline & \multicolumn{2}{|c|}{ Reference } & \multicolumn{2}{|c|}{ Before surgery } & \multicolumn{2}{|c|}{ Alter surgery } \\
\hline Inadequacy & 13.9 & $(13.6 \cdot 14.2)$ & 16.8 & $\left({ }^{4} 4.0-19.6\right)^{*}$ & 13.9 & $(11.4-16.4)$ \\
\hline Social inadequacy & 12.3 & $(12.0-12.6)$ & 15.8 & $(13.4-18.2)^{4}$ & 9.3 & $(7.1-11.5)^{* *}$ \\
\hline Rigidily & 30.6 & $(30.2-31.0)$ & 27.3 & $(25.2-29.4)^{* *}$ & 27.8 & $(25.8-29.8)^{\star *}$ \\
\hline Grievance & 18.2 & $(18.0-18.4)$ & 21.2 & $(19.1-23.3)^{* *}$ & 19.4 & $(17.3-21.5)$ \\
\hline Selt-satisfaction & 13.9 & $(13.7 \cdot 14.1)$ & 12.5 & $(10.8-14.2)$ & 13.0 & $(11.6-14.4)$ \\
\hline Dominance & 11.9 & $(11.7-12.1)$ & 13.6 & $(11.5-15.7)$ & 15.6 & $(13.7-17.5)^{* k 1}$ \\
\hline Selfesteem & 28.0 & $(27.9-28.1)$ & 24.4 & $(22.2-26.6)^{i x / 4}$ & 26.5 & $(24.5-28.5)$ \\
\hline
\end{tabular}

Separate variance $t$ test for differences between the values of the study group (betore and after surgery) and the values of the reference group ("p<0.05; * $p<0.01 ; " * *<<0.001)$. 
These results demonstrate a discontented and self-defensive attitude towards others. The patients were concerned about their health and were inclined to react to psychological stress with physical complaints. They were reserved, falled to express themselves and had difficulties making interpersonal contact. The test results of the NPV showed elevated scores on the inadequacy, social inadequacy, and grievance scales. The rigidity and self-esteem scales were reduced (Table 2 ).

The patients were tense and depressed with feelings of insecurity and despair. They were socially incompetent, felt distrustful and impatient towards others and had a lowered self-esteem. With regard to the SIG, the patients showed a low frequency of expressing themselves, negative feelings, positive feelings and insecurity, and a low level of tension when doing so (Table 3). In other words, the patients had an indifferent attitude towards certain aspects of interpersonal behaviour.

Table 3. Comparison of the SIG scores before and after surgery (mean \pm SD).

\begin{tabular}{|lcccc|}
\hline & \multicolumn{2}{c}{ Before surgery } & \multicolumn{2}{c|}{ After surgery } \\
& Tension & Frequency & Tension & Frequency \\
\hline Positive feelings & $2.4 \pm 0.9$ & $2.7 \pm 0.7$ & $2.0 \pm 0.9^{*}$ & $3.1 \pm 0.8^{* *}$ \\
Negative feelings & $2.5 \pm 0.8$ & $2.7 \pm 0.5$ & $2.2 \pm 0.8$ & $3.0 \pm 0.6^{*}$ \\
Self-expression & $2.6 \pm 1.0$ & $2.7 \pm 0.7$ & $2.0 \pm 0.9^{* *}$ & $3.1 \pm 0.7^{*}$ \\
Insecurity & $2.1 \pm 0.7$ & $3.4 \pm 0.4$ & $1.8 \pm 0.6^{*}$ & $3.5 \pm 0.7$ \\
\hline Total & $2.3 \pm 0.8$ & $3.0 \pm 0.5$ & $2.0 \pm 0.7^{*}$ & $3.2 \pm 0.6^{*}$ \\
\hline
\end{tabular}

Paired Student $t$ test; " $p<0.05$, *" $p<0.001$.

\section{Psychological profile after surgery}

Compared to the reference values the postoperative NVM showed normal values except for the somatisation scale(Table 1). The improvement on the shyness scale was significant, implying that the patients were no longer shy or introvert and had no difficulties in making interpersonal contact (Figure 1). However, they were still concerned about their health and inclined to react to psychological stress with physical complaints. With regard to the NPV, the improvements of the sociall inadequacy and grievance scales were significant (Figure 2). The dominancy and rigidity scales were elevated compared to the reference values, and the social inadequacy scale was reduced in contrast with the elevated value before surgery. The social incompetence disappeared 
and the patients were no longer distrustful of others, and their self-esteem was within normal values. The elevated score on the dominancy scale showed that the patients felt more self-confident and were more dominant in social activities than before surgery. Their self-esteem returned to normal values. With regard to the SIG the patients showed a higher frequency of expressing themselves, negative feelings, positive feelings and insecurity after surgery (Table 3). The level of experienced tension was reduced. Their indifferent attitude changed to assertiveness.

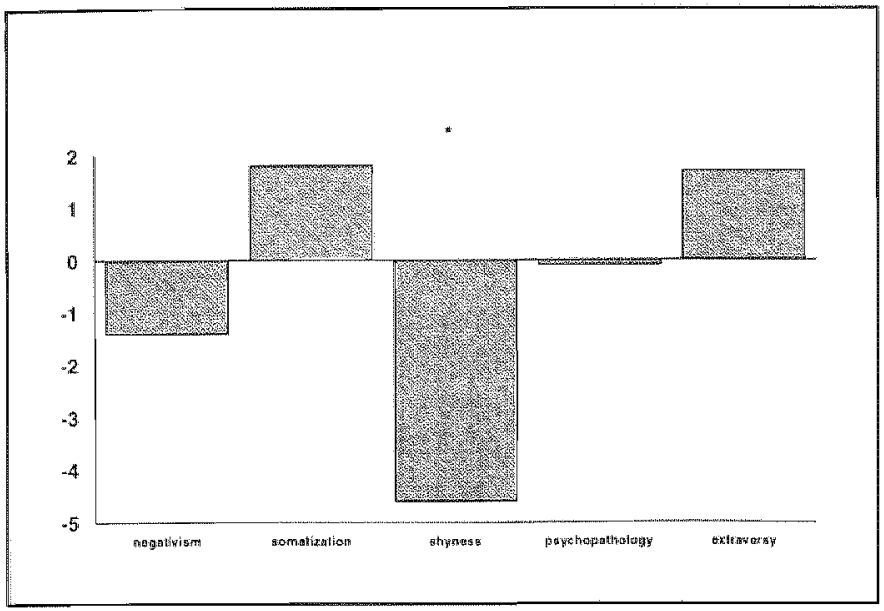

Figure 1. Difference between the NVM scales before and after surgery. Paired Student test; $* 0<0.05$.

The effect of clinical parameters on psychological outcome

Multiple regression analysis revealed that the percentage excess weight loss significantly influenced the following psychometric test results after surgery: inadequacy $\left(r^{2}=0.068 ; p=0.038\right)$, social inadequacy $\left(r^{2}=0.063 ; p=0.045\right)$ and self-esteem $\left(r^{2}=0.102 ; p=0.014\right)$ of the NPV and extroversion $\left(r^{2}=0.068\right.$; $p=0.040)$ and somatisation $\left(r^{2}=0.123 ; p=0.008\right)$ of the NVM. A greater percentage excess weight loss was related to better psychological stability and social interactibility, and a higher self-esteem.

The variables surgical procedure and surgical complications showed no correlation with the psychological test results after surgery and were not entered in the multiple regression analysis. 


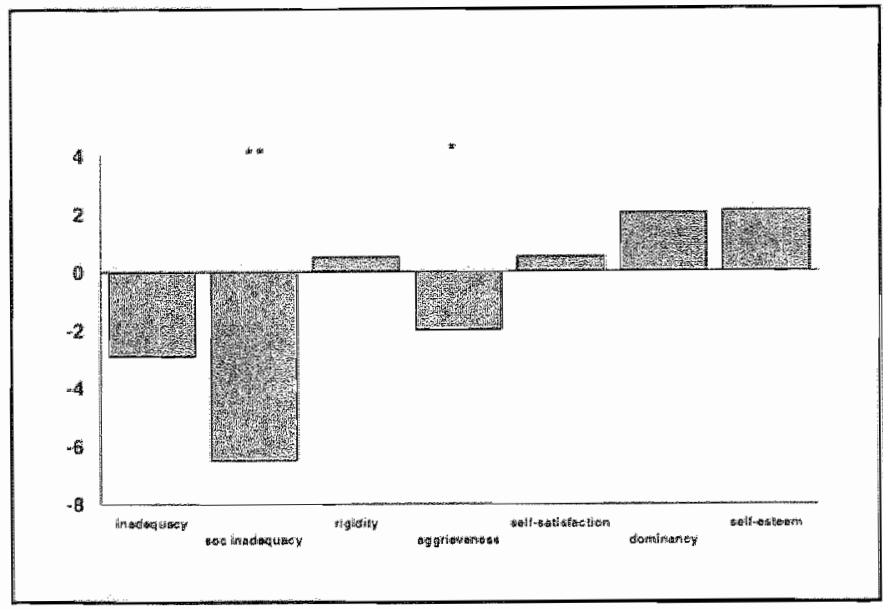

Figure 2. Difference between the NPV scales before and after surgery. Paired Student $t$ test: *p<0.05, * $p<0.001$.

Predictors for surgical outcome

The self-esteem scale of the NPV before surgery was the only independent variable entered in the multiple regression analysis that correlated significantly with the percentage excess weight loss $\left(r^{2}=0.154 ; p=0.002\right)$. This signifies that patients with a low self-esteem were more likely to achieve better weight loss after surgical treatment. The self-esteem scale before surgery predicted $15.4 \%$ of the variance of the percentage excess weight loss.

\section{DISCUSSION}

Studies regarding the psychological aspects of weight reducing surgery generally report the analysis of short term results. Waters et al. ${ }^{12}$ conducted a prospective study on mental health in 157 patients undergoing a gastric bypass. The improvement of mental health indices at 6 and 12 months after surgery eroded to preoperative values two years after surgery. The authors pointed out that these patients may rely on medical and clinical visits to improve psychologically. To investigate the effect of surgical treatment on the psychological outcome of morbidly obese patients without the placebo-effect of the intensive medical support in the first years after surgery, it is essential to assess long-term results. The literature lacks studies reporting long-term 
results (more than five years) of the psychological functioning of morbidly obese patients after sustained weight loss.

The preoperative psychological profile of the morbidly obese patients in this study demonstrated depression, feelings of insecurity and despair, somatisation, denial of emotional stress, difficulties making interpersonal contact, poor social adjustment and low self-esteem. Most population studies. fail to demonstrate increased psychopathology of the obese population, however, morbidly obese persons are not, or scarcely, included in these studies $^{1,2}$. Clinical studies are essential to investigate the psychological functioning of morbidly obese persons, since population studies of morbidly obese individuals are almost impossible to carry out as a result of the low prevalence.

Hafner et al ${ }^{18}$ found in a population of 142 morbidly obese patients before gastric restrictive surgery, a higher level of anxiety, somatisation and depression compared to a normal weight control group, although the abnormalities found were clinically modest. Several studies using the MMPI to assess the psychalogical status demonstrate mild to maderate levels of hypochondriasis, depression, hysteria and psychopathic deviate $e^{5,19.20}$. These findings are in agreement with the long-term results of our study. The majority of the clinical studies do demonstrate significant psychopathology ${ }^{21-24}$. The diagnosis usually includes affective and adjustment disorders. These studies indicate that psychological disturbances do exist to some extent in the morbidly obese population. However, since the prevalence of significant psychopathology varies largely between these studies (15\%-72\%), the results of these studies should be interpreted with caution.In the present study, an improvement of the psychological status was found independent of the type of surgical procedure, suggesting that the preoperative psychopathology is the result of morbid obesity and can be reversed by successful weight loss. Most studies regarding the psychological functioning after surgically induced weight loss, report positive changes irrespective of the surgical procedure used $\mathrm{d}^{6-9}$.

The most frequently reported changes are increased self-esteem, assertiveness and self-confidence, improved social activity and interpersonal relationships and decreased depression and anxiety. In the present study, similar psychological improvements were established after sustained longw term weight loss. The improved psychological functioning was mainly determined by weight loss, despite the occasional presence of surgical complications. The fact that patients experienced a significant improvement of their psychological functioning when surgical complications also occurred, highlights the severity of mental and emotional suffering of morbidly obese patients. Apparently these patients prefer a non-obese state with surgical complications above an obese state.

The strongest predictor of weight loss found in this study was the self-esteem scale of the NPV before surgery, although the explained variance was only 
$15.4 \%$. The low explained variance is not surprising since weight loss is mainly induced by the surgical intervention. Some variation in postoperative weight loss can be explained by the patients' compliance. Morbidly obese patients with a low self-esteem are possibly the patients with the greatest psychological suffering and therefore the best motivated patients to comply with postoperative dietary and medical instructions. Several studies have been performed to identify pre-surgical factors to predict the outcome of surgical treatment ${ }^{25-28}$, but did not yield a consistent and reproducible predictor for surgical success. In a systematic review of the literature, Vallis and Ross ${ }^{28}$ suggest that distress due to obesity can be an important psychological predictor for the outcome of surgical treatment.

In conclusion, the preoperative psychological disturbances of morbidly obese patients undergoing surgical treatment, disappear almost completely after surgical treatment. The psychological improvement remains after sustained, long-term weight reduction and is mainly determined by weight loss.

The outcome of this study provides evidence that the pathogenesis of morbid obesity has no psychological basis. It should caution us to view morbid obesity largely as a disease and to approach morbidly obese patients in a less negative way than is usually adopted. 


\section{REFERENCES}

1. Stunkard AJ, Wadden TA. Psychosocial consequences of obesity and dieting. Research and clinical findings. In: Stunkard AJl, Wadden TA (eds). Obesity. Theory and Therapy. Raven Press: New York 1993.

2. Wadden TA, Stunkard AJ. Social and psychological consequences of obesity. Ann Int Med 1985:103:1062-7.

3. Rand CSW. Macgregor AMC. Morbidly obese patients' perceptions of social discrimination before and after surgery for obesity. South Med $\mathbb{J} 1990 ; 83: 1390-5$.

4. Halmi $K \mathrm{~A}_{\mathrm{n}}$ Stunkard A., Mason EE. Emotional responses to weight reduction by three methods: gastric bypass, jejunoileal bypass, diet. Am J Clin Nutr 1980;33:446-51.

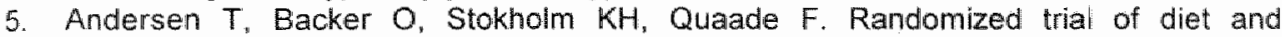
gastroplasty compared with diet alone in morbid obesity. N Eng J Med 1984,310:352-6.

6. Solow C. Silberfarb PM, Swift K. Psychosocial effects of intestinal bypass surgery for severe obesity. N Eng J Med 1974;290;300-4.

7. La Manna A, Ricci GB, Giorgi I, Gossemberg M, La Manna L, Catona A. Psychological effects of vertical banded gastroplasty on pathologically obese patients. Obesity Surgery $1992 ; 2: 239-43$.

8. Solow C. Psychosocial aspects of intestinal bypass surgery for massive obesity: Current status. Am J Clin Nutr 1977:30:103-8.

9. Harris MB, Green D. Psychasocial effects of gastric reduction surgery for obesity. Int $J$ Obes 1982;6:527-39.

10. Mason EE, Maher JW, Scott DH, Rodriquez EM, Doherty C. Ten years of vertical banded gastroplasty for severe abesity. Probl Gen Surg 1992;9:280-9.

11. Reinhold RB. Critical analysis of long term weight loss following gastric bypass. Surg. Gynecol \& Obstet 1982;155:385-94.

12. Waters GS, Pories WJ, Swanson MS, Meelheim HD, Flickinger EG, May HJ. Long-term studies on mental health after Greenville gastric bypass. Am $\mathbb{J}$ Surg 1991;161:154-8

13. Gastrointestinal surgery for severe obesity: National Institutes of Health Consensus Development Conference Statement. Am J Clin Nutr 1992;55:615S-9S.

14. Lutelin F, Van der Ploeg FAE (eds). Handleiding GIT. Swets \& Zeitlinger: Lisse 1983.

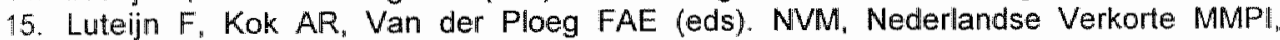
handleiding. Swets \& Zeitlinger: Lisse 1980.

16. Luteijn F, Starren J, Van Dijk $H$ (eds). Handleiding Nederlandse Persoonlijkheidsvragenlijst (herziene uitgave). Swets \& Zeitlinger: Lisse 1985.

17. Arrindell WA, Groof PM, Walburg IA (eds). Handleiding Schaal voor Interpersoonlijk Gedrag, SIG. Deell. Swets \& Zeitlinger: Lisse 1984.

18. Hafner RJ. Watts JMck Rogers J. Psychological status of morbidly obese women before gastric restriction surgery. J Psychosom Res 1987;31:607-12.

19. Rosen LW. Aniskiewics AS. Psychosocial functioning of two groups of morbidly obese patients. Int J Obes 1983;7:53-9.

20. Johnson SF. Swenson WM, Gastineau CF. Personality characteristics in obesity: Relation of MMPI profile and age of onset of obesity to success in weight reduction. Am J Cin Nutr 1976;29:626-32.

21. Black DW, Goldstein RB, Mason EE. Prevalence of mental disorder in 88 morbidly obese bariatric climic patients. Am J Psychiatry 1992;149:227-34.

22. Sullivan M, Karlsson J, Sjöström L, Backman L, Bengtsson C, Bouchard C, Dahlgren $S$,

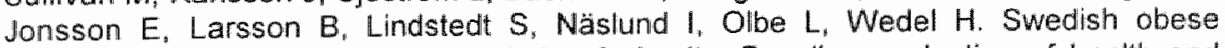
subjects (SOS) - an intervention study of obesity. Baseline evaluation of health and psychosocial functioning in the first 1743 subjects examined. Int J Obes 1993:17:503-12. 
23. Gertler R, Ramsey-Stewart G. Pre-operalive psychiatric assessment of patients presenting for gastric bariatric surgery (surgical control of morbid obesity). Aust NZ Surg 1986;56:157-61.

24. Hutzler JC, Keen J, Molinari V. Carey L. Super obesity: A psychiatric profile of patients electing gastric stapling for the treatment of obesity. J Clin Psychiatry 1981;42:458-62.

25. Barrash J, Rodriquez EM, Scott DH, Mason EE. Sines JO. The utility of MMPI subtypes for the prediction of weight loss after bariatric surgery. Int J Obes $1987: 11: 115-28$.

26. Grana $\mathrm{AS}$, Coollidge $\mathrm{FL}$, Merwin MM. Personality profiles of the morbidlly obese. J Clin Psychol 1989;45:762-5.

27. Olsson SA, Ryden O, Danielssion A, Nilsson-Ehle P. Weight reduction after gastroplasty: The predictive value of surgical, metabolic and psychological variables. Int $J$ Obes 1984:8:245-58.

28. Vallis TM, Ross MA. The role of psychological factors in bariatric surgery for morbid obesity: Identification of psychological predictors of success. Obesity surgery $1993 ; 3: 346-359$. 
Chapter 3.3

\section{A PROSPECTIVE COST-EFFECTIVENESS ANALYSIS OF VERTICAL BANDED GASTROPLASTY FOR THE TREATMENT OF MORBID OBESITY}

Wim G. van Gemert, Eddy M.M. Adang, Monica Kop, Gemma Vos, Jan-Willem M. Greve, Peter B. Soeters.

Submitted for publication 


\section{ABSTRACT}

Objective: A prospective, prevalence-based cost-effectiveness analysis of surgical treatment of morbid obesity.

Patients and methods: Twenty-one consecutive morbidly obese patients entered the study. All patients underwent a vertical banded gastroplasty (VBG) and were tested before surgery, and one and two years after surgery. Quality of life was assessed by the Nottingham Health Profile part $\|$ and II and a visual analogue scale for quality of life assessment. A prevalence-based cost-ofillness analysis of morbid obesity was performed and the cost-effectiveness of VBG was assessed, expressed as the costs per quality adjusted life year (QALY) gained. The study was performed according to the intention to treat principle, and therefore treatment failures were accounted for.

Results: VBG resulted in a significant weight loss and improved quality of life at one and two years after surgery. Quality of life outcome was influenced by weight loss and revisional surgery. The improved quality of life combined with 3.6 life years gained after VBG resulted in 12 QALY's gained (lifelong scenario). The lifelong costs of illness of morbidly obese persons ranged from 8304 US\$ to 9367 US\$. The total direct costs of VBG were 5865 US\$. The percentage of patients performing paid labor increased from $19 \%$ before VBG to $48 \%$ after VBG, resulting in an average productivity gain of 2765 US\$ per year. The cost-effectiveness analysis revealed that surgical treatment of morbid obesity by means of VBG saves 4004 US\$ to 3928 US $\$$ per QALY (overall dominance).

Conclusion: Because treatment of morbid obesity with VBG results in QALY"s gained and less costs, there is no doubt that this procedure should be introduced or continued from a societal point of view.

\section{INTRODUCTION}

Morbid obesity is a progressive disease of fat storage defined as a body mass index over $40 \mathrm{~kg} / \mathrm{m}^{2}$ or an excess body weight of more than $100 \%$ above ideal body weight as determined by the 1983 height/weight tables of the Metropolitan Life Insurance Company ${ }^{\dagger}$. The disease is accompanied by a high incidence of obesity-related comorbidity such as diabetes, cardiovascular and pulmonary disease $e^{2.3}$, which are responsible for chronic disability, accelerated mortality and a poor quality of life ${ }^{4,5}$. Although evidence is accumulating that severe obesity cannot be ascribed to psychopathological determinants, morbidly obese patients are still poorly understood $d^{6,7}$. Morbidly obese patients are still subject to extreme prejudice and discrimination from the public, but also from health-care professionals ${ }^{8}$. As a consequence, the morbidly obese carry an enormous psychosocial burden and have difficulties in finding good 
education or employment and above all are not taken seriously by the predominant part of the medical profession.

The high and increasing prevalence of obesity (body mass index $>30 \mathrm{~kg} / \mathrm{m}^{2}$ ) and related comorbidity is accompanied by increasing health care costs. A conservative estimate of the economic costs of obesity related illness amounts to $5.5-7.8 \%$ of the total costs of illness in the US ${ }^{9}$. With respect to morbid obesity (body mass index $>40 \mathrm{~kg} / \mathrm{m}^{2}$ ), a cost-of-illness analysis is to our knowledge not available. Epidemiological studies of morbid obesity are difficult because the prevalence is relatively low and morbidly obese persons are difficult to trace. On the other hand, the prevalence of comorbidity among morbidly obese individuals is very high and is responsible for considerable health care costs ${ }^{10}$.

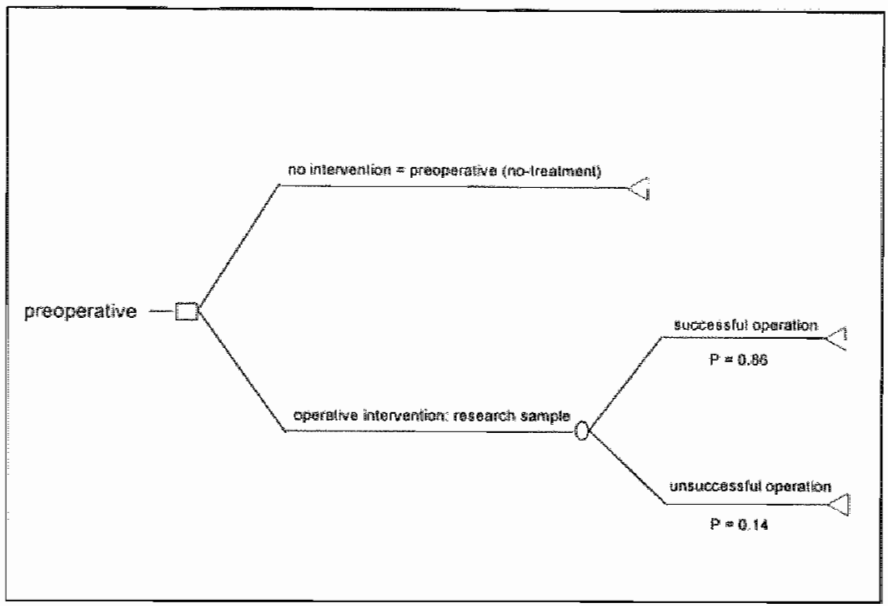

Figure 1. Study design. This flow diagram shows the study design of the present study according to the intention to treat approach.

$\square$ decision node: It signifies a decision to be made among the alternative branches emanating from it; 0 chance node: Represents an uncertain situation which results in a true state, successful or unsuccessful; ot terminal node: Indicates that the path's end is reached.

To investigate the benefit to society of surgical treatment of morbid obesity the costs of treatment must be weighed aglainst the improved health status resulting in life years gained and improved quality of life. Because conservative treatment of morbid obesity is largely ineffective ${ }^{11}$, the $\mathrm{NIH}$ endorsed the vertical banded gastroplasty and the gastric bypass as the accepted treatment of morbid obesity ${ }^{12}$. Vertical banded gastroplasty results in 
an excess weight loss of approximately $60 \%$ and results in an improved quality of life and decreased obesity-related comorbidity ${ }^{45,13-15}$. From this point of view it is expected that the treatment of morbid obesity is cost-effective.

Two alternatives were compared in the present study. One alternative of which the inputs were a prevalence-based cost-of-illness analysis based on a morbidly obese population, and a preoperative quality of life assessment of the research population. This alternative was referred to as "the no-treatment group". The second alternative incorporated total (direct and indirect) costs, quality of life outcome and life years gained after surgical treatment. The latter alternative was referred to as "the treatment group" (Figure 1).

\section{PATIENTS AND METHODS}

\section{Patients}

Twenty-one consecutive morbidly obese patients were included in this study and questionnaires were administered by mail one month before surgery, and one and two years after surgery. All patients were treated with the vertical banded gastroplasty (VBG). At the end of the second year $90 \%$ of the patients were discharged from medical follow-up. The surgical technique is described in detail elsewhere ${ }^{14}$. At all time points body weight, weight loss, and complications were registered. The study was performed according to the intention to treat principle, and therefore treatment failures were accounted for (Figure 1). Failure of surgical treatment was defined as a percentage excess weight loss lless than $25 \%$ (unsatisfactory weight loss according to Maclean) ${ }^{16}$. In case of treatment fallure, the same costs as counted in the no-treatment group were used. This study was approved by the local medical ethical committee and all patients gave their informed consent before participating in this study.

\section{Quality of life analysis}

Quality of life tests included the Nottingham Health Profile part I (NHP-I), the Nottingham Health Profile part II (NHP-II) ${ }^{1 \%}, 18$ and a Visual Analogue Scalle for quality of life assessment (VAS) ${ }^{11}$. The NHP-l is a questionnaire designed as a comprehensive instrument to measure perceived health on six specific domains of life: mobility, energy, pain, sleep, social isolation, and emotional reaction. The scores are not enumerated to an aggregated score of all domains, but constitute a profile of six independent domains (range 0 [best score] to 100 [worst score]). The NHP-II is a questionnaire related to those areas of task performance most affected by health. It consists of seven statements that refer to the effects of health problems on occupation, ability to perform domestic tasks, hobbies, personal relationships, sex life and holidays (range 0 [best score] to 21 [worst score]). The VAS scores quality of life on a 
linear scale ranging from the worst imaginable quality of life (score of 0 ) to the best imaginable quality of life (score of 10). The relation between quality of life outcome and weight loss, surgical complications and revisional surgery was investigated by stratification. Weight loss was classified as good, satisfactory, and unsatisfactory according to the criteria of Maclean et al. ${ }^{16}$.

\section{Cost-of-illness analysis}

The prevalence of morbid obesity-related comorbidities were obtained from surgical study populations. The prevalence of diseases in the total population was obtained from data of the Central Bureau of Statistics of The Netherlands ${ }^{19}$. The proportion of diseases attributable to morbid obesity was calculated from the prevalence and relative risk of diseases in the morbidly obese population compared to the general population. The costs of treatment of diseases in the general population was obtained from data of the Institute of Public Health Care of The Netherlands ${ }^{20}$. The proportion of health care costs attributable to the treatment of morbid obesity-related comorbidity is calculated by means of the population attributable risk (PAR). The PAR is calculated according to: $P A R=P(R R-1) /(P(R R-1)+1)(P=$ the prevalence of morbid obesity; $R R=$ the relative risk of morbid obesity-related diseases) ${ }^{21}$. The cost-of-illness analysis was performed for two scenario's: an estimated prevalence of morbid obesity of $0.25 \%$ (optimistic) and $1.00 \%$ (pessimistic). The results of the costof-illness analysis were introduced as the costs of no treatment in the costeffectiveness analysis.

\section{Cost-effectiveness analysis}

For the cost-analysis of the treatment group a distinction was made between direct and indirect disease-related costs. Costs were based on real prices, not on charges. To calculate the direct costs of surgical treatment all medical performances per patient were counted: operations including revisional surgery, pre- and postoperative diagnostic and therapeutic procedures, including management of surgical complications, outpatient visits, and the days occupying a hospital bed. Operation costs included health professionals' time: surgeon, resident, anaesthesiologist, and nursing staff time were included. Also supplies, equipment, costs of housing, feeding, administration, and management, were included. Indirect costs of treatment (e.g. productivity losses) were defined as: "The value of potentially lost/gained production from present age until the age of retirement (assumed: 65 years)". The incremental value of indirect costs was determined by interviewing patients about their productivity status before and two years after surgery. The productivity status two years after surgery is regarded as being stable, and extrapolated to the age of retirement. The study population was divided into six categories: paid labor, unpaid labor, housekeeping, school, sick leave and retirement. Productivity was calculated by multiplying the working hours per year by the 
price per hour of paid labor (14.63 US $\$$ assumed to Dutch standards). Housekeeping and unpaid labor were valued as $2 / 3$ of paid labor. The other categories generated 0 productivity. The life expectancy of the general population with the mean age of the study population was obtained from the tables of vital statistics ${ }^{22}$. The life years gained of the morbidly obese population as a result of surgical treatment were calculated with the DEALE method based on the mortality rate deducted from the study from Drenick et al. ${ }^{10,23}$. The improvement of quality of life was defined as the improvement on the VAS scale transformed to a Figure between 0 and 1 . The number of quality adjusted life years (QALY's) gained were calculated by multiplying the improvement in quality of life by the life expectancy gained after VBG. The total incremental costs were determined as the costs attributable to morbid obesity (costs-of-illness) multiplied by the life expectancy of a morbidly obese population minus the direct and indirect costs of surgical treatment and the costs related to failure of the operation. Cost-effectiveness was then determined as the total incremental costs divided by the total number of QALY's gained.

\section{STATISTICS}

Differences between the quality of life scores and weight loss data at the different time points were analyzed with a repeated measures ANOVA. Differences between the groups after stratification were analyzed with a Bonferroni multi-comparison ANOVA. Statistical significance was considered present when $p<0.05$. Data are expressed as the mean value $\pm S D$. Data were analyzed using the Statistical Package for Social Science (SSPS release 7.0., SPSS Inc., Chicago).

\section{RESULTS}

\section{Weight loss and complications}

None of the 21 patients included in this study were lost to follow-up. The mean age before surgery was $33.1 \pm 8.4$ years and the male:female ratio was $1: 20$. The mean body weight and body mass index decreased significantly at one and two years after VBG (Table 1). Two years after VBG, 15 patients had a good result, three patients a satisfactory result, and three patients an unsatisfactory result according to the classification of Maclean. Surgical complications were encountered in 14 patients and consisted of staple line disruption (5), esophagitis (4), metabolic deficiencies (3), stoma stenosis (2), incisionall hernia (2), food impaction (2) and pouch enlargement (1). Revisional 
surgery was required in five patients for staple line disruption, in two patients for stoma stenosis, and in one patient for pouch enlargement.

Table 1. Patient characteristics.

\begin{tabular}{|lccc|}
\hline & Before VBG & \multicolumn{2}{c|}{ After VBG } \\
\hline Number & 21 & 1 year & 2 year \\
Age (years) & $33.1(8.4)$ & 21 & 21 \\
Male:female & $1: 20$ & $34.1(8.4)$ & $35.1(8.4)$ \\
BM (kg) & $125.6(25.8)$ & $1: 20$ & $1: 20$ \\
BMl $\left(\mathrm{kg} / \mathrm{m}^{2}\right)$ & $47.22(7.15)$ & $79.7(19.0)^{*}$ & $77.1(17.3)^{*}$ \\
\hline
\end{tabular}

Data are presenied as the mean value (SD). $\mathrm{VBG}=$ vertical banded gastroplasty; $B M=$ body mass; $B M I=$ bady mass index. * $p<0.001$ for differences with the values before VBG (repeated measures ANOVA).

Table 2. Quality of life outcome.

\begin{tabular}{|c|c|c|c|c|c|c|}
\hline \multirow{2}{*}{ NHP-I domains } & \multicolumn{2}{|c|}{$\begin{array}{c}\text { Before VBG } \\
n=21\end{array}$} & \multicolumn{2}{|c|}{$\begin{array}{l}1 \text { year after VBG } \\
n=21\end{array}$} & \multicolumn{2}{|c|}{$\begin{array}{c}2 \text { year after VBG } \\
m=2 \|\end{array}$} \\
\hline & & & & & & \\
\hline Mobility & 34.3 & $(18.3)$ & 4.0 & $(10.0)$ & 0.0 & $(\| \mathrm{I})$ \\
\hline $\begin{array}{l}\text { Energy } \\
\text { Pain }\end{array}$ & 68.0 & $(33.1)$ & 11.2 & $(25.6)^{x}$ & 19.8 & $(30.0)^{* x \times x}$ \\
\hline $\begin{array}{l}\text { Pain } \\
\text { Sleep }\end{array}$ & 21.1 & $(19.5)$ & 4.9 & $(17.7)^{\star}$ & 8.5 & $(16.0)$ \\
\hline Sleep & 22.6 & $(27.8)$ & 12.2 & (25.6) & 24.9 & $(34.4)$ \\
\hline Social isolation & 25.7 & $(26.9)$ & 10.0 & $(19.9)$ & 17.0 & $(19.4)$ \\
\hline Emotional reaction & 35.0 & $(25.2)$ & 11.8 & $(23,9)^{n}$ & & $(27.4)$ \\
\hline NHP-II & 16.7 & $(3.3)$ & 8.0 & $(1.7)^{\text {sint }}$ & 9.6 & $(3.9)^{k * * 1}$ \\
\hline VAS & 4.6 & $(2.3)$ & 8.2 & $(2.2)^{\star \sin }$ & 7.1 & $(2.9)^{* *}$ \\
\hline
\end{tabular}

Data are presented as the mean value (SD). NHP-I = Nottingham Health Profile part I [range 0 (best score) - 100 (worst score]; NHP- II = Nottingham Health Profile part II [range 7 (best score) -21 (worst score)]; VAS = Visual Analogue Scale [range 0 (worst score) - 10 (best score)]. " $p<0.05 ;{ }^{* *} p<0.01 ; * * 0<0.001$ for differences with the scores before VBG (repeated measures ANOVA) 


\section{Quality of life}

One year after VBG a significant improvement on the NHP-I was found on the domains: mobility, energy, pain and emotional reaction (Table 2). Overall scores on the NHP-II and the VAS improved significantly. The second year after VBG quality of life outcome on the NHP-I, the NHP-II and the VAS were still significantly improved, however, compared to the results one year after VBG the quality of life outcome showed some decrease.

Stratification by weight loss according to the Maclean criteria resulted in a significant improvement on the domain mobility of the NHP-I in favor of the subgroup with satisfactory or good weight loss. Stratification by overall complications did not yield significant differences, however, more specifically stratification by revisional surgery demonstrated a significant difference on the domain energy of the NHP-I in favor of the subgroup without revisional surgery.

Table 3. Prevalence, relative risk and population attributable risk for morbid obesity-related comorbidity.

\begin{tabular}{|lccccc|}
\hline & $\begin{array}{c}\text { Total } \\
\text { population } \\
\text { Prevalence }\end{array}$ & Prevalence & RR & PAR1 & PAR2 \\
\hline Diabetes mellitus & $2.0 \%$ & $24 \%$ & 12 & $2.7 \%$ & $9.9 \%$ \\
Coronary heart disease & $2.4 \%$ & $13 \%$ & 5.4 & $1.1 \%$ & $4.2 \%$ \\
Hypertension & $7.3 \%$ & $45 \%$ & 6.2 & $1.3 \%$ & $4.9 \%$ \\
Cholecystolithiasis & $0.5 \%$ & $20 \%$ & 40 & $8.9 \%$ & $28.1 \%$ \\
Osteoarthritis & $6.9 \%$ & $33 \%$ & 4.8 & $0.9 \%$ & $3.7 \%$
\end{tabular}

$\mathrm{RR}=$ relative risk; PAR $1=$ population attributable risk assuming a prevalence of $0.25 \%$ of morbid obesity ( $=37500$ persons); PAR2=population attributable risk assuming a prevalence of $1.00 \%$ of morbid obesity ( $=150000$ persons).

Costs-of-illness

The most relevant morbid obesity-related comorbidities for which data were available were entered in the cost-of-illness analysis. The prevalence of diabetes mellitus, coronary heart disease, hypertension, cholecystolithiasis and osteoarthritis in the morbidly obese population was estimated from the surgical literature $e^{2,10,15,24-32}$ (Table 3). Based on the prevalence of morbid obesity of $0.25 \%$ and $1.00 \%$, the costs of illness attributable to morbid obesity 
amounted to 37 million US\$ and 131.3 million US\$ per year respectively (Table 4). When expressed in costs per morbidly obese person the amounts were 987 US\$ and 875 US\$ per year, respectively.

Table 4. Costs of illness attributable to morbid obesity.

\begin{tabular}{|c|c|c|c|}
\hline & \multirow[t]{2}{*}{ Total popullation } & \multicolumn{2}{|c|}{ Morbid obesity } \\
\hline & & PAR & PAR2 \\
\hline Diabetes mellitus & 366.5 US\$ & 9.9 US\$ & 36.3 US\$ \\
\hline Coronary heart disease & 740.5 US\$ & $8.2 \cup S \$$ & $31.1 \cup S \$$ \\
\hline Hypertension & 374.5 US $\$$ & $4.9 \cup S \$$ & $18.4 \cup S \$$ \\
\hline Cholecystolithiasis & 140.5 US\$ & $12.5 \cup S \$$ & 39.5 US\$ \\
\hline Osteoarthritis & 161 US\$ & 1.5 USS & 6.0 US\$ \\
\hline Total & 1783 US\$ & 37.0 US\$ & $131.3 \cup 5 \$$ \\
\hline Costs per person & $112.9 \times 10^{-6}$ US\$ & $987 \times 10^{-1}$ US\$ & $875 \times 10^{-13}$ US\$ \\
\hline
\end{tabular}

Amounts are given in millions. PAR1=population attributable risk assuming a prevalence of $0.25 \%$ of morbid obesity ( $=37500$ persons); PAR2=population attributable risk assuming a prevalence of $1.00 \%$ of morbid obesity ( $=150000$ persons).

\section{Cost-effectiveness}

The total direct costs of VBG for morbid obesity were 5865 US $\$$, including operations ( 2601 US $\$$ ), laboratory (300 US $\$$ ), radiology (219 US\$), endoscopy (22 US\$), physiotherapy (25 US\$), hospital stay (2 192 US\$), and outpatient visits (506 US\$).

As a result of VBG for morbid obesity 3.6 life years were gained. The mean improvement on the VAS scale was 0.25 resulting in 12 QALY's gained, when a lifelong scenario was considered. The incremental costs of illness over a period of 47.8 years were -8029 US $\$$, when a prevalence of morbid obesity of $0.25 \%$ was assumed to -7118 US\$, when a prevalence of morbid obesity of $1.00 \%$ was assumed. All values were discounted to present values at a $5 \%$ rate. The percentage of patients performing paid labor increased from $19 \%$ before VBG to $48 \%$ after VBG and the percentage of patients having sick leave decreased from $38 \%$ to $10 \%$ (Table 5 ). Subsequently, the mean yearly income after taxes of the patients performing paid labor increased from 2215 US $\$(0-18$ 000 US $\$$ ) to 5429 US $\$(0-25000$ US $\$)(p<0.05)$. The number of patients performing unpaid labor or full-time housekeeping remained the 
same. Overweight as the reason for unemployment was more common before than after VBG $(47 \%$ vs $18 \% ; p<0.05)$. The increased employment rate and decreased sick leave after VBG resulted in a productivity gain of 2765 US\$/year.

Table 5. Occupational status.

\begin{tabular}{|lccc|}
\hline Category & Before VBG & After VBG & $\%$ change \\
\hline Paid labor & $19 \%$ & $48 \%$ & $29 \%{ }^{*}$ \\
Unpaid labor & $19 \%$ & $19 \%$ & $0 \%$ \\
House-keeping & $24 \%$ & $23 \%$ & $-1 \%$ \\
School & $0 \%$ & $0 \%$ & $0 \%$ \\
Sick leave & $38 \%$ & $10 \%$ & $-28 \%^{*}$ \\
Retirement & $0 \%$ & $0 \%$ & $0 \%$ \\
$*$ p< & 0.05 & &
\end{tabular}

The cost-effectiveness of VBG was established by a decrease in costs and a gain in QALY's (overall dominancy) for both scenario's. When the incremental indirect costs (productivity gain) were included in the cost-effectiveness analysis, the cost-effectiveness of VBG was even more dominant (Table 6).

Table 6. Costs of VBG for morbid obesity.

\begin{tabular}{|c|c|c|c|c|c|}
\hline & & $\begin{array}{c}\text { Total costs } \\
\text { of VBG }\end{array}$ & $\begin{array}{l}\text { Lifelong costs- } \\
\text { of-iliness }\end{array}$ & $\begin{array}{l}\text { Incremental } \\
\text { indirect costs }\end{array}$ & $\begin{array}{c}\text { Total } \\
\text { incremental } \\
\text { costs }\end{array}$ \\
\hline \multirow{2}{*}{ No VBG } & $0.25 \%$ & - & 9367 US $^{\sharp}$ & 45879 US\$" & \\
\hline & $1.00 \% "$ & - & 8304 US\$ $^{\prime \prime}$ & 45879 US\$ $\$$ & \\
\hline \multirow{2}{*}{ VBG } & $0.25 \%$ & 5865 US\$ & 1338 US\$ $^{*}$ & - & -48043 US\$ \\
\hline & $1.00 \%$ & 5865 US\$ & 1186 US\$ $\$$ & - & -47132 US\$ \\
\hline
\end{tabular}

* Assuming a prevalence of morbid obesity of $0.25 \%$ or $1.00 \%$.

\# Discounted to present values at a $5 \%$ rate. 


\section{DISCUSSION}

The present study shows a significant improvement in the quality of life of morbidly obese patients after VBG and confirms the results of an earlier crosssectional study in which a postoperative group was compared to a preoperative group ${ }^{5}$. Quality of life showed maximum improvements on the domains energy and mobility of the NHP-I and overall on the NHP-II. This finding agrees with the statement of Stunkard and Wadden ${ }^{7}$, that the psychosocial benefit of weight-reducing surgery is the result of increased mobility which enables the formerly obese person to participate in social and physical activities. It also increases their chances to acquire successful employment and job promotion. Analogous to the previous finding $s^{5}$, the improvement of quality of life after VBG is only dependent on weight loss and not dependent on complications ${ }^{5}$. This finding is in agreement with others ${ }^{33.34}$ and highlights the mental and physical suffering of the morbidly obese. The quality of life outcome two years after VBG was slightly less than the outcome one year after VBG. Waters et al..$^{35}$ conducted a prospective study on mental health in 157 patients undergoing a Greenville gastric bypass and found an improvement of mental health indexes six and 12 months after surgery which eroded to preoperative values two years after surgery. Because the frequency and intensity of clinical visits decrease with time, the authors pointed out that these patients may rely on medical and clinical visits to improve psychologically. Furthermore, it is plausible that two years after successful surgery patients adapt to their present health status and rate their quality of life accordingly lower ${ }^{36}$. However, according to the data of the present study, they would again chose for surgical treatment.

The cost-of-illness study of morbid obesity shows that the estimated costs of diseases attributable to morbid obesity ranges from 37 million US $\$$ to 131.3 million US\$, which is $0.1 \%$ to $0.5 \%$ of the total health care costs in the Netherlands. However, some comments have to be made regarding this costof-illness analysis. The prevalence of morbid obesity is not exactly known. For this reason, the minimum prevalences of morbid obesity were used to prevent overestimation of the costs attributable to morbid obesity. Furthermore, obesity-related comorbidities were not entered in the analysis if the prevalence was too low or if not all required information was available. Comorbidities such as heart failure, liver steatosis and pulmonary disease were not included in the analysis. Therefore, the present cost-of-illness analysis gives a minimum estimate of the costs attributable to morbid obesity. Until now cost-of illness studies have only been performed for overweight $\left(B M \mid>25 \mathrm{~kg} / \mathrm{m}^{2}\right)$ and obesity $\left(\mathrm{BM} />30 \mathrm{~kg} / \mathrm{m}^{2}\right)$, but not for morbid obesity $\left(\mathrm{BM} \mid>40 \mathrm{~kg} / \mathrm{m}^{2}\right)$. The conservative estimates of the economic costs attributable to overweight and obesity are $3 \%-8 \%$ of total health care costs in countries such as France, Scandinavia, Australia, and the USA ${ }^{9.37-39}$. In the Netherlands the cost of overweight is $3 \%$ of 
total health care costs and the cost of obesity is $1 \%$ of total health care costs ${ }^{40}$. Due to the lower prevalence of morbid obesity the percentage of total health care costs spent on morbid obesity is lower compared to overweight and obesity. However, since the prevalence of comorbidities is much higher in morbid obesity, a considerable percentage of total health care costs is spent on this disease. Because the prevalence of morbid obesity is estimated to be $6 \%$ in the USA, the costs of morbid obesity will be higher compared to the results of the present study ${ }^{10}$. It is therefore to be expected that costeffectiveness of the surgical treatment of morbid obesity will be even more favorable in the USA, based on the results of the present study.

In this study, surgical treatment of morbid obesity was compared to no treatment, because surgical treatment is the only effective treatment of morbid obesity and there is no comparable alternative treatment ${ }^{11}$. The costeffectiveness analysis revealed that surgical treatment of morbid obesity by means of VBG saves 4004 US\$ to 3928 US\$ per QALY (overall dominance). Because treatment of morbid obesity with VBG results in QALY's gained and less costs, there is no doubt that this procedure should be introduced or continued from a societal point of view ${ }^{41}$. The decreased costs of morbid obesity after VBG are caused by the reduction of obesity-related comorbidities and productivity gain. Some debate exists about the effect of weight loss on health status. Many epidemiological studies show that an elevated body weight is associated with an increased morbidity and mortality ${ }^{42,43}$. On the other hand, some observational epidemiological studies show that weight loss is associated with an increased mortality ${ }^{44}$. However, all studies investigating the surgical treatment of morbid obesity show a decreased morbidity after weight loss ${ }^{10,25,26,29,31,32,45-48}$.

The present study showed a significant increase of paid labor and decrease of sick leave, which resulted in a significant increase of yearly income. Several studies on economic changes showed increased employment and income after surgical treatment for morbid obesity ${ }^{49-51}$. Successful weight loss after surgical treatment results in a higher employment rate and job promotion and as a consequence a higher yearly income.

The analysis of data presented in this paper demonstrates, that treatment of morbid obesity by means of VBG is cost-effective. The cost-effectiveness of treatment with VBG is determined by the fact, that weight loss results in decreased morbid obesity-related comorbidities, and in QALY's and productivity gained. 


\section{REFERENCES}

1. 1983 Metropolitan Height and Weight Tables. Statistical Bulletin Metropolitan Insurance Company $1983 ; 64: 2$.

2. Kral JG. Morbid obesity and related health risks. Ann Int Med 1985;103:1043-7.

3. Bray AB. Complications of obesity. Ann Int Med 1985;103:1052-62.

4. Kral JG. Sjöström LV, Sullivan MBE. Assessment of quality of life before and after surgery for severe obesity. Am J Clin Nutr 1992;55:611S-4S.

5. Van Gemert WG, Adang EMM, Greve JWM, Soeters PB. Quality of life assessment of morbidly obese patients: Effect of weight-reducing surgery. Am J Clin Nutr 1998:67: $197-201$.

6. Stunkard AJ, Wadden TA. Psychosocial consequences of obesity and dieting. Research and clinical findings. In: Stunkard AJ, Wadden TA, eds. Obesity. Theory and Therapy. New York: Raven press, 1993.

7. Stunkard AJ, Wadden TA. Psychological aspects of severe obesity. Am $₫$ Clin Nutr $1992 ; 55: 524$ S-32S.

8. Rand CWS, Macgregor AMC. Morbidly obese patients' perceptions of social discrimination before and after surgery for obesity. South Med $\mathbb{1} 1990 ; 83: 1390-5$.

9. Colditz GA. Economic costs of obesity. Am J Clin Nutr 1992;55:503S-7S.

10. Drenick EJ. Definition and health consequences of morbid obesity. Surg Clin North Am $1979 ; 59: 963-76$.

11. Van Itallie TB. Morbid obesity. A hazardous disorder that resists conservative treatment. Am J Clin Nuir 1980;33:358-363.

12. Consensus Development Conference Panel. Gastrointestinal surgery for severe obesity. Ann Int Med 1991:115:956-961.

13. Mason EE, Maher JW, Scott DH, et al.: Ten years of vertical banded gastroplasty for severe obesity. Problems Gen Surg 1992;9:280-9.

14. Van Gemert WG, Greve JWM, Soeters PB. Long-term results of verticall banded gastroplasty: Marlex versus Dacron banding. Obes Surg 1997;7:128-35.

45. Brolin RE. Results of obesity surgery. Gastroenteral Clin North Am 1987;16:317-37.

16. Maclean LD, Rhode BM, Shizgal HM. Gastroplasty for obesity. Surg Gynecol Obstet 1981:153:200-8.

17. Hunt SM, McEwen J, McKenna SP. Measuring health status: A new method for clinicians and epidemiologists. J R Coll Gen Pract 1985;35:185-8.

18. McDowell I, Newell C. Measuring Health. A guide to rating scales and questionnaires. Oxford University Press, Oxford, 1996.

19. Vademecum of Health Statistics in the Netherlands 1996. Central Bureau of Statistics/Ministry of Public Health. 's-Gravenhage, SDU/CBS 1995.

20. Costs of diseases in The Netherlands. Institute of Public Health/Institute of Technology Assessment. Erasmus University Rotterdam, 1994.

21. Seidell JC. The impact of obesity on health status: Some implications for health care costs. Int J obes 1995;19:S13-S16.Statistical yearbook 1996.

22. Centrall Bureau of Statistics. "s-Gravenhage, CDU/CBS 1996.

23. Beck JR, Kassirer JP, Pauker SG. A convenient approximation of life expectancy (The "DEALE). Am J Med 1982;73:883-8.

24. Seidell JC, Bakx KC, Deurenberg P, Burema J. Hautvast JGAJ, Huygen FJA. The rellation between overweight and subjective health according to age, social class, slimming behavior and smoking habits in Dutch adults. Am $J$ Public Health 1986;76:1410-15. 
25. Pories WJ, MacDonald KG, Morgan EJ, Sinha MK, Dohm GL, Swanson MS, Barakat HA, Khazania $P G$, Leggett-Frazier $N$, Long SD, O'Brien KF, Caro JF. Surgical treatment of obesity and tis effect on diabetes: 10-y follow-up. Am J Clin Nutr 1992;55:582S-5S.

26. Pories WJ, Swanson MS, MacDonald KG, Long SB, Morris PG, Brown BM, Barakat HA, deRamon RA, Israel $\mathrm{G}$, Dolezal $J M_{1}$, Dohm $\mathrm{L}$. Who would have thought it? An operation proves to be the most effective therapy for adult-onset diabetes mellitus. Ann Surg $1995 ; 222: 339-52$.

27. Surgical management of morbid obesity. Eds WO Griffen, KJ Printen. Marcel Dekker Inc. New York/Basel 1987.

28. Angel A, Winocur JT, Roncari DAK. Morbid obesity - The problem and its consequences. In: Surgery for the morbidly obese patient. Eds. M Deitel. Lea \& Febiger. Philadelphia/London, 1989.

29. Flickinger EG, Pories WJ, Meelheim HD, Sinar DR, Blose IL, Thomas FT. The Greenville gastric bypass. Progress report at 3 years. Ann Surg 1984;199:555-60.

30. Felson DT, Anderson $\mathrm{JJ}$, Naimark A. Walker AM, Meenan RF. Obesity and knee osteoarthritis. The Framingham Study. Ann Int Med 1988;109:18-24.

31. Brolin RE. Critical analysis of results: Weight loss and quality of data. Am J Clin Nutr 1992:55:577S-81S.

32. Brolin RE. Results of obesity surgery. Gastraenterol Clin North Am 1987;16:317-37.

33. Saltzstein EC, Gutmann MC. Gastric bypass for morbid obesity. Arch Surg 1980: 115:21-8.

34. Ryden $O$, Olsson S, Danielsson A, Nilsson-Ehle P. Weight loss after gastroplasty. Psychological sequelae in relation to clinical and metabolic observations. I Am Coll Nultr $1989 ; 8: 15-23$.

35. Waters GS, Pories WJ, Swanson MS, Meelheim HD, Flickinger EG, May HJ. Long-term studies on mental health after the Greenville gastric bypass operation for morbid obesity. Am J Surg 1991;161:625-34.

36. Adang EMM, Kootstra G, Engel GL, Baeten CGMI. Quality of life ratings in patients with chronic illnesses. JAMA 1997;277:1038.

37. Lévy $E$, Lévy $P$, Le Pen $C$, Basdevant A. The economic cost of obesity: The French situation. Int J Obes 1995:19:788-792.

38. Sjöström L, Narbro K, Sjöström D. Costs and benefits when treating obesity. Int J Obes $1995 ; 19: \mathrm{S} 9-\mathrm{S} 12$.

39. Segal $L$, Carter $R$, Zimmet $P$. The cost of obesity: The Australian perspective. Pharmacoeconomics 1994:5:42-52.

40. Seidell JC. The impact of obesity on health status: Some implications for health care costs. Int J Obes 1995;19:S13-S6.

41. Laupacis A, Feeny D. Detsky AS, Tugwell PX. How attractive does a new technology have to be to warrant adoption and utilisation? Tentative guidelines for using clinical and economic evaluations. Cian Med Ass J 1992;146:473-81.

42. Sjöström L. Morbidity of severely obese subjects. Am J Clin Nutr 1992;55:508S-15S.

43. Sjöström L. Mortality of severely obese subjects. Am J Clin Nutr 1992;55:516S-23S.

44. Pamuk ER, Williamson DF, Madans J, Serdula MK, Kleinman JC, Byers T. Weight loss and mortality in a national cohort of adults, 1971-1987. Am J Epidemiol 1992;136: 686-97.

45. Hall $\Downarrow C$, Watts $J M_{n}$ O'Brien PE, Dunstan RE, Walsh JF, Slavotinek AH, Elmslie RG Gastric surgery for morbid obesity. The Adelaide Study. Ann Surg 1990;211:419-27.

46. Foley EF, Benotti PN, Borlase BC, Hollingshead J, Blackburn GL. Impact of gastric restrictive surgery on hypertension in the morbidly obese. Am J Surg 1992;163:294-7.

47. Hocking MP. Duerson MC, O'Leary JP, Woodward ER. Jejunoileal bypass for morbid obesity. Late follow-up in 100 cases. N Engl J Med 1993;308:995-9. 
48. Benotti BN, Bistrian B, Benotti JR, Blackburn $G$, Forse RA. Heart disease and hypertension in severe obesity: The benefits of weight reduction. Am J Clin Nutr 1992; 55:586S-90S.

49. Hawke $A, O^{\prime} B r i e n ~ P$, Watts $J$ et al. Psychosocial and physical activity changes after gastric restrictive procedures for morbid obesity. Aust N Z J Surg 1990;60:855-8.

50. Martin LF, Tan TL. Holmes PA et al. Preoperative insurance status influences postoperative complication rates for gastric bypass. Am J Surg 1991;161:625-34.

51. Näslund I, Agren G. Social and economic effects of bariatric surgery. Obes Surg 1991;1: $137-40$. 
$-92-$ 
Chapter 4

METABOLIC ASPECTS OF MORBID OBESITY AND THE EFFECT OF SURGICAL TREATMENT 
$-94-$ 
Chapter 4.1

REDUCTION OF SLEEPING METABOLIC RATE AFTER VERTICAL BANDED GASTROPLASTY

Wim G. van Gemert, Klaas R. Westerterp, Jan Willem M. Greve, Peter B. Soeters. Int J Obes 1998;22:343-348 


\section{ABSTRACT}

Objective: To investigate whether long-term weight loss after vertical banded gastroplasty (VBG) results in a sustained reduction of sleeping metabolic rate (SMR) as a persistent risk factor for weight regain.

Design: Longitudinal clinical intervention study of morbidly obese patients undergoing $V B G$.

Patients: Group I: six patients in which body composition and SMR were measured before and at 3,6 and 12 months after VBG. Group II (long-term effect): nine patients in which body mass (BM) was measured before VBG, and body composition and SMR were measured $98 \pm 30$ months after VBG.

Measurements: Body composition was assessed by deuterium dilution and hydrostatic weighing. SMR was measured (SMRm) in a respiration chamber and predicted (SMRp) based on body composition.

Results: in group 1, fat mass and fat free mass decreased significantly after VBG $(p<0.05$ ). SMRm decreased from $11.1 \pm 1.8$ (s.d.) MJ/d before VBG to $8.1 \pm 0.9 \mathrm{MJ} / \mathrm{d}(p<0.05)$ at 12 months after $V B G$. In group II at a mean of 98 months after VBG, the SMRm $(6.9 \pm 0.7 \mathrm{MJ} / \mathrm{d})$ was lower than the preoperative value of group I $(p<0.05)$. SMRm was lower than SMRp at all intervals after VBG $(p<0.05)$. The ratio measured $w s$ predicted SMR was in group I: $1.02 \pm 0.05$ before VBG, $0.91 \pm 0.08$ at 12 months after VBG $(p<0.05)$, and in group III: $0.94 \pm 0.08$ at a mean of 98 months after VBG $(p<0.05)$.

Conclusion: The reduction of SMR adjusted for body composition after VBG is sustained as long as weight loss is maintained. The sustained and disproportional reduction of SMR may reflect the persistent susceptibility of the postobese to weight regain.

\section{INTRODUCTION}

There is accumulating evidence for a low habitual energy expenditure as a risk factor for obesity". The most important determinant of total energy expenditure is resting energy expenditure, which is mainly determined by body size and composition. There remains considerable interindividual variation in resting metabolic rate (RMR), even when controlled for body size and composition, which is in part genetically determined ${ }^{2}$. Keesey et al. ${ }^{3}$ hypothesized that morbidly obese subjects strive to maintain a predetermined body weight and that weight loss is counteracted by a disproportional reduction of energy expenditure. This would explain the persistent propensity to overweight and weight regain after weight loss. This hypothesis is supported by the clinical observation that morbidly obese patients who reach and maintain ideal body weight for several years following surgical treatment return rapidly to their 
morbidly obese status when unlimited eating capacity is regained as a result of a technical failure.

Kleiber ${ }^{4}$ demonstrated a logarithmic relationship between body weight and resting metabolic rate for many different animal species. By means of this relationship the RMR can be predicted. However, this relationship holds only when the subject is at its normally maintained physiological body weight. After weight loss the measured energy expenditure will be lower than the predicted energy expenditure because the weight loss is counteracted by a disproportional decrease in energy expenditure. The normally maintained and defended physiological body weight of morbidly obese persons may be preset at a higher level. It would explain why conservative treatment does not achieve long-term weight loss and is associated with high initial failure rates or recidivism ${ }^{5}$. Garrow ${ }^{6}$ demonstrated that the decrease in metabolic rate is more than could be accounted for by the loss of lean tissue mass, and furthermore, that the energy equivalent of the body weight lost is affected by the rate of weight loss. At high rates of weight loss, the body weight lost is composed of a mixture of adipose tissue and lean tissue, while at low rates of weight loss, the body weight lost consists almost completely of adipose tissue ${ }^{6}$.

The results of studies regarding the role of energy expenditure in the pathogenesis of obesity are conflicting ${ }^{7}$. The majority of these studies did not include morbidly obese subjects and investigated energy expenditure over a short time after moderate dietary induced weight loss. In the present study, a surgical study model was preferred in which morbidly obese patients undergo surgical treatment. Surgical treatment generally results in a substantial and long-lasting weight ${ }^{\circ} \mathrm{ss}^{\mathrm{B}}$, and consequently, larger changes in resting energy expenditure are expected and long-term effects can be studied. To study the effect of weight loss on energy expenditure in a surgical study model, it is important to perform a restrictive surgical procedure, such as a vertical banded gastroplasty (VBG), where weight loss is purely the result of a restricted intake.

The hypothesis tested in this study, was that long-term weight loss after VBG results in a sustained and disproportionate reduction of sleeping metabolic rate (SMR) as a persistent risk factor for weight regain.

\section{PATIENTS AND METHODS}

\section{Patients}

Two series of patients were included in the analysis. Group $\|$ consisted of six patients measured before VBG and 3,6 and 12 months after VBG in a prospective manner. A second group of patients several years after VBG was studied to investigate whether the results of the first study could be confirmed after sustained (long-term) weight reduction. Initially, group II consisted of 10 patients measured once, more than 36 months after VBG and with $>40 \%$ 
excess weight loss. Preoperatively, only the body mass (BM) was measured in the latter group. One patient of group II was excluded from the study, because this patient developed a septic episode during the study period, as a result of an enterocutaneous fistula after correction of an incisional hernia. The study protocol and the equipment used were identical for both groups. All patients gave their written informed consent before participation in the study.

\section{Body composition measurements}

Body composition was assessed by deuterium oxide dilution and hydrostatic weighing. The patients drank the deuterium oxide solution at 23.00 after collection of a baseline urine sample. The deuterium oxide dilution was measured in the urine sample of the second voiding in the morning, resulting in an equilibration time of 9-10 hours. The dose of deuterium oxide solution $\left(99.8 \%{ }^{2} \mathrm{H}_{2} \mathrm{O}\right)$ was approximately $0.1 \mathrm{~g}^{2} \mathrm{H}_{2} \mathrm{O} / \mathrm{kg}$ body water resulting in an excess enrichment of $100 \mathrm{ppm}$. Total body water before administration was estimated from age- and gender-specific formulae". Isotope abundance in the urine samples was measured with an isotope ratio mass spectrometer (VG Isogas, Aqua Sira, Cheshire, UK). Total body water was calculated as the deuterium dilution space divided by 1.04 for correction of a $4 \%$ over-estimation of the dilution space ${ }^{10}$.

Whole body density was determined by hydrostatic weighing. Total BM and underwater weight were measured to the nearest $0.05 \mathrm{~kg}$ on a digital scale (Mettler, 240C, Greifensee, Switzerland). Simultaneously, residual lung volume was measured by the Helium dilution technique (Mijnhardt Volugraph. Breda, The Netherlands).

A three body-compartment model was used to calculate fat mass (FM) and fat free mass (FFM) from $B M$, water mass and body volume ${ }^{11}$.

\section{Energy expenditure measurement}

SMR was measured in a respiration chamber. The patients were instructed to maintain their normal diet for at least 3 days prior to the experiment. SMR was measured during an overnight stay (20.00-07.30h) in a respiration chamber. The subject were not allowed to eat in the chamber and coffee or tea were allowed until 22.00h. SMR was measured over a period of three consecutive hours during minimal activity level as judged from Doppler radar observation. In the respiration chamber, the oxygen and carbon dioxide concentration of the ingoing and outgoing air were measured with a paramagnetic analyser (Magnos 6G, Hartman \& Braun, Frankfurt, Germany) and an infrared analyser (URAS 3G, Hartman \& Braun, Frankfurt, Germany) respectively ${ }^{12}$. Energy expenditure was calculated using Weir's formula ${ }^{13}$.

SMR, as measured in the respiration chamber (SMRm), was compared with a predicted value (SMRP) based on FFM and FM using a regression formula: $S M R p=0.85+0.102 F F M+0.024 F M(14)$. Westerterp et al. combined the data 
of 11 studies with a total of 290 healthy subjects with a wide range of body weight $(38-215 \mathrm{~kg}$ ) in a multiple regression analysis to predict basal metabolic rate $(B M R)^{14}$. BMR was calculated from FFM and FM. In the present study, the regression formula developed to predict BMR turned out to predict SMR very well. A regression formula to predict SMR based on the preoperative data of group $I$ is practically the same as the regression formula developed by Westerterp et al. ${ }^{14}$. The latter regression formula was chosen for the present study since it is better validated.

\section{Statistics}

$B M, F F M$ and $F M(\mathrm{~kg})$ and SMR $(\mathrm{MJ} / \mathrm{d})$ are expressed as the mean value \pm SD. Data were analysed using the Statistical Package for Social Science (SPSS release 6.1.2., SPSS Inc, Chicago). Differences within the group are tested with the Wilcoxon Signed Ranks test and differences between groups are tested with the Mann-Whitney $U$ test. Statistical significance was considered present at $p<0.05$.

\section{RESULTS}

\section{Patients}

The preoperative characteristics of group I and II were comparable, except for the male:female ratio (Table 1). The mean period after surgical treatment was $98 \pm 30$ months ( $40-150$ months) for the patients of group II and the mean percentage excess weight loss was $57 \pm 13 \%$.

Table 1. Preoperative characteristics of group I and II (mean \pm SD).

\begin{tabular}{|lcc|}
\hline & Group I & Group II \\
\hline Number & 6 & 9 \\
Age & $28 \pm 7$ & $32 \pm 5$ \\
Male:female & $5: 1$ & $3: 7$ \\
BM $(\mathrm{kg})$ & $155.5 \pm 31.1$ & $131.1 \pm 17.0$ \\
BMl $\left(\mathrm{kg} / \mathrm{m}^{2}\right)$ & $48.1 \pm 7.0$ & $45.7 \pm 5.7$ \\
\hline
\end{tabular}

Group | consists of six patients measured in a prospective manner after vertical banded gastroplasty (VBG). Group $\| 1$ (long-term effect) consists of nine patients measured once, $98 \pm$ 30 months after VBG and with $57 \pm 13 \%$ excess weight loss. The only significant difference between groups is the male:female ratio $(p<0.05)$. $B M=$ body mass, $B M=b o d y$ mass index. 
The body weight curve after VBG of both groups shows a rapid weight loss in the first 6 months and a slow weight loss from 6-12 months. At 12 months after VBG, stable body weight was achieved in both groups (Figure 1).

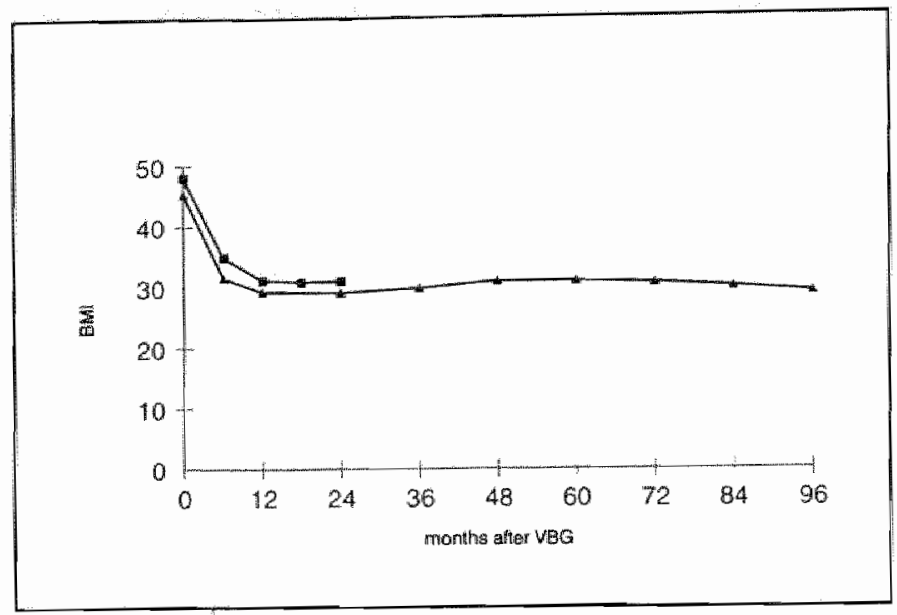

Figure 1. Body weight curve after vertical banded gastroplasty (VBG). The body weight curve expressed as BMI (body mass index $\left(\mathrm{kg} / \mathrm{m}^{2}\right)$ ) exhibits a rapid weight loss in the first six months after VBG. From 6-12 months after VBG, little body weight is lost and stable body weight is achieved at 12 months after VBG. The squares represent group I and the triangles represent group $\mathrm{II}$.

Table 2. Body composition at different intervals after vertical banded gastroplasty (VBG) (mean \pm SD).

\begin{tabular}{|c|c|c|c|c|c|}
\hline & \multicolumn{4}{|c|}{ Group 1} & \multirow{2}{*}{$\begin{array}{l}\text { Group } 11 \\
>36 \text { months }\end{array}$} \\
\hline & 0 months & 3 months & 6 months & 12 months & \\
\hline $\mathrm{BM}(\mathrm{kg})$ & $155.5 \pm 31.1$ & $123.2 \pm 28.2^{*}$ & $107.4 \pm 25.9^{*}$ & $102.3 \pm 24.1^{*}$ & $93.2 \pm 10.5^{* n}$ \\
\hline$F M(k g)$ & $74.0 \pm 28.6$ & $49.2 \pm 22.3^{*}$ & $36.6 \pm 17.0^{*}$ & $30.0 \pm 11.4^{*}$ & $39.0 \pm 8.2^{* *}$ \\
\hline FFM $(\mathrm{kg})$ & $84.5 \pm 13.6$ & $73.9 \pm 13.7^{*}$ & $70.8 \pm 13.6^{*}$ & $72.3 \pm 13.0^{*}$ & $54.2 \pm 7.2^{w t}$ \\
\hline
\end{tabular}

Group I consists of six patients measured in a prospective manner after VBG. Group II (longterm effect) consists of nine patients measured once, $98 \pm 30$ months after VBG, and with 57 $\pm 13 \%$ excess weight loss. $B M=$ body mass, $F M=f a t$ mass, FFM=fat free mass. ${ }^{*} p<0.05$. *" $p<0.01$ for differences with the preoperative values of group I (differences within group I are tested with the Wilcoxon Signed Ranks test and between group I and i! with the MannWhitney U Test). 


\section{Body composition}

The mean BM, FFM and FM of group I were significantly reduced after VBG $(p<0.05)$ (Table 2). The mean body weight lost at one year after VBG was $53.2 \pm 16.0 \mathrm{~kg}$ and consisted for $83 \pm 41 \% \mathrm{FM}$ and $17 \pm 15 \% \mathrm{FFM}$. During rapid weight loss in the first six months after VBG, the mean body weight lost was $48 \pm 11 \mathrm{~kg}$ and consisted for $78 \pm 27 \%$ FM and $22 \pm 14 \%$ FFM. From $6-12$ months after VBG, the body weight lost was only $5 \pm 12 \mathrm{~kg}$ and was entirely composed of FM. In the latter period, the FFM showed a slight recovery.

The mean BM of group II was also significantly reduced after VBG $(131 \pm 17$ vs $93 \pm 11 ; p<0.01$ ).

\section{Energy expenditure}

The mean SMRm of group I was significantly reduced at all intervals after VBG compared to the preoperative value $(p<0.05$ ) (Table 3 ).

Before VBG the mean SMRm of group I was not different from the mean SMRp resulting in a SMRm/p ratio of $1.02 \pm 0.05$. At three and six months after VBG, during rapid weight loss the mean SMRm of group I was significantly reduced compared to the mean SMRp $(p<0.05)$ and remained so in the weight-stable post-obese situation at 12 months after VBG $(p<0.05)$ (Figure 2).

Consequently, the SMRm/p ratio dropped below 1.0 at three and six months after VBG, during rapid weight loss, and remained lower than 1.0 in the weight-stable post-obese situation at 12 months after VBG in group I $(p<0.05)$ (Figure 3 ).

Table 3. Measured (SMRm) and predicted sleeping metabolic rate (SMRp) at different intervals after vertical banded gastroplasty (VBG) (mean \pm SD).

\begin{tabular}{|lccccc|}
\hline & \multicolumn{4}{c}{ Group I } & Group II \\
\hline SMRm & $11.1 \pm 1.8$ & $8.4 \pm 1.6^{*}$ & $7.9 \pm 1.6^{*}$ & $8.1 \pm 0.9^{*}$ & $6.9 \pm 0.7^{* *}$ \\
SMRp & $10.9 \pm 1.5$ & $9.6 \pm 1.6^{*}$ & $9.0 \pm 1.6^{*}$ & $9.0 \pm 1.6^{*}$ & $7.3 \pm 0.8^{* *}$ \\
SMRm/p & $1.02 \pm 0.05$ & $0.88 \pm 0.06^{*}$ & $0.88 \pm 0.04^{*}$ & $0.91 \pm 0.08^{*}$ & $0.94 \pm 0.08^{*}$
\end{tabular}

Group I consists of six patients measured in a prospective manner after VBG. Group II (long* term elfect) consists of 9 patients measured once, $98 \pm 30$ months after VBG, and with $57 \pm$ $13 \%$ excess weight loss. SMRm/p=ratio measured $v$ s predicted energy expenditure. "p<0.05, * p<0.01 for differences with the preoperative values of group I (differences within group I are tested with the Wilcoxon Signed Ranks test and between group I and II with the Mann. Whitney U Test). 


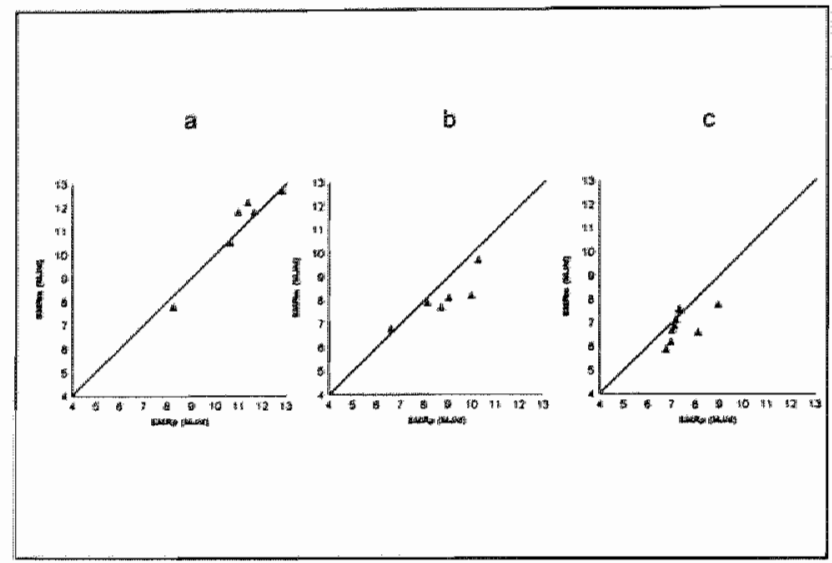

Figure 2. Measured (SMARm) and predicted (SMRp) sleeping metabalic rate in the weightstable situations. These figures show the individual values of SMARm and SMRp in the weight-stable situations: group I before vertical banded gastroplasty (VBG) (a), group $\|$ at 12 months after VBG (b), and group II >3 y after VBG (c). The individual values of group I before $V B G$ are distributed around the reference line SMARm/p=1, while 12 months after $V B G$ in group I and in group II the individual values are distributed below the reference line.

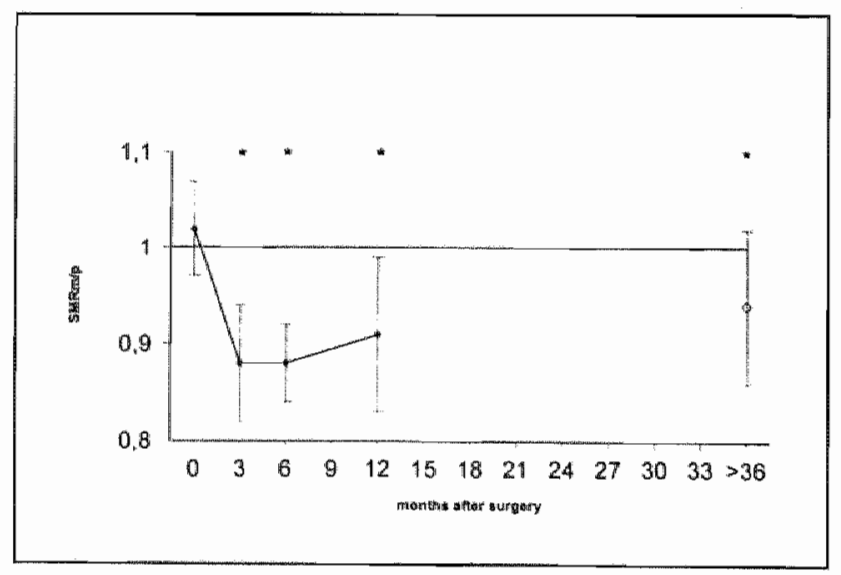

Figure 3. The ratio measured ws predicted sleeping metabolic rate (SMRm/p) of group I and 11. The SMRm/p ratio of group I before vertical banded gastroplasty (VBG) is approximately ane. At 3,6 and 12 months after VBG the SMRm/p ratio of group I drops below 1.0 (closed circles). The SMRm/p ratio of group II $>3$ y after VBG is also below 1.0 (open circles). The error bars represent the s.d. " $p<0.05$ for differences with the preoperative value of group 1 (differences within group I are tested with the Wilcoxon Signed Ranks test and between group I and II with the Mann-Whitney $U$ test). 
The results of the prospective measurements of group I could be confirmed in group II, in which the long-term effects of sustained weight loss on SMR were studied. In group II the mean SMRm was lower than the mean SMRp $(p<0.05)$, and also lower than the preoperative mean SMRm of group $I(p<0.01)$. The $S M R m / p$ ratio of group II was significantly lower than the preoperative $S M R m / p$ ratio of group I $(p<0.05)$.

\section{DISCUSSION}

In the present study, the measured SMR was equal to the predicted SMR in the weight-stable obese situation, in which the patients were apparently at their predetermined physiological body weight. As soon as weight loss occurs the measured SMR drops below the predicted SMR. At three and six months after VBG, the reduction of SMR is at least partially explained by a prevailing negative energy balance, since the patients were still losing weight. However, a long-term stable weight reduction after VBG, results in a measured SMR which is still significantly lower than the predicted SMR, implying that the disproportionate reduction of SMR is sustained as long as weight loss is maintained.

Reports in the literature are conflicting regarding the effect of weight loss on the disproportionate reduction in energy expenditure. Although many studies showed a reduced energy expenditure disproportional to weight loss ${ }^{15-25}$, other studies could not confirm these results ${ }^{26-33}$. Most of the studies in which the subjects are used as their own controls, show a reduction of RMR larger than expected, based on body composition ${ }^{15,16,18,20-22}$. In contrast, the majority of studies comparing stable post-obese subjects with weight-matched controls, did not yield a disproportionate reduction in $\operatorname{RMR}^{26-29,31}$. The latter studies had in common that the study population was recruited by advertisement and some of these studies had a high drop out rate, which introduces a selection bias.

Furthermore, most of these studies have a small sample size which creates the risk that an actual difference may be overlooked. An overview of 11 studies comparing post-obese with matched controls, revealed a subnormal resting energy expenditure for a given body composition in all studies, however, the differences were significant in only three studies ${ }^{34}$. Because the difference in resting energy expenditure is only $4-5 \%$, the sample sizes of these studies were not large enough to detect this difference consistently. A pooled analysis of these 11 studies by Astrup ${ }^{34}$ provided a larger sample size, and the $4-5 \%$ difference in resting energy expenditure became significant.

In the present study, the SMR was adjusted for body composition by using the ratio measured VS predicted SMR, in which the predicted SMR incorporates FFM as well as FM. The way in which RMR is expressed is 
important, since it can change the conclusions drawn. Heska et al. ${ }^{15}$ measured RMR and FFM in 35 obese subjects enrolled in a conservative weight loss program. The RMR-FFM ratio did not change with weight loss. However, regression analysis showed that the RMR declined to a greater degree than the FFM alone. The additional decline correlated significantly with the loss of FM. Hoffmans et al. ${ }^{355}$ reported a significant contribution of FM to the explained variance in SMR or RMR in normal and moderately obese subjects. In most studies RMR is expressed per unit FFM, without correction for FM, resulting in an overestimation of measured RMR, since FM contributes significantly to RMR. This error becomes more significant with increasing degrees of obesity and thus, greater FM.

The disproportionate reduction of RMR in post-obese individuals may reflect the genetic component of obesity. Once a defect in energy metabolism is established, it is important to identify the underlying mechanisms. Different mechanisms leading to obesity seem to be involved and emphasize the heterogeneous nature of obesity, for example, an altered responsiveness of the sympathoadrenal system ${ }^{36}$, defects in substrate oxidation ${ }^{37}$ and lower levels of thyroid hormones ${ }^{25}$. These mechanisms can cause a disproportionate reduction of RMR in post-obese individuals and, with that, a susceptibility to weight regain. Further research is necessary to investigate in depth the mechanisms responsible for the defects in energy metabolism.

In conclusion, the data of the present study demonstrate a normal SMR adjusted for body composition in the morbidly obese patients prior to VBG, while long-term weight loss after VBG results in a SMR which is significantly lower than expected, based on body composition. The sustained disproportionate reduction of SMR may explain the persistent susceptibility of the post-obese subjects to weight regain. As a consequence, the treatment of morbid obesity may only be successful when the therapeutic measures taken have a lifelong effect. 


\section{REFERENCES}

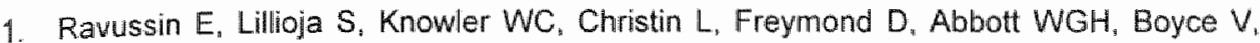
Howard $B V$, Bogardus $C$. Reduced rate of energy expenditure as a risk factor for bodyweight gain. N Eng $\mathbb{N}$ Med 1988;318:467-72.

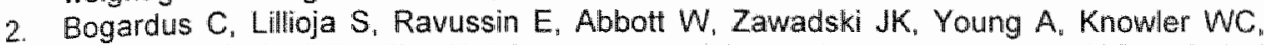
Jacobowitz $R$, Moll PP. Familial dependence of the resting metabolic rate. $N$ Eng $\mathbb{M}$ Med $1986: 313: 96-100$.

3. Keesey RE. Metabolic defense of body weight set-point. In: Stunkard AJ, Stellar E (eds). Eating and its disorders. Raven Press, New York, 1984, pp 87-95.

4. Kleiber M. The Fire of Life. Krieger RE, New York, 1975.

5. Van Itallie TB. Morbid obesity. A hazardous disorder that resists conservative treatment. Am J Clin Nutr 1980;33:358-363.

6. Garrow JS (eds). Treat obesity seriously. A clinical manual. Churchill Livingstone Inc., New York 4981.

7. Saltzman $E$, Roberts $S B$. The role of energy expenditure in energy regulation: Findings from a decade of research. Nutrition Reviews 1995;53:209-20.

8. Renquist KE. Surgical treatment of obesity in America: Data according to the National Bariatric Surgery Registry. Probl Gen Surg 1992;9:231-8.

9. Deuremberg $P$. Weststrate $\mathrm{JA}_{\mathrm{s}}$ Seidell JC. Body mass index as a measure of body fatness: Age- and sex-specific prediction formulas. Br J Nutr 1991;65:105-14.

10. Schoeller DA, Van Santen E, Peterson DW, Dietz W, Jaspan J, Klein PD. Total body water measurement in humans with ${ }^{18} \mathrm{O}$ and ${ }^{2} \mathrm{H}$ labeled water. Am a Clin Nutr $1980 ; 33: 2686-93$.

11. Siri WE. Body composition from fluid spaces and density: Analysis of methods. In:

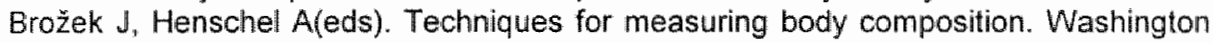
DC: National Academy of Sciences, 1956, pp 239-280.

12. Schoffelen PFM, Westerterp KR, Saris WHM, Ten Hoor F. A dual-respiration chamber system with automated calibration. J Appl Physiol 1997:83(6) (In press).

13. Weir JB. New methods for calculating metabolic rate with special reference to protein metabolism. J Physioll 1949;109:1-9.

14. Westerterp KR, Donkers JHHLM, Fredrix EWHM, Boekhoudt P. Energy intake, physical activity and body weight: A simulation model. $\mathrm{Br} J$ Nutr 1995;73:337-47.

15. Elliof DL, Goldberg L, Kuehl KS, Bennett WM. Sustained depression of the metabolic rate after massive weight loss. Am J Clin Nutr 1989;49:93-6.

16. Heshka S, Yang M, Wang J, Burt P. Pi-Sunyer FX. Weight loss and change in resting metabolic rate. Am J Clin Nutr 1990,52:981-6.

17. Geissler CA, Miller DS, Shah M. The daily metabolic rate of the post-obese and the lean. Am J Clin Nutr 1987:45:914-20.

18. Leibel $R L$, Rosenbaum $M_{1}$ Hirsch $J$. Changes in energy expenditure resulting from altered body weight. N Eng I Med 1995;332:621-8.

19. Buscemi $S$, Caimi $G$, Verga $S$. Resting metabolic rate and postabsorptive substrate oxidation in morbidly obese subjects before and after massive weight loss. Int J Obes $1996 ; 20: 41-6$.

20. Valtueña S, Blanch $S$, Barenys $M$, Solà $R$, Salas-Salvadó J. Changes in body composition and resting energy expenditure after rapid weight loss: Is there an energymetabolism adaptation in obese patients? Int J Obes 1995:19:119-25.

21. Racette SB, Schoeller DA, Kushner RF, Neil KM, Herling-laffaldano K. Effects of aerobic exercise and dietary carbohydrate on energy expenditure and body composition during weight reduction in obese women. Am J Clin Nutr 1995;61:486-94. 
22. Froidevaux F, Schutz $Y$, Christin L, Jequier $E$. Energy expenditure in obese women before and during weight loss, after refeeding, and in the weight-relapse period. Am $J$ Clin Nutr 1993;57:35-42.

23. De Boer JO, Van Es AJH, Roovers LA, Van Raaij JMA, Hautvast JGAJ. Adaptation of energy metabolism of overweight women lo low-energy intake, studied with whole-body calorimeters. Am d Clin Nutr 1986;44:585-95.

24. Lean MEJ, James WPT. Metabolic effects of isoenergetic nutrient exchange over 24 hours in relation to obesity in women. Int $J$ Obes 1988;12:15-27.

25. Astrup $A$, Buemann $B$, Toubro $S$, Ranneries $C$, Raben $A$ : Low resting metabolic rate in subjects predisposed to obesity: A role for thyroid status. Am J Clin Nutr 1996;63:87983.

26. Astrup $A_{1}$ Buemann B, Christensen NJ, Madsen J. 24-Hour energy expenditure and sympathetic activity in postobese women consuming a high-carbohydrate diet. Am $J$ Physiol 1992;262:E282-E288.

27. Amatruda JM Statt MC, Welle SL. Total and resting energy expenditure in obese women reduced to ideal body weight. J Clin Invest 1993;92:1236-1242.

28. De Peuter R, Withers RT, Brinkman M, Tomas FM, Clark DG. No difference in rates of energy expenditure between post-obese women and their matched, lean controls. Int J Obes 1992;16:801-8.

29. Larson DE, Ferraro RT, Robertson DS, Ravussin E. Energy metabolism in weight-stable postobese individuals. Am J Clin Nutr 1995:62:735-9.

30. Wadden TA, Foster GD, Letizia KA, Mullen JL. Long-term effects of dieting on resting metabolic rate in obese outpatients. JAMA 1990;264:707-11.

31. Buemann B, Astrup A, Madsen J, Christensen NJ. A 24-h energy expenditure study on reduced-obese and nonobese women: Effect of B-blockade. Am $J$ Clin Nutr $1992 ; 56: 662-70$.

32. Nelson $K M$, Weinsier $R L$, James $L D$, Darnell $B$, Hunter $G$, Long $C L$. Effect of weight reduction on resting energy expenditure, substrate utilization, and the thermic effect of food in moderately obese women. Am J Clin Nutr 1992;55:924-33.

33. Ravussin $E$, Burnand $B$, Schutz $Y$, Jéquier $E$. Twenty-four-hour energy expenditure and resting metabolic rate in obese, moderately obese, and control subjects. Am J Clin Nutr $1982 ; 35: 566-73$.

34. Astrup A. Obesity and metabalic efficiency. Ciba Foundation Symposium 1996;201:159173.

35. Hoffmans M Pfeifer WA, Gundlach BL, Nijkrake HGM, Oude Ophuis AJM, Hautvast JGAJ. Resting metabolic rate in obese and normal weight women. Int $J$ Obes $1979 ; 3: 111-8$.

36. Astrup $A$, Andersen $T$. Christensen $\mathrm{NJ}$ : Impaired glucose-induced thermogenesis and arterial norepinephrine response persist after weight reduction in obese humans. Am J Clin Nutr 1990;51:331-7.

37. Astrup A, Buemann B. Toubro $S$, Raben A: Defects in substrate oxidation involved in the predisposition to obesity. Proc Nutr Soc 1996;55:817-28. 
Chapter 4.2

ENERGY, SUBSTRATE AND PROTEIN METABOLISM

BEFORE, DURING AND AFTER MASSIVE WEIGHT LOSS

Wim G. van Gemert, Klaas R. Westerterp, Ton J.M. Wagenmakers, Bernadette A.C. van den A.cker, Dave Halliday, Jan Willem M. Greve, Peter B. Soeters.

Submitted for publication 


\section{ABSTRACT}

The purpose of this study was to gain better insight in energy, substrate and protein metabolism of morbidly obese patients before and after vertical banded gastroplasty (VBG).

Measurements were performed in eight morbidly obese patients before and after VBG and included: total energy expenditure (TEE; doubly labeled water method), sleeping metabolic rate (SMR; respiration chamber), body composition (deuterium oxide component of doubly labeled water), substrate metabolism ( $48 \mathrm{~h}$ dietary records, $48 \mathrm{~h}$ urine collection and gaseous exchange in the respiration chamber) and whole body protein turnover (primedcontinuous infusion of $\mathrm{L}-\left[1-{ }^{13} \mathrm{C}\right]$-leucine).

Three and 12 months after VBG the TEE decreased as a result of a decreased SMR (64\%) and non-SMR (36\%). The physical activity index (PAl), defined as TEE/SMR, was low and did not change after weight loss. Three months after VBG, during rapid weight loss, fat mass (FM) and fat free mass (FFM) were lost, while 12 months after VBG, when body weight plateaued. weight loss consisted almost completely of FM. Protein and carbohydrate oxidation decreased significantly after VBG, although protein oxidation did not decrease enough to prevent loss of FFM. An increased fat oxidation caused a dramatic loss of FM. The energy used for protein turnover was approximately $24 \%$ of SMR and did not change after weight loss. The protein synthesis expressed as a percentage of protein breakdown increased from $82 \%$ to $91 \%$ during semi-starvation at three months after VBG, reflecting a protein-sparing process as the gap between protein synthesis and degradation narrows.

Compensatory processes that oppose weight loss of morbidly obese patients exist as demonstrated by the disproportional reduction of SMR and non-SMR, and a low PAI.

\section{INTRODUCTION}

Although the pathogenesis of morbid obesity is not yet elucidated, it becomes more and more clear that morbid obesity is the result of genetic and metabolic disturbances, which cause an energy imbalance. Total energy expenditure (TEE) can be divided into resting and non-resting energy expenditure. Resting energy expenditure (REE) is the largest component of total energy expenditure, and is mainly determined by body size and composition. Several studies showed that weight loss of obese subjects results in a reduction of REE larger than expected from changes in body composition ${ }^{1-7}$. There are also some studies that underline the role of a decreased non-resting energy expenditure (NREE) in the reduced TEE ${ }^{4,8,9}$. From the data of these studies it appears that weight loss of obese persons is not only associated with a 
reduced REE, but also with a reduced NREE, which may account for the poor long-term efficacy of conservative treatments for obesity.

Under normal circumstances the contribution of NREE to TEE is approximately $30 \%$, and is mainly determined by spontaneous physical activity $^{10}$. A low physical activity, possibly accompanied by a low protein turnover, may lead to the development and maintenance of morbid obesity because they favor a positive energy balance.

One of the components of REE is the whole body protein turnover. The contribution of protein turnover to REE is estimated to be $15 \%$, and possibly higher in obese persons ${ }^{11-14}$. Protein turnover is closely controlled and represents a mechanism by which the energy expenditure might be regulated. Since protein is the largest solid component of lean body mass, the capacity of protein turnover to influence energy expenditure may be considerable. Therefore, a reduced whole body protein turnover could explain the disproportional reduction of REE in relation to the altered body composition in obese persons after weight loss.

Most studies concerning the pathophysiologal processes associated with obesity, do not include morbidly obese subjects and investigations are performed over a short-time period after moderate dietary induced weight loss. Morbidly obese patients undergoing surgical treatment constitute a group of patients with a substantial and long-lasting weight loss ${ }^{15}$. Consequently, larger metabolic changes are expected and long-term effects can be studied. Furthermore, to study the metabolic effects of weight loss it is important to perform a restrictive surgical procedure, such as a vertical banded gastroplasty (VBG), which induces weight loss purely as the result of restricted intake.

In the present study, the effect of massive weight loss after VBG on energy, substrate and protein metabolism of morbidly obese patients was investigated.

\section{PATIENTS AND METHODS}

\section{Patients}

Eight morbidly obese patients, who fulfilled the criteria for surgical treatment, were included in the study ${ }^{16}$ (Table 1). A VBG was performed in all patients. The technique of the VBG is described in detail elsewhere ${ }^{17}$. Measurements were performed before VBG, three months and 12 months after VBG. All patients gave their written informed consent before participation in the study. 
Table 1. Patient characteristics.

\begin{tabular}{|cccccc|}
\hline Sex & Age $(\mathrm{y})$ & Height $(\mathrm{m})$ & $\begin{array}{c}\text { Body mass } \\
(\mathrm{kg})\end{array}$ & BMI $\left(\mathrm{kg} / \mathrm{m}^{2}\right)$ \\
\hline 1 & female & 42 & 1.72 & 163.5 & 55.3 \\
2 & female & 32 & 1.64 & 116.9 & 43.5 \\
3 & fermale & 28 & 1.70 & 113.9 & 39.4 \\
4 & female & 24 & 1.70 & 113.2 & 39.2 \\
5 & male & 60 & 1.78 & 119.8 & 37.8 \\
6 & 54 & 1.59 & 135.2 & 53.5 \\
7 & temale & 1.73 & 137.7 & 46.0 \\
8 & female & 24 & 1.64 & 140.6 & 52.3 \\
\hline
\end{tabular}

\section{Energy expenditure}

Sleeping metabolic rate (SMR) was measured during an overnight stay $(20.00 \mathrm{~h}-07.30 \mathrm{~h})$ in a respiration chamber. The subjects were not allowed to eat in the chamber and coffee or tea were allowed until 22.00h. SMR was calculated over a period of three consecutive hours during minimal activity level as judged from Doppler radar observation. In the respiration chamber, the oxygen and carbon dioxide concentrations of the ingoing and outgoing air were measured with a paramagnetic analyser (Magnus 6G, Hartman \& Braun, Frankfurt, Germany) and an infrared analyser (URAS 3G, Hartman \& Braun, Frankfurt, Germany) respectively ${ }^{18}$. Energy expenditure was calculated using Weir's formula ${ }^{19}$. Total energy expenditure (TEE) was measured with the doubly labeled water method. Doubly labeled water was administered to the patients at $23.00 \mathrm{~h}$ after collection of a baseline urine sample. The dose was a mixture of $10 \% \mathrm{H}_{2}{ }^{18} \mathrm{O}$ in water and $99.8 \%{ }^{2} \mathrm{H}_{2} \mathrm{O}$. Patients received a weighed

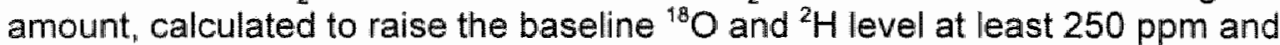
$150 \mathrm{ppm}$, respectively. Initial urine samples were collected from the second voiding around $8.00 \mathrm{~h}$ the next morning. Final urine samples were collected after seven and 14 days at $8.00 \mathrm{~h}$ in the morning and $18.00 \mathrm{~h}$ in the evening. Carbon dioxide production was calculated from isotope ratios in baseline, initial, and final urine samples with the equation from Schoeller et al ${ }^{20}$. Carbon dioxide production was converted to energy expenditure using the mean $R Q$ measured in the respiration chamber. The non-sleeping metabolic rate (NSMR) was calculated as. TEE minus SMR. Physical activity in daily life was expressed as the physical activity index (PAI): PAI $=$ TEE/SMR.

\section{Body composition}

Body composition was assessed by means of the deuterium oxide component of doubly labeled water. The deuterium oxide dilution was measured in the urine sample of the second voiding in the morning, resulting in an equilibration 
time of 9 to $10 \mathrm{~h}$. Total body water before administration was estimated from age- and gender-specific formulae ${ }^{21}$. Isotope abundance in the urine samples was measured with an Isotope Ratio Mass Spectrometer (VG Isogas, Aqua Sira "Cheshire, UK). Total body water was calculated as the deuterium dilution space divided by 1.04 for correction of a $4 \%$ over-estimation of total body water $^{22}$. Fat free mass (FFM) was calculated assuming $73.2 \%$ hydration ${ }^{23}$. Body mass (BM) was measured to the nearest $0.05 \mathrm{~kg}$ on a digital scale (Mettler, 240C, Greifensee, Switzerland). Fat mass (FM) was calculated as BM minus FFM.

\section{Substrate metabolism}

To measure substrate metabolism under free living conditions, the patients kept a dietary record and collected urine in an outpatient setting for $48 \mathrm{~h} \mathrm{just}$ before entering the respiration chamber. Dietary records were analyzed by the same dietician at all time points. Energy intake before surgery was adjusted for TEE, assuming that all nutrients were equally underreported. At three and 12 months after surgery the dietary intake was not adjusted for TEE, because the patients were at an energy imbalance at that time. The carbohydrate, lipid, and protein oxidation were obtained from measurements of oxygen consumption $\left(\mathrm{VO}_{2}\right)$ and carbon dioxide production $\left(\mathrm{VCO}_{2}\right)$ in the respiration chamber and total urinary nitrogen excretion as described by $\mathrm{Frayn}^{24}$. Nitrogen in urine was measured by standard automated techniques in the hospital clinical laboratory. Twenty-four hour protein oxidation was calculated from $24 \mathrm{~h}$ urinary nitrogen excretion, assuming a combustion of 6.25 gram protein per gram nitrogen excreted. Carbohydrate and lipid oxidation were calculated from the gaseous exchange in the respiration chamber during $12 \mathrm{~h}$. Carbohydrate and lipid oxidation values were extrapolated to $24 \mathrm{~h}$ values by adjusting for TEE minus protein oxidation.

\section{Whole body protein turnover}

Whole body protein turnover was determined by means of a primedcontinuous infusion of $L-\left[1-{ }^{13} \mathrm{C}\right]$-leucine (99 MPE, Cambridge Isotope Laboratories, Woburn, MA), one week before the energy expenditure measurements. After an overnight fast, a $4 \mathrm{~h}$ primed $(0.5 \mathrm{mg} / \mathrm{kg})$, continuous infusion of $\left[1-{ }^{13} \mathrm{C}\right]$-leucine dissolved in normal saline was administered at a rate of $0.5 \mathrm{mg} / \mathrm{kg} / \mathrm{h}$ through an antecubital vein using a calibrated pump (model 561, IVAC). Just before the start of the $\left[1{ }^{13} \mathrm{C}\right]$-leucine continuous infusion, the whole body bicarbonate pool was primed with $\mathrm{NaH}^{13} \mathrm{CO}_{3} 10.08$ $\mathrm{mg} / \mathrm{kg}$ ). Blood samples were drawn from an intravenous venflon in the contralateral hand. Blood and breath samples were taken immediately before the start of the primed-continuous infusion and at $120,150,180,210$, and 240 minutes after starting the infusion. Blood samples were drawn in chilled-on-ice heparinized tubes and plasma was obtained by centrifugation $(3,500 \mathrm{rpm}$ at 
$4^{\circ} \mathrm{C}$ for 5 min.), frozen and stored at $-80^{\circ} \mathrm{C}$ until analysis. Plasma $\left[1-{ }^{13} \mathrm{C}\right] \alpha-$ ketoisocaproic acid (KIC) enrichment (used as precursor pool for protein synthesis and lewcine oxidation) was measured using a quinoxalinoltrimethylsilyl derative on a GC-MS system (Finnigan Incos XL, San Jose, CA) as previously described ${ }^{25}$. Expired air samples were obtained by having the subjects breath normally for $3 \mathrm{~min}$ into a $6.75 \mathrm{~L}$ mixing chamber. After $3 \mathrm{~min}$, a $15 \mathrm{ml}$ Vacutainer(B) tube was filled with a sample of mixed air. ${ }^{13} \mathrm{CO}_{2}$ enrichment in the expired air was measured with a GC continuous flow Isotope Ratio Mass Spectometer (Finnigan MAT-252). Recovery of ${ }^{13} \mathrm{CO}_{2}$ in breath was assumed to be $74 \% \%^{26.27}$. Steady state was achieved after $2 \mathrm{~h}$ of tracer infusion, as indicated by plasma $\mathrm{KIC}$ enrichment and ${ }^{13} \mathrm{CO}_{2}$ enrichment in breath samples. During the first and last hour of the infusion, the total $\mathrm{CO}_{2}$ production rate of the subjects was measured by means of a computerized open-circuit ventilated hood system (oxycon- $\beta$. Mijnhard, The Netherlands).

Calculations of the rate of protein turnover were performed as described by Matthews et al. ${ }^{28}$. In short, leucine turnover $(Q)$ is measured from dilution of [1$\left.{ }^{13} \mathrm{C}\right]$-leucine infusion in plasma $\mathrm{KIC}$ at isotopic steady state: $\left.Q=\pi\left(E / E_{p}\right)-1\right]$. where $i$ is the tracer infusion rate ( $\mu$ mol per $\mathrm{kg}$ per $h$ ); $\mathbb{E}_{i}$ is the enrichment of the $\left[1-{ }^{13} \mathrm{C}\right]$-leucine infused (MPE); $\mathrm{E}_{p}$ is the plasma KIC enrichment at steady state (MPE). The rate of leucine oxidation is $\mathrm{O}=\mathrm{F}^{13} \mathrm{CO}_{2}\left[\left(1 / \mathrm{E}_{p}\right)-\left(1 / \mathrm{E}_{i}\right)\right] \times 100$, where $\mathrm{F}^{13} \mathrm{CO}_{2}$ is the rate of ${ }^{13} \mathrm{CO}_{2}$ released by leucine tracer oxidation ( $\mu \mathrm{mol}$ ${ }^{13} \mathrm{C}$ per $\mathrm{kg} \mathrm{per} \mathrm{h}$ ). From these calculations the rate of leucine incorporation into protein (protein synthesis, $S$ ) and leucine release from protein (protein breakdown, $B$ ) is obtained using the formula: $Q=S+O=1+B_{n}$ where $I$ is protein intake which was zero in this study. The leucine parameters were converted to corresponding estimates of whole body protein turnover by multiplying the leucine values by the constant ( $24 \mathrm{~h}$ per day $/ 590 \mu \mathrm{mol}$ leucine per gm protein) to give values in gm protein per day ${ }^{28}$.

\section{STATISTICS}

Data are expressed as the mean value $\pm S D$. Differences between the groups were tested with the Wilcoxon Signed Rank test. The relation between variables were tested by multiple regression analysis (enter-method). Statistical significance was considered present at $p<0.05$.

\section{RESULTS}

\section{Patients}

Eight patients were included in the study and no patients were lost to followup. Patient characteristics are listed in Table 1. Body weight decreased 
significantly after VBG (Figure 1). The greatest weight loss occurred in the first three months, and after 12 months patients were still losing some weight.

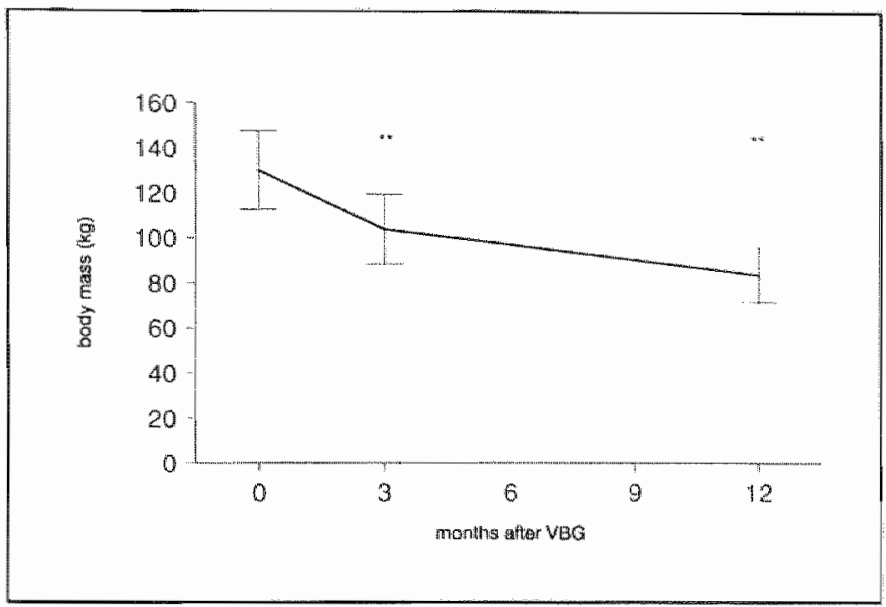

Figure 1. Body mass (kg) after vertical banded gastroplasty (VBG). ** $p<0.0001$ for differences with the preoperative values (Wilcoxon Signed Rank test).

Table 2. Changes in body composition after vertical banded gastroplasty (VBG).

\begin{tabular}{|lccc|}
\hline & Before VBG & \multicolumn{2}{c|}{ After VBG } \\
& & 3 months & 12 months \\
\hline BM $(\mathrm{kg})$ & $130.1 \pm 17.5$ & $103.8 \pm 15.6^{* *}$ & $83.8 \pm 12.4^{*}$ \\
FFM $(\mathrm{kg})$ & $61.8 \pm 9.2$ & $53.0 \pm 6.2^{*}$ & $52.4 \pm 4.4$ \\
FM $(\mathrm{kg})$ & $68.3 \pm 11.7$ & $50.8 \pm 11.1^{* *}$ & $31.4 \pm 12.1^{\prime}$ \\
\hline
\end{tabular}

Data are expressed as mean $\pm S D$. VBG = vertical banded gastroplasty; $B M=$ body mass; $F F M=$ fat free mass; $F M=$ fat mass. " $p<0.01,{ }^{* *} p<0.0001$ for differences with the values before VBG. " $p<0.001$ for differences with the values three months after VBG (Wilcoxon Signed Rank test).

Body composition

As a result of rapid weight loss during the first three months after VBG, FM and FFM decreased significantly (Table 2). The body weight lost in this period $(26.3 \mathrm{~kg})$, consisted for $66.5 \% \mathrm{FM}$ and for $33.5 \% \mathrm{FFM}$. During the next nine 
months, in which weight loss was much slower, only the fat mass decreased significantly. During the latter period, body weight lost $(20 \mathrm{~kg})$ consisted for $97 \%$ FM and only $3 \%$ FFM.

\section{Energy expenditure}

TEE, SMR and NSMR decreased significantly after VBG, also when adjusted for FFM (Table 3). To investigate whether the FFM becomes metabolically less active after weight loss, the individual values of FFM and SMR at three and 12 months after VBG were compared to the regression line of FFM and SMR before VBG. The regression line of FFM and SMR before VBG was described as: SMR $(\mathrm{MJ} / \mathrm{d})=1.89+0.105 \mathrm{FFM}(\mathrm{kg})$. The values of FFM and SMR three and 12 months after VBG are situated below the regression line, indicating that the FFM becomes metabolically less active after significant weight loss (Figure 2). The TEE decreased $2.5 \mathrm{~kJ} / \mathrm{min}$ from before to 12 months after VBG, while the SMR and NSMR decreased $1.6 \mathrm{~kJ} / \mathrm{min}$ and $0.9 \mathrm{~kJ} / \mathrm{min}$, respectively, in the same period. The reduction of TEE was mainly the result of a decreased SMR $(64 \%)$, but also of a decreased NSMR (36\%). The PAI was low and did not change significantly during or after weight loss (Table 3 ).

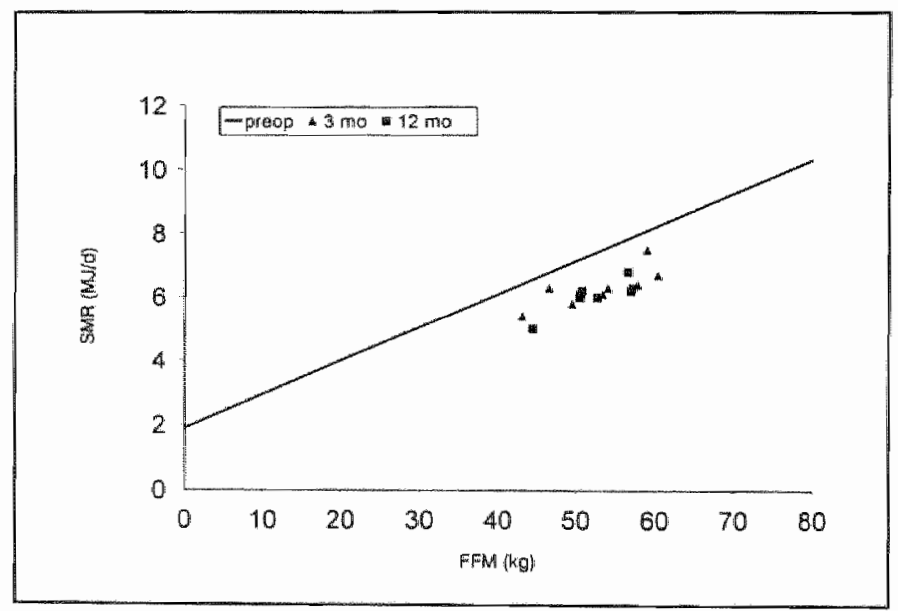

Figure 2. The individual values of sleeping metabolic rate (SMR) in relation to fat free mass (FFM) at three months (triangles) and 12 months (squares) after vertical banded gastroplasty (VBG) are compared with the regression line of SMR and FFM before surgery $(S M R=1.89+0.105 F F M)$. The values of SMR in relation to FFM after VBG are situated below the regression line indicating that the FFM becomes less metabolically active after weight lloss. 
Table 3. Energy expenditure indices before and after vertical banded gastroplasty (VBG).

\begin{tabular}{|lccc|}
\hline & Before VBG & \multicolumn{2}{c|}{ After VBG } \\
& & 3 months & 12 months \\
\hline TEE $(\mathrm{J} / \mathrm{min})$ & $9400 \pm 1300$ & $6700 \pm 1000^{*}$ & $6900 \pm 1200^{*}$ \\
TEE/FFM $\left(\mathrm{J} \cdot \mathrm{min}^{-1} \cdot \mathrm{kg}^{-1} \mathrm{y}\right)$ & $154 \pm 11$ & $127 \pm 18^{*}$ & $131 \pm 18^{*}$ \\
SMR $(\mathrm{J} / \mathrm{min})$ & $5800 \pm 8.00$ & $4400 \pm 400^{*}$ & $4200 \pm 300^{*}$ \\
SMR/FFM $\left(\mathrm{J} \cdot \mathrm{min}^{-1} \cdot \mathrm{kg}^{-1}\right)$ & $95 \pm 9$ & $83 \pm 6^{*}$ & $81 \pm 4^{*}$ \\
NSMR $(\mathrm{J} / \mathrm{min})$ & $3600 \pm 600$ & $2300 \pm 700^{*}$ & $2700 \pm 1000^{*}$ \\
NSMA $\left(\mathrm{J} \cdot \mathrm{min}^{-1} \cdot \mathrm{kg}^{-1}\right)$ & $59 \pm 6$ & $44 \pm 13^{*}$ & $50 \pm 17$ \\
PAI & $1.63 \pm 0.08$ & $1.52 \pm 0.13$ & $1.62 \pm 0.19$ \\
\hline
\end{tabular}

Data are expressed as mean \pm SD. TEE = total energy expenditure SMR = sleeping metabolic rate; $N S M R=$ non-sleeping metabolic rate; $\mathrm{PAl}=$ physical activity index. ${ }^{*} \mathrm{p}<0.001$ lor differences with the values before surgery (Wilcoxon Signed Rank test).

\section{Substrate metabolism}

Energy and substrate intake decreased significantly at three and 12 months after VBG (Table 4). After surgery " a slight decrease of protein content and increase of carbohydrate content of the consumed diet was observed, although these changes were not significant. Before VBG patients were in energy balance, while during weight loss an energy deficit occurred at three $(\triangle E E 5160 \mathrm{~kJ} / \mathrm{d})$ and 12 months after VBG $(\triangle E E 3830 \mathrm{~kJ} / \mathrm{d})$. Protein and carbohydrate oxidation decreased, while fat oxidation increased during weight loss after VBG (Table 5).

Table 4. Substrate intake before and after vertical banded gastroplasty (VBG).

\begin{tabular}{|lccc|}
\hline & Before VBG & \multicolumn{2}{c|}{ After VBG } \\
& & 3 months & 12 months \\
\hline Energy intake $(\mathrm{kJ} / \mathrm{d})$ & $13540 \pm 1970$ & $4490 \pm 1400^{*}$ & $6110 \pm 3330^{*}$ \\
Protein $(\mathrm{kJ} / \mathrm{d})$ & $2290 \pm 320$ & $550 \pm 310^{* *}$ & $850 \pm 520^{*}$ \\
Protein $(\%)$ & $16.9 \pm 2.3$ & $12.3 \pm 4.5$ & $13.9 \pm 5.3$ \\
Fat $(\mathrm{kJ} / \mathrm{d})$ & $4990 \pm 1150$ & $1690 \pm 810^{*}$ & $2010 \pm 750^{* *}$ \\
Fat $(\%)$ & $36.9 \pm 6.6$ & $37.6 \pm 9.5$ & $32.9 \pm 7.0$ \\
Carbohydrate $(\mathrm{kJ} / \mathrm{d})$ & $6260 \pm 1150$ & $2250 \pm 820^{*}$ & $3250 \pm 150^{*}$ \\
Carbohydrate $(\%)$ & $46.2 \pm 14.5$ & $50.1 \pm 15.8$ & $53.2 \pm 9.1$ \\
\hline
\end{tabular}

Data are expressed as mean $\pm \mathrm{SD}$. ${ }^{\mathrm{p}} \mathrm{p}<0.001$ and ${ }^{* *} \mathrm{p}<0.0001$ for differences with the values before VBG (Wilcoxon Signed Rank test). 
Table 5. Substrate oxidation betore and after vertical banded gastroplasty (VBG).

\begin{tabular}{|lccc|}
\hline & Before VBG & \multicolumn{2}{c|}{ After VBG } \\
& & 3 months & 12 months \\
\hline EE $(\mathrm{kJ} / \mathrm{d})$ & $13540 \pm 1970$ & $9650 \pm 1460^{* * *}$ & $9940 \pm 1400^{* *}$ \\
PTO $(\mathrm{kJ} / \mathrm{d})$ & $2360 \pm 1250$ & $1370 \pm 830^{*}$ & $960 \pm 400^{* *}$ \\
$\mathrm{LPO}(\mathrm{kJ} / \mathrm{d})$ & $5030 \pm 1890$ & $6330 \pm 1320^{* *}$ & $5540 \pm 2010$ \\
$\mathrm{CHO}(\mathrm{kJ} / \mathrm{d})$ & $6150 \pm 1420$ & $1950 \pm 1410^{\text {*** }}$ & $3440 \pm 2230^{*}$ \\
\hline
\end{tabular}

Dala are expressed as mean $\pm S D$. $E E=$ energy expenditure; $P T O=$ protein oxidation; $L P O$ $=$ lipid oxidation; $\mathrm{CHO}=$ carbohydrate oxidation. ${ }^{*} \mathrm{p}<0.05$ and ${ }^{* *} p<0.001$ and ** $p<0.0001$ for differences with the values before VBG (Wilcoxon Signed Rank test).

A

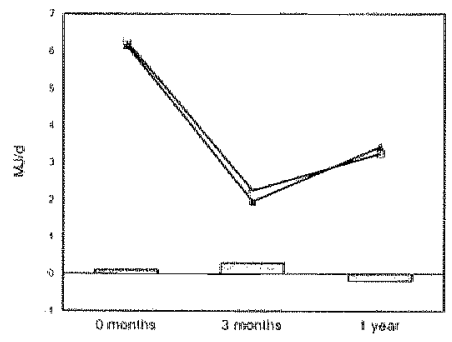

B

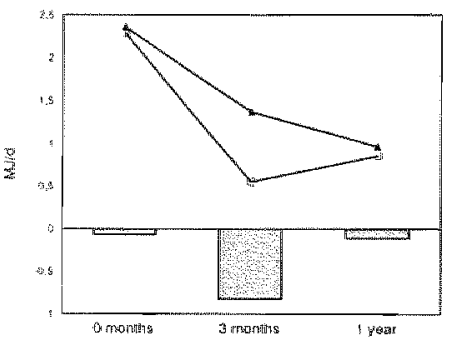

C

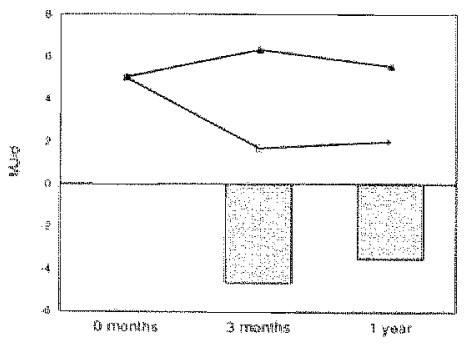

Figure 3. Carbohydrate, protein and fat intake and oxidation are shown in the figures $A, B$ and $C$ resp. The intake is represented by squares and the oxidation by triangles. The bars represent the difference between intake and oxidation. A decreased intake of all nutrients after vertical banded gastroplasty (VBG) results in a decreased carbohydrate and protein oxidation and an increased fat oxidation. Mainly fat mass is lost, but also some fat free mass is lost at three months after VBG caused by the discrepancy between protein intake and oxidlation. 
Carbohydrate intake and oxidation remained in balance during weight loss (Figure 3a). At three months after VBG protein intake decreased, however protein oxidation decreased to a lesser extent resulting in a loss of protein mass (Figure $3 b$ ). Twelve months after VBG, protein intake and oxidation were in balance again. Fat intake decreased at three and 12 months after VBG, while fat oxidation increased, resulting in a loss of fat mass (Figure $3 \mathrm{c}$ ).

Whole body protein turnover

Weight loss after VBG caused a significant decrease of protein oxidation, breakdown, and synthesis when expressed as gm protein per day (Table 6). When expressed as gm protein per $\mathrm{kg}$ FFM per day, protein oxidation and breakdown decreased significantly during rapid weight loss at three months after VBG, but protein synthesis did not change. At 12 months after $V B G$, the protein oxidation, breakdown, and synthesis, expressed as gm protein per day. were not significantly different from preoperative values.

Table 6. Protein oxidation (PO), protein breakdown (PB) and protein synthesis (PS) before and after vertical banded gastroplasty (VBG).

\begin{tabular}{|lrcc|}
\hline & Before VBG & \multicolumn{2}{c|}{ After VBG } \\
& & 3 months & 12 months \\
\hline PO $(\mathrm{gm} / \mathrm{d})$ & $77.1 \pm 20.7$ & $31.9 \pm 7.4^{* * *}$ & $49.1 \pm 22.0^{*}$ \\
$\mathrm{PO}\left(\mathrm{gm} / \mathrm{fm} \cdot \mathrm{d}^{-1} \mathrm{~h}\right)$ & $1.25 \pm 0.29$ & $0.60 \pm 0.13^{* * *}$ & $0.94 \pm 0.43$ \\
$\mathrm{~PB}(\mathrm{gm} / \mathrm{d})$ & $444.6 \pm 79.3$ & $347.5 \pm 37.9^{* * *}$ & $339.9 \pm 69.9^{* *}$ \\
$\mathrm{~PB}\left(\mathrm{gm} / \mathrm{fm} \cdot \mathrm{d}^{-1}\right)$ & $7.21 \pm 0.81$ & $6.58 \pm 0.50^{*}$ & $5.45 \pm 0.98$ \\
$\mathrm{PS}(\mathrm{gm} / \mathrm{d})$ & $367.5 \pm 78.1$ & $315.6 \pm 32.7^{*}$ & $290.8 \pm 59.8^{*}$ \\
$\mathrm{PS}\left(\mathrm{gm} / \mathrm{fm} \cdot \mathrm{d}^{-1}\right)$ & $5.96 \pm 0.90$ & $6.00 \pm 0.39$ & $5.51 \pm 0.77$ \\
\hline
\end{tabular}

Data are expressed as mean \pm SD. Protein oxidation, breakdown, and symthesis are expressed as grams protein per day $(\mathrm{gm} / \mathrm{d})$ and as grams protein per $\mathrm{kg}$ fat free mass per day (gm/fm/ $\left.d^{-1}\right)$. * $p<0.05$, and $p<0.001$, and * $p<0.0001$ for differences with the preoperative values (Wilcoxon Signed Rank tesit).

The individual values of protein turnover ( $\mathrm{gm}$ protein/day) in relation to $\mathrm{FFM}$, at three and twelve months after VBG were mostly located below the regression line of protein turnover in relation to FFM before VBG (protein turnover = $23.4+6.82 \mathrm{FFM}$ ), suggesting that the protein turnover of FFM decreased as a result of weight loss, especially at three months after VBG (Figure 4). Protein synthesis expressed as a percentage from PB was $82.4 \%$ before VBG, $90.9 \%$ at three months after VBG ( $p<0.011)$, and $85.7 \%$ at 12 months after VBG (ns). 
Assuming that each mol oxygen consumed is linked to the synthesis of six mol ATP, and that the energy expenditure associated with protein turnover is 1.04 $\mathrm{kcal} / \mathrm{gm}$ protein, the contribution of protein turnover to SMR was $23.2 \% \pm 2.0 \%$ before VBG, $24.0 \% \pm 1.0 \%$ at three months after VBG, and $24.3 \% \pm 3.4 \%$ at 12 months after $V B G^{11,13}$.

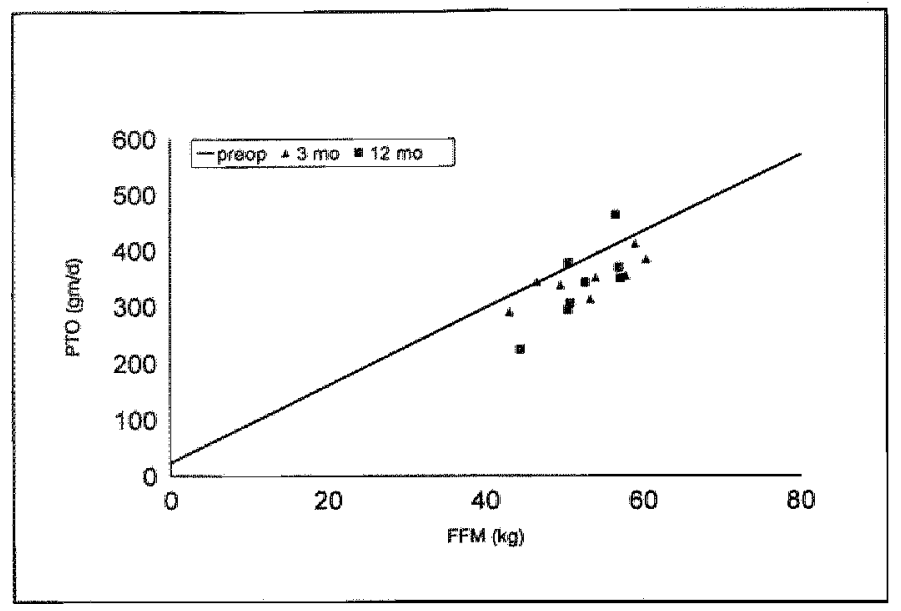

Figure 4. The individual values of protein turnover (PTO) in relation to fat free mass FFM at three months (triangles) and 12 months (squares) after vertical banded gastroplasty (VBG) are compared with the regression line of the preoperative PTO and FFM. The individual values are mainly situated below the regression line, especially at three months after VBG.

\section{DISCUSSION}

A low habitual energy expenditure is often identified as a risk factor for obesity $^{29,30}$. In the present study, the reduction of energy expenditure was mainly the result of a decreased SMR $(64 \%)$, but also of a decreased NSMR $(36 \%)$. This reduction was larger than expected based on the reduction of FFM. The reduced energy expenditure during the first three months after VBG is probably an adaptation to semi-starvation.

However, at 12 months after VBG when weight loss is very low, the reduction of energy expenditure may be an expression of the defense of body weight setpoint and may reflect the persistent susceptibility of the formerly obese to weight regain. Several studies in which the subjects were used as their own controls, showed a reduction of resting metabolic rate larger than expected based on body composition ${ }^{1,2,4,6,7}$. Others showed that also TEE, as 
determined by weight maintenance energy requirements, reduced disproportionally following weight loss $\mathrm{s}^{4.8}$. The present study revealed a significant decrease of NSMR, although the PAl did not change significantly. Westerterp et al. ${ }^{31}$ also found a low PAl in morbidly obese patients before and after weight loss. Furthermore, a negative relation between PAl and fat reduction after VBG was found. A possible explanation for the latter is, that patients are not able to maintain or increase activity levels as a result of a drastically decreased eating capacity after VBG. Ferro-Luzzi and Martino ${ }^{32}$ identified in an epidemiological survey, a critical level of PAI less than 1.80 , below which the risk of obesity increases sharply. From this point of view, the PAl of the present study population, which is below 1.80 at all time points, may be a reflection of their propensity to become and remain obese.

The composition of the body weight lost is dependent on the rate of weight loss. Rapid weight loss during the first three months after VBG resulted in significant loss of FM and also FFM. On the other hand, slow weight loss after three months resulted in loss of FM only, while FFM was spared. Many underfeeding studies with overweight subjects showed that body weight lost is mainly composed of FM $(71.7 \%-85.2 \%)$ and FFM is lost to a lesser degree $(14.8 \%-28.3 \%)^{1,2.47 .33}$. Palombo et al ${ }^{34}$ studied the composition of weight loss in 82 morbidly obese patients after gastric bypass. They found that FFM was mainly lost in the initial period of rapid weight loss, and that loss of FFM was minimal at one year after gastric bypass when body weight plateaued. The same phenomenon was demonstrated in our previous findings, and in the energy balance studies of Garrow ${ }^{35,36}$. The data of these studies indicate, that treatment modalities resulting in an extended slow weight loss are preferable, because slow weight loss results in loss of FM, while FFM is spared.

An oxidative hierarchy operates in inverse proportion to the size of available macronutrient stores and interconversion between the macronutrients is negligible ${ }^{37}$. Carbohydrate and protein oxidation are under tight autoregulation. However, there is a poor acute feedback between fat intake and fat oxidation. In the present study population of morbidly obese patients in which the FM constitutes the largest body compartment, fat oxidation increased while fat intake decreased resulting in a massive loss of fat mass. On the other hand, carbohydrate and protein oxidation decreased and increased simultaneously with carbohydrate and protein intake. During semi-starvation protein oxidation decreased to a lesser extent than protein intake, resulting in a loss of FFM. At one year after $V B G$, when energy balance was almost regained, protein balance was restored. From these data it appears that protein oxidation reaches a minimum limit during semi-starvation. Garrow ${ }^{38}$ identified an optimum rate of weight loss of $4.2 \mathrm{MJ} /$ day at which FFM is spared and only FM is lost. Because a lower limit for protein oxidation seems to exists, it is important to consider the possibility of the development of a protein deficiency syndrome during semi-starvation. In a carefully designed study, 
MacLean et al. ${ }^{39}$ found protein mainutrition in 47 out of 96 morbidly obese patients following gastroplasty. These results emphasize the need of nutritional assessment and support of these patients after weight reducing surgery, especially during the phase of rapid weight loss.

It is noteworthy, that the ratio of carbohydrate/protein/fat intake remained unchanged during and after weight loss, although energy intake decreased drastically. The observed changes in body composition can be explained by a normal physiological mechanism: a decreased carbohydrate intake results in lower insulin levels followed by an increased lipolysis and decreased carbohydrate and protein oxidation. The data of the present study suggest that the adaptive response to fasting is mainly regulated by the carbohydrate restriction, as was also demonstrated by others ${ }^{37,40}$. Sugerman et al. ${ }^{41}$ performed a randomized prospective study comparing VBG with Roux-en-Y gastric bypass that included preoperative dietary separation of "sweets eaters" versus "non-sweets eaters". It appeared that the RouX-en-Y gastric bypass was superior to VBG with respect to sweets eaters, probably because of the development of dumping syndrome symptoms after carbohydrate untake. After VBG sweets eaters lost significantly less weight than non-sweets eaters, which can be explained by the fact that the hyperinsulinaemia does not resolve in patients in whom the carbohydrate intake is not adequately reduced. Brolin et al. ${ }^{42}$ found that the intake of milk, ice and solid sweets was significantly higher in the patients after VBG compared to Roux-en-Y gastric bypass. These results indicate that a successful bariatric procedure must protect against excessive carbohydrate intake either by the surgical procedure itself or by intensive dietary support after surgery.

A sustained reduction of body weight is associated with a compensatory reduction in energy expenditure, especially REE, which oppose the maintenance of a reduced body weight $t^{1,2,4,6,7}$. Because the contribution of protein turnover to REE is estimated to be $15 \%$ and even higher in obese subjects, we investigated whether changes in protein turnover could explain the disproportional reduction of energy expenditure after weight loss ${ }^{1 / 14}$. The results of the present study showed that the energy expended per $\mathrm{kg}$ FFM decreased three and 12 months after VBG. The protein turnover per $\mathrm{kg}$ FFM was also decreased three months after VBG, but did not convincingly decrease at 12 months after VBG. Furthermore, protein turnover expressed as a percentage of SMR did not change during and after weight loss. This interesting phenomenon was also observed by others and suggests that protein turnover is not a major contributor to the disproportional reduction of SMR, but just one of the compensatory processes ${ }^{11}$. In the present study population, protein synthesis decreased to a lesser extent than protein breakdown, especially when expressed per $\mathrm{kg}$ FFM. Protein synthesis expressed as a percentage of protein breakdown increased during semistarvation, reflecting a protein-sparing process as the gap between protein 
synthesis and degradation narrows. Protein-sparing during semi-starvation was also demonstrated in other studies ${ }^{43.44}$. Jensen et al. ${ }^{45}$ showed that obesity is associated with greater proteolysis and that the antiproteolytic actions of insulin are impaired due to insulin resistance. This implicates that obese patients are even more at risk for protein deficiency during weight loss compared to normal weight persons. Garlick et al ${ }^{46}$ investigated the influence of low-energy diets on protein turnover in obesity and concluded that the decrease in dietary energy did not influence protein turnover, but dietary protein was necessary to maintain protein turnover rates. Because the proteinsparing found in this study cannot completely prevent loss of protein mass during semi-starvation, careful metabolic follow-up and nutritional support is needed after weight reducing surgery.

From the results of this study it is concluded, that compensatory processes exist which oppose weight loss of morbidly obese patients. The disproportional reduction of SMR and NSMR during and after weight loss demonstrates the propensity to weight regain, which is also reflected in a low PAI. The intake of all macronutrients decreases drastically after VBG, which results in a massive weight loss. Slow weight loss results in loss of FM only, while rapid weight loss results in loss of FM and FFM, probably because there is a lower limit to protein oxidation. The adaptive response to semi-starvation appears to be mainly regulated by carbohydrate restriction. Although semi-starvation results in a significant decrease of protein turnover, it is not a major contributor to the reduction of SMR, but just one of the compensatory processes. A proteinsparing mechanism during semi-starvation is likely to exist which does not completely prevent loss of FFM during rapid weight loss.

From a clinical point of view, it is concluded, that surgical procedures for the treatment of morbid obesity should preferably induce a protracted slow weight loss to prevent loss of FFM. Furthermore, excessive carbohydrate intake must be controlled for to ensure satisfactory weight loss, and adequate dietary protein must be supplied to prevent protein deficiency. Nutritional assessment and support are therefore necessary after weight reducing surgery. 


\section{REFERENCES}

1. Elliot $D L$ Goldberg L, Kueh KS, Bennett WM. Sustained depression of the metabolic rate after massive weight loss. Am J Clin Nutr 1989;49:93-6.

2. Heshka S. Yang M: Wang J, Burt P. Pi-Sunyer FX. Weight loss and change in resting metabolic rate. Am J Clin Nutr 1990;52:981-6.

3. Geissler $C A$. Miller DS, Shah $M$. The daily metabolic rate of the post-obese and the lean. Am J Clin Nutr 1987;45:914-20.

4. Leibel RL, Rosenbaum $M_{1}$ Hirsch $J$. Changes in energy expenditure resulting from altered body weight. N Eng J Med 1995;332:621-8.

5. Buscemi $S$, Caimi $G$, Verga $S$. Resting metabolic rate and postabsorptive substrate oxidation in morbidly obese subjects before and after massive weight loss. Int $J$ Obes $1996: 20: 41-6$.

6. Valtueña $S$, Blanch S, Barenys $M$, Solà $R$, Salas-Salvadó J. Changes in body composition and resting energy expenditure after rapid weight loss: Is there an energymetabolism adaptation in obese patients? Int J Obes 1995;19:119-25.

7. Froidevaux $F$, Schutz $Y$, Christin L, Jequier $E$. Energy expenditure in obese women before and during weight loss, after refeeding, and in the weight-relapse period. Am $J$ Clin Nutr 1993:57:35-42.

8. Weigle DS, Sande KJ, Iverius P, Monsen ER, Brunzell JD. Weight loss leads to a marked decrease in nonresting energy expenditure in ambulatory human subjects. Metabolism 1988;37:930-6.

9. Weigle DS, Brunzell JD: Assessment of energy expenditure in ambulatory reducedobese subjects by the techniques of weight stabilisation and exogenous weight replacement. Int J Obes 1990;14:69-81.

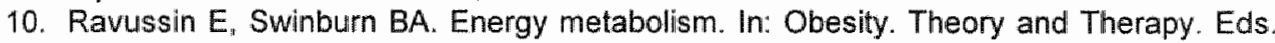
AJ Stunkard "TA Wadden. Raven Press, New York 1993.

11. Reeds PJ, Fuller MF. Nicholson BA. Metabolic basis of energy expenditure with particular reference to protein. In: Substrate and energy metabolism in man. Eds. IS Garrow, D Halliday. John Libbey, London/Paris 1985.

12. Welle $S$, Barnard $R R$, Statt M. Amatruda JM. Increased protein tumover in obese women. Metabolism 1992:41:1028-34.

13. Welle $S$. Nair KS. Relationship of resting metabolic rate to body composition and protein turnover. Am J Physiol 1990;258:E990-E8.

14. Bruce AC, McNurlan MA, McHardy KC, Broom J, Buchanan KD, Galder AG, Milne $E_{\text {i }}$ McGaw BA, Garlick PJ, James WPT. Nutrient oxidation patterns and protein metabolism in lean and obese subjects. Int J Obes 1990; $14: 631-46$.

15. Renquist KE. Surgical treatment of obesity in America: Data according to the National Bariatric Surgery Registry. Probl Gen Surg 1992;9:231-8.

16. Gastrointestinal surgery for severe obesity: National Institutes of Health Consensus Development Conference Statement. Am J Clin Nutr 1992;55:615S-9S.

17. Van Gemert WG, Greve JWM, Soeters PB. Long-term results of vertical banded gastroplasty: Marlex versus Dacron banding. Obes Surg 1997;7:128-135.

18. Schoffelen PFM, Westerterp KR, Saris WHM, Ten Hoor F. A duall-respiration chamber system with automated calibration. J Appl Physiol 1997;83(6):2064-2072.

19. Weir JB. New methods for calculating metabolic rate with special reference to protein metabolism. I Physiol 1949;109:1-9.

20. Schoeller DA, Ravussin $E$, Schutz $Y$, Acheson $K J$, Baertschi $P$, Jequier $E$. Energy expenditure by doubly labeled water: Validation in humans and proposed calculation. Am J Physiol 1986;250:R823-R30. 
21. Deurenberg $P$, Weststrate JA, Seidell JC. Body mass index as a measure of body fatness: Age- and sex-specific prediction formulas. Br J Nutr 1991;65:105-1.4.

22. Schoeller DA, Van Santen $E$, Peterson DW, Dietz W, Jaspan J, Klein PD. Total body water measurement in humans with ${ }^{18} \mathrm{O}$ and ${ }^{2} \mathrm{H}$ labeled water. Am $\mathrm{J}$ Clin Nutr 1980;33:2686-93.

23. Pace N, Rathbun EN. Studies on body composition III. The body water and chemically combined nitrogen content in relation to fat content. J Biol Chem 1945; 158:685-91.

24. Frayn $\mathrm{KN}$. Calculation of substrate oxidation rates in vivo from gaseous exchange. $J$ Appl Physiol 1983;55:628-34.

25. Ford $\mathrm{GC}_{\text {, }}$ Cheng $\mathrm{KN}$, Halliday D. Analysis of $\left[1{ }^{13} \mathrm{C}\right] \mathrm{KIC}$ in plasma by capillary gas chromatography/mass spectrometry in protein turnover studies. Biomed Mass Spectrom 1985:12:432-6.

26. Hoerr RA, Yu Y, Wagner DA, Burke JF, Young VR. Recovery of ${ }^{13} \mathrm{C}$ in breath from $\mathrm{NaH}^{13} \mathrm{CO}_{3}$ infused by gut and vein: Effect of feeding. Am J Physiol 1989:257:E426-E38.

27. Leijssen DPC, Elia M. Recovery of ${ }^{13} \mathrm{CO}_{2}$ and ${ }^{14} \mathrm{CO}_{2}$ in human bicarbonate studies: $A$ criticall review with original data. Clin Sci 1996;91:665-77.

28. Matthews DE, Motil KJ, Rohrbaugh DK, Burke JF, Young VR, Bier DM. Measurement of leucine metabolism in man from a primed ${ }$ continuous infusion of $L-\left[1-{ }^{13} \mathrm{C}\right]$ leucine. Am $J$ Physiol 1980;238:E473-E9.

29. Roberts SB, Savage J, Coward WA, Chew B, Lucas A. Energy expenditure and energy intalke in infants born to lean and overweight mothers. N Eng J Med 1988;318:461-6.

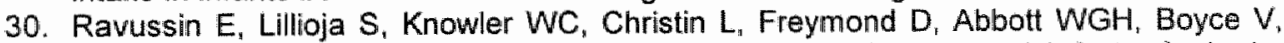
Howard BV, Bogardus C. Reduced rate of energy expenditure as a risk factor for bodyweight gain. N Eng J Med 1988;318:467-72.

31. Westerterp KR, Saris WHM, Soeters PB, ten Hoor F. Determinants of weight loss after vertical banded gastroplasty. Int J Obes 1991;15:529-34.

32. Ferro-Luzzi A, Martino L. Obesity and physical activity. In: The origins and consequences of obesity. Wiley, Chichester. Ciba Foundation Symposium $1996 ; 201: 207-227$.

33. Ravussin $E$, Burnand $B$, Schutz $Y$, Jequier $E$. Energy expenditure before and during energy restriction in obese patients. Am J Clin Nutr 1985;41:753-9.

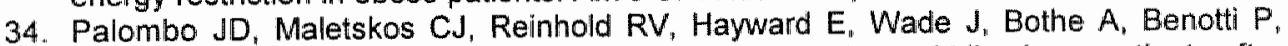
Bistrian BR, Blackburn GL. Composition of weight loss in morbidly obese patients after gastric bypass. J Surg Res 1981;30:435-42.

35. Van Gemert WG, Westerterp KR, Greve JWM, Soeters PB. Reduction of sleeping metabolic rate after vertical banded gastroplasty. Int J Obes 1998;22:34:3-8.

36. Garrow JS. Combined medical-surgical approaches to treatment of obesity. Am J Clin Nutr 1980;33:425-30.

37. Astrup $A$, Buemann $B$, Toubro $S$, Raben $A$. Defects in substrate oxidation involved in the predisposition to obesity. Proc Nutr Soc 1996;55:817-28.

38. Garrow JS. Treat obesity seriously. A clinical manual. Edinburgh: Churchill Livingstone, 1981.

39. MacLean LD. Rhode BM. Shizgal HM. Nutrition following gastric operations for morbid obesity. Ann Surg 1983;198:347-55.

40. Klein S, Wolfe RR. Carbohydrate restriction regulates the adaptive response to fasting. Am I Physiol E631-36.

41. Sugerman HJ, Starkey JV, Birkenhauer R. A randomized prospective trial of gastric bypass versus vertical banded gastroplasty for morbid abesity and their effects on sweets versus non-sweets eaters. Ann Surg 1987,205:613-22.

42. Brolin RE, Robertson LB, Kenler HA, Cody RP. Weight loss and dietary intake after vertical banded gastroplasty and Roux-en-Y gastric bypass. Amn Surg 1994;220:782-90. 
43. Vazquez JA, Adibi SA. Protein sparing during treatment of obesity: Ketogenic versus nonketogenic very low calorie diet. Metabolism 1982:41:406-14.

44. Hoffer LJ, Forse RA. Protein metabolic effects of a prolonged fast and hypocaloric refeeding. Am J Physiol 1990;258:E832-40.

45. Jensen MD. Haymond MW. Protein metabolism in obesity: Effects of body fat distribution and hyperinsulinemia on leucine turnover. Am J Clin Nutr 1991;53:172-6.

46. Garlick P., Clugston GA, Waterlow JC. Influence of low-energy diets on whole-body protein turnover in obese subjects. Am I Physiol 1980;238:E235-44. 
Chapter 5

GENERAL DISCUSSION 
Do the morbidly obese deserve our conscientious treatment?

The cultural ideal of thinness in our modern society has resulted in a deeprooted antipathy towards obesity. Obese persons are being stigmatized as lazy, dirty, stupid, ugly, cheats and lies'. Sadly, health-care professionals share the same prejudice and physicians consider their obese patients to be weak-willed, ugly and awkward ${ }^{2}$. Medical professionals appear to have no problems performing coronary or peripheral bypass surgery for smokers with vascular occlusive disease or treating severe trauma patients who had a traffic accident as a result of alcohol intoxication. However, they treat their obese patients with the same ungrounded prejudice and despise as the common public, without proper knowledge about this disease. Is this justified or should obese patients be treated seriously?

In this thesis we investigated whether morbid obesity is caused by psychosocial or metabolic determinants. First, the psychosocial aspects of morbid obesity and the effect of weight loss after surgical treatment were investigated. These studies demonstrated that the morbidly obese have an impaired quality of life and suffer from psychological disorders as a result of their overweight, since all psychopathology disappears and their quality of life improves after weight loss. These finding are widely supported by the literature ${ }^{3-6}$. However, we have to keep in mind that the studies presented in this thesis deal with a surgical population of morbidly obese patients and the results cannot simply be extrapolated to the whole morbidly obese population. As a matter of fact, some studies show negative psychological reactions after conservative treatment of morbid obesity in contrast to surgical treatment ${ }^{7,8}$. It was striking to discover that the significant improvement of psychosocial functioning after surgical treatment was only influenced by weight loss and not by complications or the type of surgical intervention, demonstrating the severe degree of emotional suffering of morbidly obese patients. Although no relation was found between psychosocial functioning and the different surgical modalities, it can be hypothesized that the improvement of psychosocial functioning is greater after a malabsorptive procedure compared to a restrictive procedure. Because the former results in a considerable weight loss while the eating capacity decreases to a lesser extent. A prospective comparative study could offer the solution with respect to this matter. Despite the cross-sectional study design of our first quality of life study and psychological study, the results are supported by our second prospective quality of life study and reports in the literature $e^{3-6}$. Therefore, we can conclude that morbid obesity is not a "psychological disease".

After establishing the role of psychosocial determinants as being the result rather than the cause of morbid obesity, the metabolic aspects of morbid 
obesity and the effect of surgical treatment were investigated. The studies presented in this thesis demonstrate that weight loss in morbidly obese patients is counteracted by a disproportional reduction of energy expenditure, which would explain the persistent propensity of the morbidly obese to overweight and weight regain after weight loss. These data support the existence of a "body weight setpoint theory", which states that every living being strives to maintain and defend a predetermined body weight ${ }^{9.10}$. Other studies in which the subjects are used as their own controls, showed a reduction of resting metabolic rate larger than expected based on body composition $^{11,12}$. In other studies as well as ours, a reduction of non-resting energy expenditure also contributes to the decreased total energy expenditure of morbidly obese patients after weight loss ${ }^{13,14}$. The morbidly obese are characterized by a low physical activity index that does not increase after weight loss and which might be a reflection of the susceptibility to become or remain obese ${ }^{15.16}$. From these data it is concluded that compensatory processes do exist that oppose weight loss of morbidly obese patients. Since our study showed that protein turnover does not contribute significantly to the disproportional reduction of energy expenditure, other pathological processes must be responsible for the energy imbalance leading to morbid obesity. Leptin seems to play an important role in the pathogenesis of morbid obesity. and since its discovery in 1994 modern biology has moved into the field of obesity research ${ }^{17}$. Because leptin limits food intake and increases energy expenditure, the results of the studies presented in this thesis can be explained by leptin deficiency or leptin resistance. However, almost monthly new molecules with an important role in energy metabolism are identified and the (patho)physiology of leptin is not as simple as it seemed to be in rodent models of obesity. Human obesity appears to be far more complex than the genetic obesity in rodent models. Other factors of interest, besides leptin, are lipoprotein lipase, neuropeptide $Y$ and $\mathrm{TNF}^{18-20}$. All these regulatory factors working in close interaction are probably involved in the pathophysiology of morbid obesity and associated comorbidities such as insulin resistance.

Surgical treatment is considered as the treatment of choice for morbid obesity, since conservative treatment is unlikely to produce long-lasting weight reduction ${ }^{7.8}$. In our studies it was demonstrated that satisfactory long-term weight loss can be achieved with surgical treatment, although a high number of reoperations were necessary to achieve a good overall result after vertical banded gastroplasty. It appears that a certain group of morbidly obese patients do not respond well to a restrictive procedure and fare better with a malabsorptive procedure like a gastric bypass. This is also supported by data of our study and others demonstrating that conversion of a failed vertical banded gastroplasty to a gastric bypass is more effective than restoration of the vertical banded gastroplasty ${ }^{21,22}$. With respect to this matter, Sugerman et 
al. found that the gastric bypass was more effective than the vertical banded gastroplasty for patients with a large intake of carbohydrates in the form of simple sugars, the so called "sweets eaters" ${ }^{\text {"23. }}$. An explanation can be found in the fact, that patients with a gastric bypass develop dumping symptoms after ingestion of large quantities of carbohydrates "which does not occur in patients with a vertical banded gastroplasty. The search for the ideal operation is still continuing. In the recent years new techniques, like the adjustable silicone gastric banding (Lap-band(2) and laparoscopic gastric bypass, are introduced and are gaining quickly in popularity ${ }^{24,25}$. Most likely, there is not one ideal operation for all morbidly obese patients, and it is therefore important to establish proper selection criteria for the different types of operations. From the studies presented in this thesis it emerges, that a suitable bariatric procedure must fulfil definite criteria. Surgical procedures for the treatment of morbid obesity should preferably cause an extended slow weight loss to prevent loss of fat free mass. Excessive carbohydrate intake must be controlled for to ensure sufficient weight loss and adequate dietary protein must be supplied to prevent protein deficiency. Nutritional assessment and support are therefore necessary after weight reducing surgery. Further research is required to investigate the effectiveness of the different surgical techniques and the proper selection criteria.

Morbid obesity is accompanied by a wide range of medical comorbidity, such as diabetes mellitus, pulmonary disease, and heart disease ${ }^{26}$. Successful surgical treatment of morbid obesity not only results in substantial weight loss, improved quality of life and psychological status, but also in a marked improvement of the obesity-related comorbidity ${ }^{27}$. As a result, chances to acquire successful employment or job-promotion are greatly increased as shown in our study. Because of these effects the vertical banded gastroplasty for the treatment of morbid obesity is cost-effective. It would be interesting to perform a prospective cost-effectiveness analysis for the different surgical procedures over a longer period of time.

After this résumé we must conclude, that the wide-spread prejudice and discrimination of morbidly obese patients by the public and especially physicians, is ungrounded and based on lack of knowledge regarding this disease. Morbidly obese patients do not deserve our despise, but instead deserve our conscientious treatment. 


\section{REFERENCES}

1. Wadden TA, Stunkard AJ. Psychosocial consequences of obesity and dieting. In: Obesity. Theory and Therapy. Eds. AJ Stunkard, TA Wadden. Raven Press: New York, 1993.

2. Maddox GL, Liederman G. Overweight as a social disability with medical implications. J Med Educ 1969:44:214-20.

3. La Manna A, Ricci GB, Giorgi I, Gossemberg M, La Manna L, Catona A. Psychological effects of vertical banded gastroplasty on pathologically obese patients. Obes Surg $1992 ; 2: 239-243$.

4. Solow C, Silberfarb PM, Swift K. Psychosocial effects of intestinal bypass surglery for severe obesity. N Eng J Med 1974:290:300-304.

5. Rand CSW, Macgregor AMC. Successful weight loss following obesity surgery and the perceived liability of morbid obesity. Int J Obes 1991; 15:577-579.

6. Hafner RJ. Watts JM, Rogers J. Quality of life after gastric bypass for morbid obesity. Int J Obes 1991:15:555-560.

7. Halmi KA, Stunikard AJ, Mason EE. Emotional responses to weight reduction by three methods: Gastric bypass, jejunoileal bypass, diet. Am J Clin Nutr 1980;33:446-451.

8. Andersen $T$, Backer $O$, Stokholm $K H$, Quaade $F$. Randomized trial of diet and gastroplasty and diet alone in morbid obesity. N Eng J Med 1984;310:352-356.

9. Kleiber M. The Fire of Life. Krieger RE: New York, 1975.

10. Keesey RE. Metabollic defense of body weight setpoint. In: Eating and its disorders. Eds. AJ Stunkard, E Stellar. Raven Press: New York, 1984.

11. Heska $S$, Yang $M$. Wang J. Burt $P$, Pi-Sunder $F X$. Weight loss and change in resting metabolic rate. Am J Clin Nutr 1990;52:981-986.

12. Racette SB, Schoeller DA, Kushner RF, Neil KM, Herling-Laffalidano K. Effects of aerobic exercise and dietary carbohydrate on energy expenditure and body composition during weight reduction in obese women. Am J Clin Nutr 1995;61:486-494.

13. Leibel RL, Rosenbaum M. Hirsch J. Changes in energy expenditure resulting from altered body weight. N Eng J Med 1995;332:621-628.

14. Weigle DS, Sande KJ, Iverius P. Monsen ER, Brunzell JD. Weight loss leads to a marked decrease in nonresting energy expenditure in ambulatory human subjects. Metabolism 1988:37:930-936.

15. Westerterp KR, Saris WHM, Soeters PB. Ten Hoor F. Determinants of weight loss after" vertical banded gastroplasty. Int J Obes 1991:15:529-534.

16. Ferro-Luzzi $A_{4}$ Martino $L$. Obesity and physical activity. In: The origins and consequences of obesity. Wiley, Chichester. Ciba Foundation Symposium $1996 ; 201: 207-227$.

17. Zhang $Y$, Proenca $R$, Maffei M. Barone M, Leopold L, Friedman JM. Positional cloning of the mouse obese gene and its human homologue. Nature 1994;372:425-431.

18. Auwerx J, Staels B. Leptin. The Lancet 1998;351:737-742.

19. Kern PA. Obesity. Common symptom of diverse gene-based metabolic dysregullations. J Nutr 1997;127:1917S-1922S.

20. Rohner-Jeanrenaud F, Cusin I, Sainsbury A, Zahkrzewska KE, Jeanrenaud B. The loop system between neuropeptide $Y$ and leptin in normal and obese rodents. Horm Metab Res $1996: 28: 642-648$.

21. Sugerman HJ, Wolper JL. Failed gastroplasty for morbid obesity. Revised gastroplasty versus RouX-Y gastric bypass. Am J Surg 1984;148:331-336.

22. Kfoury $E$, Vanguri A. Distal Roux-en-Y gastric bypass conversion operation for failed vertical banded gastroplasty. Obes Surg 1993;3;41-43. 
23. Sugerman $H J$, Starkey JV, Birkenhauer R. A randomized prospective trial of gastric bypass versus vertical banded gastroplasty for morbid obesity and their effects on sweets versus non-sweets eaters. Ann Surg 1987;205;613-622.

24. Belachew $M$, Jacquet $P$. Lardinois $F$, Karler $C$. Vertical banded gastroplasty vs adjustable silicone banding in the treatment of morbid obesity: A preliminary report. Obes Surg 1993;3:275-278.

25. Lönroth $H$, Dalenbâck $J$, Haglind $E$, Lundell L. Laparoscopic gastric bypass. Another operation in bariatric surgery. Surg Endosc 1996;10:636-638.

26. Kral JG. Morbid obesity and related health risks. Ann Int Med 1985; 03:1043-1047.

27. Brolin RE. Results of obesity surgery. Gastroenterol Clin North Am 1987;16:317-337. 


\section{SUMMARY}

In the introduction (chapter 1), the scope of the problem "morbid obesity" is depicted by means of a literature review of the morbidity and mortality associated with morbid obesity and epidemiological aspects of this disease. The history of surgical treatment of morbid obesity is described. Furthermore, the aim of this thesis is explained in this chapter. The main purpose of this thesis was to investigate the effectiveness of the surgical treatment of morbid obesity together with the psychosocial and metabolic consequences, and to find promoting factors of morbid obesity (psychosocial/metabolic) in a population of morbidly obese patients undergoing surgical treatment.

In chapter 2, the surgical treatment of morbid obesity, as performed by the department of general surgery of the University Hospital Maastricht, is evaluated.

In chapter 2.1, a retrospective study is presented in which the long-term results of vertical banded gastroplasty with a Marlex band $(n=17)$, as originally described by Mason, were compared with the vertical banded gastroplasty with a Dacron band $(n=32)$. Five years postoperatively, the percentage excess weight of the group with a Dacron band was significantly lower compared to the percentage excess weight of the group with a Marlex band ( $39.3 \%$ vs $59.2 \% ; p<0.05)$, due to band-related complications in the latter group. The complications of the group with the Marlex band responsible for the weight regain were erosion and disruption of the Marlex band. Eight years after operation, the percentage excess weight was comparable between both groups, due to renewed weight loss of the Marlex group following reoperation. It was concluded, that the Dacron band is superior to the Marlex band in vertical banded gastroplasty, because sustained weight loss is satisfactory and morbidity is low.

In chapter 2.2, the revisional surgical procedures after failed vertical banded gastroplasty were evaluated in a retrospective study. Restoration of the vertical banded gastroplasty $(n=26)$ was compared with conversion to a Roux-en- $Y$ gastric bypass $(n=15)$. The mean body mass index dropped from $46.8 \mathrm{~kg} / \mathrm{m}^{2}$ to $34.2 \mathrm{~kg} / \mathrm{m}^{2}$ after initial vertical banded gastroplasty $(n=116)$ and from $48.8 \mathrm{~kg} / \mathrm{m}^{2}$ to $33.5 \mathrm{~kg} / \mathrm{m}^{2}$ after initial gastric bypass $(n=20)(p<0.001)$, however, significantly more revisional surgery was necessary after vertical banded gastroplasty to achieve this result. Kaplan-Meier analysis revealed that $56 \%$ of the patients will require revisional surgery after initial vertical banded gastroplasty over a 12 -year period, compared to $12 \%$ after gastric bypass $(p<0.01)$. After restoration of the vertical banded gastroplasty $68 \%$ will need further revisional surgery over a 5-year period, while no further revisional procedures were necessary after conversion to gastric bypass $(p<0.05)$. The complication rate after restoration of the vertical banded gastroplasty and 
conversion to gastric bypass was high and comparable (33\%). It was concluded, that conversion of a failed vertical banded gastroplasty to a gastric bypass was more effective compared to restoration of the vertical banded gastroplasty, because the former provides satisfactory and sustained weight loss without requiring further revisional surgery.

In chapter 3, the psychosocial and economic aspects of morbid obesity and the influence of surgical treatment are described.

In chapter 3.1, the quality of life of morbidly obese patients and the effect of surgically induced weight loss were investigated in a controlled cross-sectional study. A postoperative group $(n=62)$ was compared with a preoperative control group $(n=20)$. Quality of life was assessed with the Nottingham Health profile part I and part II and a visual analogue scale. The control group exhibited an impaired quality of life on almost all tests. The quality of life outcome of the postoperative group was significantly better with the Nottingham Health Profile part II $(p<0.00001)$, the scales mobility $(p<0.00001)$, energy $(P<0.0001)$ and emotional reaction $(P<0.0001)$ of the Nottingham Health Profile part I and the visual analogue scale $(p<0.00001)$. Quality of life outcome was related to weight loss and the length of follow-up. The unemployment rate was higher in the control group compared to the postoperative group and overweight as the reason for unemployment was also higher in the control group. It was concluded, that the quality of life of morbidly obese patients is better after surgically induced weight loss.

In chapter 3.2, the psychological functioning of morbidly obese patients and the effect of surgical treatment were investigated in a cross-sectional study $(n=62)$. Three psychological tests were administered before and after surgical treatment. The psychological profile before surgery showed somatisation, depression, denial of emotional stress, social incompetence and indifferent attitude towards certain aspects of interpersonal behavior. All psychopathology, except for somatisation, disappeared after successful weight loss as a result of surgical treatment. It was concluded, that the psychological disturbances are the result, rather than the cause of morbid obesity, because the psychopathology before surgery reversed after surgically induced weight loss.

In chapter 3.3 , a prospective, prevalence-based cost-effectiveness analysils of vertical banded gastroplasty for the treatment of morbid obesity is presented $(n=21)$. Quality of life was investigated with the Nottingham Health Profile part I and part II and a visual analogue scale. A prevalence-based cost-of-illness analysis of morbid obesity was performed and the cost-effectiveness of vertical banded gastroplasty was assessed, expressed as costs per quality adjusted life year (QALY). Treatment with vertical banded gastroplasty resulted in a significant improvement of quality of life. Lifelong costs of illness of morbidlly obese patients ranged from 8304 US\$ to 9367 US\$. Total direct costs of 
vertical banded gastroplasty, including treatment failures, were 5865 US\$. The percentage of patients performing paid labor increased from $19 \%$ before to $48 \%$ after vertical banded gastroplasty, resulting in an average productivity gain of 2765 US\$ per year. The cost-effectiveness analysis revealed that vertical banded gastroplasty saves 4004 US\$ to 3928 US\$ per QALY (overall dominancy). It was concluded, that vertical banded gastroplasty for the treatment of morbid obesity results in QALY's gained and less costs, and that this procedure should be introduced or continued from a societal point of view.

In chapter 4, two studies are presented in which energy, substrate and protein metabolism of morbidly obese patients and the effect of weight loss are investigated.

In chapter 4.1, it was investigated whether long-term weight loss after vertical banded gastroplasty results in a sustained reduction of the sleeping metabolic rate. Sleeping metabolic rate was measured in a respiration chamber and body composition with deuterium dilution and hydrostatic weighing. Furthermore, sleeping metabolic rate was predicted with a regression formula based on body composition. The patients in the first group $(n=6)$ were measured in a prospective manner until one year after surgery. To investigate the long-term effects, a second group of patients more than three years after surgery was measured $(n=9)$. Three months after surgery, during rapid weight loss, fat mass and fat free mass were lost in group I, while 12 months after surgery, during stable weight loss, only fat mass was lost. The measured sleeping metabolic rate was lower than the predicted sleeping metabolic rate at all intervals after surgery in group I and group $\|(p<0.05)$. It was concluded, that the reduction of sleeping metabolic rate after vertical banded gastroplasty is sustained as long as weight loss is maintained. The disproportional and sustained reduction of sleeping metabolic rate may reflect the persistent susceptibility of the formerly obese to weight regain.

In chapter 4.2, the energy, substrate and protein metabolism of morbidly obese patients and the effect of massive weight loss after vertical banded gastroplasty are investigated in a prospective manner $(n=8)$. Total energy expenditure was determined with the doubly labeled water method and sleeping metabolic rate in the respiration chamber. Body composition was assessed with the deuterium oxide component of doubly labeled water. Substrate metabolism under free living conditions was calculated from 48 hour dietary records, 48 hour urine collection and gaseous exchange in the respiration chamber. Whole body protein turnover was determined by means of a primed-continuous infusion of $L-\left[1-{ }^{13} \mathrm{C}\right]$-leucine. Total energy expenditure decreased significantly after weight loss as a result of a decreased sleeping metabolic rate ( $64 \%$ of the decrease in TEE) and a decreased non-sleeping metabolic rate ( $36 \%$ of the decrease in TEE). The physical activity index (total energy expenditure/sleeping metabolic rate) was low and did not change 
significantly after weight loss. Three months after surgery, during rapid weight loss, fat mass and fat free mass were lost, while 12 months after surgery, during slow weight loss, mainly fat mass was lost. The intake of all nutrients decreased dramatically as did the protein- and carbohydrate oxidation, although protein oxidation did not decrease enough to prevent loss of fat free mass. Fat oxidation increased, while fat oxidation decreased, resulting in a massive loss of fat mass. Protein turnover was approximately $24 \%$ of sleeping metabolic rate and did not change after weight loss. Protein synthesis expressed as a percentage of protein breakdown was $82 \%$ before surgery and $91 \%$ three months after surgery during semi-starvation. It was concluded, that compensatory processes exist which oppose weight loss of morbidly obese patients. This is reflected in a disproportional reduction of sleeping and nonsleeping metabolic rate and in a low physical activity index. The decrease in protein turnover does not contribute to a major degree to the reduction in sleeping metabolic rate. Slow weight loss results in a predominant loss of fat mass, while during rapid weight loss also fat free mass is lost. A proteinsparing mechanism during semi-starvation is likely to exist, but does not prevent loss of fat free mass. 


\section{SAMENVATTING}

In de introductie (hoofdstuk 1), wordt de omvang van het probleem "morbide obesitas" uiteengezet aan de hand van een literatuuroverzicht van de morbiditeit en mortaliteit geassocieerd met morbide obesitas en enkele epidemiologische aspecten van deze ziekte. De historie van de chirurgische behandeling van morbide obesitas wordt beschreven. Verder wordt de opzet van het proefschrift uiteengezet in dit hoofdstuk. Het primaire doel van dit proefschrift was om de effectiviteit van de chirurgische behandeling van morbide obesitas en de psychosociale en metabole consequenties te onderzoeken. Daarnaast hebben we getracht om aanwijzingen te vinden voor oorzakelijke factoren van morbide obesitas (psychosociaal/metabool) in een populatie van morbide obese patiënten die een chirurgische behandeling ondergaan.

In hoofdstuk 2 wordt de chirurgische behandeling van morbide obesitas, zoals verricht door de afdeling Algemene Chirurgie van het academisch Ziekenhuis Maastricht, geëvalueerd.

In hoofdstuk 2.1 wordt een retrospectieve studie gepresenteerd waarin de llange termijn resultaten van de verticale maagverdeling met een Marlex band $(n=17)$, zoals oorspronkelijk beschreven door Mason, worden vergeleken met de verticale maagverdeling met een Dacron band $(n=32)$. Vijf jaar na operatie was het percentage overgewicht van de groep met een Dacron band significant lager vergeleken met de groep met een Marlex band $339.3 \%$ vs $59.2 \% ; p<0.05$ ), als gevolg van band-gerelateerde complicaties in de laatste groep. De complicaties in de Marlex groep die verantwoordelijk waren voor de stijging van het lichaamsgewicht waren banderosies en bandrupturen. Acht jaar na operatie was het percentage overgewicht van de beide groepen vergelijkbaar als een gevolg van hernieuwd gewichtsverlies van de groep met een Marlex band na reoperaties. Er werd geconcludeerd, dat de Dacron band superieur is aan de Marlex band bij de verticale maagverdeling, omdat het lange termijn gewichtsverlies bevredigender is als gevolg van minder bandgerelateerde complicaties.

In hoofdstuk 2.2 worden de reoperaties voor mislukte verticale maagverdeling geëvalueerd in een retrospectieve studie. Herstel van de verticale maagverdeling $(n=26)$ wordt vergeleken met conversie naar een Roux-en- $Y$ gastric bypass $(n=15)$. De gemiddelde body mass index daalde van $46.8 \mathrm{~kg} / \mathrm{m}^{2}$ tot $34.2 \mathrm{~kg} / \mathrm{m}^{2}$ na initiële verticale maagverdeling $(n=116)$ en van $48.8 \mathrm{~kg} / \mathrm{m}^{2}$ tot $33.5 \mathrm{~kg} / \mathrm{m}^{2}$ na initiële gastric bypass $(n=20)(p<0.001)$. Echter significant meer reoperaties waren nodig na de verticale maagverdeling om dit resultaat te bereiken. De Kaplan-Meier analyse liet zien dat $56 \%$ van de patiënten een reoperatie nodig zullen hebben na een verticale maagverdeling over een periode van 12 jaar, vergeleken met $12 \%$ na een gastric bypass 
$(p<0.01)$. Na herstel van de verticale maagverdeling zal $68 \%$ een reoperatie nodig hebben over een periode van 5 jaar, terwijl geen verdere reoperaties meer nodig waren na conversie naar een gastric bypass $(\rho<0.05)$. Het optreden van complicaties na herstel van de verticale maagverdeling en na conversie naar gastric bypass was hoog en vergelijkbaar (33\%). Er werd geconcludeerd, dat conversie van een mislukte verticale maagverdeling naar een gastric bypass effectiever is vergeleken met herstel van de verticale maagverdeling. Conversie van de verticale maagverdeling naar een gastric bypass resulteert in een bevredigend gewichtsverlies op de lange termijn zonder de noodzaak tot verdere reoperaties.

In hoofdstuk 3 worden de psychosociale en economische aspecten van morbide obesitas en de gevolgen van chirurgische behandeling beschreven.

In hoofdstuk 3.1 wordt de kwaliteit van leven van morbide obese patiënten en het effect van gewichtsverlies na chirurgische behandeling onderzocht in een gecontroleerde, cross-sectionele studie. Een postoperatieve groep $(n=62)$ werd vergeleken met een preoperatieve controlegroep $(n=20)$. Kwaliteit van leven werd bepaald met de Nottingham Health Profile deel I en deel II en een visuele analoge schaal. De controlegroep liet een verminderde kwaliteit van leven zien ten aanzien van bijna alle testen. De kwaliteit van leven van de postoperatieve groep was significant beter wat betreft de Nottingham Health Profile deel II $(p<0.00001)$, de schalen mobiliteit $(p<0.00001)$, energie $(p<$ 0.0001 ) en emotionele reactie $(p<0.0001)$ van de Nottingham Health Profile deel I en de visuele analoge schaal $(p<0.00001)$. De kwaliteit van leven na operatie was gerelateerd aan gewichtsverlies en de lengte van follow-up. Werkeloosheid was meer frequent in de controlegroep vergeleken met de postoperatieve groep en overgewicht als de reden voor werkeloosheid was eveneens hoger in de controlegroep. Er werd geconcludeerd, dat de kwaliteit van leven van morbide obese patienten beter is na gewichtsverlies als gevolg van chirurgische behandeling.

In hoofdstuk 3.2 wordt het psychologisch functioneren van morbide obese patiënten en het effect van chirurgische behandeling onderzocht in een crosssectionele studie $(n=62)$. Drie psychologische testen werden voor en na chirurgische behandeling uitgevoerd. Het psychologische profiel voor operatie bestond uit somatisatie, depressie, ontkennen van emotionele stress, sociale incompetentie en onverschillig gedrag. Alle psychopathologie verdween na succesvol gewichtsverlies als gevolg van chirurgische behandeling, met uitzondering van somatisatie. Er werd geconcludeerd, dat de psychologische stoornissen het gevolg zijn van morbide obesitas en niet de oorzaak, omdat de psychopathologie voor operatie reversibel is na gewichtsverlies als gevolg van chirurgische behandeling.

In hoofdstuk 3.3 wordt een prospectieve "prevalence-based" kosteneffectiviteitsanalyse van de verticale maagverdeling ter behandeling van 
morbide obesitas gepresenteerd $(n=21)$. Kwaliteit van leven werd onderzocht met de Nottingham Health Profile deel I en deel II en een visuele analoge schaal voor kwaliteit van leven. Een prevalence-based cost-of-illness analyse werd verricht en de kosten-effectiviteit van de verticale maagverdeling bepaald, uitgedrukt als "quality adjusted life years" (QALY). De behandeling met de verticale maagverdeling resulteerde in een significant verbeterde kwaliteit van leven. De levenslange ziektekosten van morbide obese patiënten bedroeg $f 16.608$ tot $f$ 18.736. De totale directe kosten van de verticale maagverdeling, inclusief de mislukte behandelingen, waren $f 11.729$. Het percentage patiënten dat betaalde arbeid verricht steeg van $19 \%$ voor tot $48 \%$ na verticale maagverdeling, hetgeen resulteerde in een gemiddelde productiviteitswinst van $f 5530$ per jaar. De kosten-effectiviteitsanalyse liet zien dat de verticale maagverdeling resulteerde in een besparing van $f 8008$ tot $f 7854$ per QALY (overall dominancy). Er werd geconcludeerd, dat de verticale maagverdeling voor de behandeling van morbide obesitas resulteert in toegenomen QALY's en minder kosten, en dat deze procedure daarom vanuit een maatschappelijk gezichtspunt moet worden geintroduceerd dan wel gecontinueerd.

In hoofdstuk 4 worden twee studies gepresenteerd die het energie-, substraaten eiwitmetabolisme van morbide obese patiënten en het effect van gewichtsverlies onderzoeken.

In hoofdstuk 4.1 wordt onderzocht of lange termijn gewichtsverlies na verticale maagverdeling leidt tot een blijvende verlaging van het energiegebruik tijdens slaap. Het energiegebruik tijdens slaap werd gemeten in de respiratiekamer en lichaamssamenstelling met deuterium dilutie en onderwaterweging. Het energiegebruik tijdens slaap werd ook voorspeld met behulp van een regressie-formule gebaseerd op de lichaamssamenstelling. De patiënten van de eerste groep $(n=6)$ werden prospectief gemeten tot een jaar na operatie. Om de lange termijn effecten te onderzoeken werd een tweede groep patiënten $(n=9)$ meer dan drie jaar na operatie gemeten. Drie maanden na operatie, gedurende snel gewichtsverlies, daalde de vetmassa en vetvrije massa in groep I, terwijl 12 maanden na operatie, gedurende stabiel gewichtsverlies, alleen de vetmassa daalde. Het gemeten energiegebruik tijdens slaap was lager dan het voorspelde energiegebruik tijdens slaap gedurende alle intervallen na operatie in groep I en in groep II $(p<0.05)$. Er werd geconcludeerd, dat de reductie van het energiegebruik tijdens slaap na verticale maagverdeling aanhoudt zolang het gewichtsverlies persisteert. De disproportionele en persisterende daling van het energiegebruik tijdens slaap kan een reflectie zijn van de voortdurende ontvankelijkheid van de voorheen obese patiënten voor toename van het lichaamsgewicht. 
In hoofdstuk 4.2 wordt het energie-, substraat- en eiwitmetabolisme van morbide obese patiënten en het effect van extreem gewichtsverlies na verticale maagverdeling onderzocht in een prospectieve studie $(n=8)$. Totaal energiegebruik werd gemeten met dubbel gelabeld water en het energiegebruik tijdens slaap werd gemeten in de respiratiekamer. Lichaamssamenstelling werd bepaald met de deuterium oxide component van het dubbel gelabeld water. Het substraatmetabolisme tijdens dagelijkse omstandigheden werd berekend uit de 48-uurs dieetlijsten, 48-uurs urineverzameling en de gaswisseling in de respiratiekamer. De eiwitturnover werd bepaald middels een "primed-continuous" infusie met $\mathrm{L}-\left[1-{ }^{13} \mathrm{C}\right]$-leucine. Totaal energiegebruik daalde significant na gewichtsverlies als gevolg van een daling van het energiegebruik tijdens slaap $(64 \%$ van het totale energiegebruik) en een daling van het energiegebruik tijdens niet-slaap ( $36 \%$ van het totale energiegebruik). De fysieke activiteitsindex (totaal energiegebruik/ energiegebruik tijdens slaap) was laag en veranderde niet significant na gewichtsverlies. Drie maanden na operatie, gedurende snel gewichtsverlies, werd vetmassa en vetvrije massa verloren, terwijl 12 maanden na operatie, gedurende langzaam gewichtsverlies, vrijwel alleen vetmassa werd verloren. De inname van alle nutriënten daalde fors, alsook de eiwit- en koolhydraatoxidatie, alhoewel de daling van de eiwitoxidatie onvoldoende was om verlies van vetvrije massa te voorkomen. De vetoxidatie nam toe, terwijl de vetinname afnam, hetgeen resulteerde in een forse afname van de vetmassa. De eiwitturnover was ongeveer $24 \%$ van het energiegebruik tijdens slaap en veranderde niet tijdens gewichtsverlies. De eiwitsynthese, uitgedrukt als een percentage van de eiwitafbraak, was $82 \%$ voor operatie en $91 \%$ drie maanden na operatie gedurende semi-starvatie. $\mathrm{Er}$ werd geconcludeerd, dat er compensatoire processen bestaan die het gewichtsverlies van morbide obese patiënten tegengaan. Dit wordt weerspiegeld in een disproportionele verlaging van het energiegebruik tijdens slaap en tijdens nietslaap en tevens in een lage fysieke activiteitsindex. Een verlaagde eiwitturnover levert geen overtuigende bijdrage aan de verlaging van het energilegebruik tijdens slaap. Langzaam gewichtsverlies resulteert in een verlies van alleen vetmassa, terwijl snel gewichtsverlies leidt tot verlies van vetmassa en vetvrije massa. Het is waarschijnlijk dat er een eiwitsparend mechanisme tijdens semi-starvatie bestaat, maar dit mechanisme is niet efficiënt genoeg om verlies van vetvrije massa te voorkomen. 


\section{DANKWOORD}

Op deze plaats wil ik beginnen met het bedanken van mijn ouders. Jullie hebben altijd achter mij gestaan en mij door dik en dun gesteund. Mijn vader, en beste vriend, wil ik nogmaals apart bedanken. Alles wat ik tot nu toe heb bereikt, is mede dankzij jou.

Ook mijn vrouw, Manon, en kinderen, Storm en Wolf, wil ik bedanken. Ik heb veel waardering voor jullie onzelfzuchtige steun. Omdat ik mijn promotieonderzoek tijdens de opleiding heb verricht, werd een erg groot deel van "onze vrije tijd" besteed aan werk achter de computer of het uitvoeren van onderzoek in het ziekenhuis. Het is prijzenswaardig dat jullie in staat waren opofferingen te doen voor één van mijn persoonlijke doelen. Door jullie is het mij temeer duidelijk geworden hoe belangrijk een solide achterban is. Mijn waardering voor jullie is groter dan ik misschien heb laten blijken. Manon, Storm en Wolf, ik hou van jullie.

Dr. de Smet, beste Herman, ik heb altijd een groot respect gehad voor je kundigheid in de chirurgie en de vaderlijke wijze waarop je met "de jongens" omging. Mede dankzij jou ben ik in opleiding voor de chirurgie gekomen.

Prof.dr. Soeters, beste Peter, ik wil je bedanken voor het vertrouwen dat je in mij schonk, door mij de kans te geven dit promotie-onderzoek te verrichten. Op de dode punten wist je altijd weer te motiveren en te stimuleren. Ik heb veel plezier beleefd aan onze gesprekken, die lang niet altijd over wetenschappelijk onderzoek gingen. Niet alleen omtrent het verrichten van wetenschappelijk onderzoek, maar ook op het klinisch vlak heb ik veel van je geleerd.

Dr. Greve, beste Jan Willem, ik wil je eveneens bedanken voor je steun en inzet bij het tot stand brengen van mijn proefschrift. Aan onze gezamenlijke congresbezoeken, zoals in Praag en Cancun, heb ik veel plezier beleefd en heb ik je beter leren kennen. Als er weer eens wat mis was op computergebied was je altijd weer bereid om mij uit de brand te helpen.

Klaas Westerterp en Ton Wagenmakers wil ik bedanken voor hun hulp en inzet bij het opzetten van de protocollen, het verrichten van de experimenten en het publiceren van de resultaten.

Ik ben er trots op dat Bernadette van Acker en René van der Hulst mijn paranymfen zijn. In het bijzonder wil ik Bernadette bedanken voor haar onbaatzuchtige inzet en hulp bij het verrichten van de metabole experimenten. Zij was altijd bereid te helpen. Zonder haar hulp en "know how" waren de experimenten een puinhoop geworden.

Nico Groenman, Ruud Severeijns en Christianne Vertonnen bedankt voor jullie hulp bij de opzet, uitvoering en uitwerking van de psychologie studie. Jullie hebben mij wegwijs gemaakt op een gebied dat voor mij onbekend terrein was. 
Eddy Adang wil ik bedanken voor een erg prettige samenwerking. Door jou heb ik het belang van Medical Technology Assessment leren kennen. I $k$ heb veel plezier gehad aan onze contacten en hoop dat in de toekomst te kunnen voortzetten.

Tevens wil ik Gemma Vos van de Onderzoeksgroep azM en de studenten Meike Wersch en Monika Kop bedanken voor hun medewerking.

Esther ten Hoor, azM, en Marion Rijkers, AZVU, mede dankzij jullie organisatorische en secretariële ondersteuning is dit proefschrift tot stand gekomen.

De medewerkers van de afdelingen Klinische Chemie en het Stabiel Isotopen Research Laboratorium wil ik bedanken voor het verrichten van alle bepalingen en eveneens wil ik de afdeling Diëtetiek bedanken voor hun hulp bij het uitwerken van de dieetlijsten.

De staf en assistenten van de afdeling Algemene Heelkunde azM en de staf Kinderchirurgie Amsterdam wil ik bedanken voor hun steun en prettige samenwerking. 


\section{CURRICULUM VITAE}

Wilhelmus Gerardus van Gemert was born in Nijmegen, The Netherlands on May the $3^{\text {th }}, 1963$. In 1982, he graduated from The Canisius College in Nijmegen and started his study at the Medical Faculty of the University of Nijmegen. He received his medical degree in 1989. From 1989 till 1991, he worked as a house-officer general surgery/orthopaedic surgery at Noble's Isle of Man Hospital in Douglas, Isle of Man, and as a senior house-officer at the Royal Albert Edward Infirmary in Wigan, UK. In 1992, he started his training as a surgicall resident at the Sint Maartens Gasthuis, Venlo (Head Dr. H.L. de Smet) and continued his surgical training at the Academic Hospital Maastricht (Head Prof.dr. G. Kootstra). On januari the $1^{\text {st }} .1998$ he was registered as a general surgeon and started his fellowship Paediatric Surgery at the University of Amsterdam (Head Prof.dr. A. Vos). 
$-142-$ 
De publicatie van dit proefschrift werd financieel mogelijk gemaakt door: Diabetes Fonds Nederland Stichting KCHOMP Amsterdam Janssen-Cilaq Boston Scientific

BABS

Bioenterics

AutoSuture

Bard 